\title{
Pilot-Scale Testing of In Situ Vitrification of Arnold Engineering Development Center Site 10 Contaminated Soils
}

\author{
C. L. Timmerman \\ M. E. Peterson
}

February 1990

\author{
Report Prepared by \\ Pacific Northwest Laboratory \\ P.O. Box 999 \\ Richland, Washington 99352 \\ under Project No. 14384 \\ for \\ HAZWRAP Support Contractor Office \\ Oak Ridge, Tennessee 37831 \\ operated by \\ MARTIN MARIETTA ENERGY SYSTEMS, INC. \\ for the \\ U.S. Department of Energy \\ under subcontract DE-AC05-840R21400
}




\title{
DISCLAIMER
}

This report was prepared as an account of work sponsored by an agency of the United States Government. Neither the United States Government nor any agency thereof, nor Battelle Memorial Institute, nor any of their employees, makes any warranty, expressed or implied, or assumes any legal liability or responsibility for the accuracy, completeness, or usefulness of any information, apparatus, product, or process disclosed, or represents that its use would not infringe privately owned rights. Reference herein to any specific commercial product, process, or service by trade name, trademark, manufacturer, or otherwise, does not necessarily constitute or imply its endorsement, recommendation, or favoring by the United States Government of any agency thereof, or Battelle Memorial Institute. The views and opinions of authors expressed herein do not necessarily state or reflect those of the United States Government or any agency thereof.

\author{
PACIFIC NORTHWEST LABORATORY \\ operated by \\ BATTELLE MEMORIAL INSTITUTE \\ for the \\ UNITED STATES DEPARTMENT OF ENERGY \\ under Contract DE-ACO6-76RLO 1830
}

Printed in the United States of America

Available to DOE and DOE contractors from the

Office of Scientific and Technical Information, P.O. Box 62, Oak Ridge, TN 37831; prices available from (615) 576-8401. FTS 626-8401.

Available to the public from the National Technical Information Service,

U.S. Department of Commerce, 5285 Port Royal Rd., Springfield, VA 22161.

NTIS Price Codes, Microfiche A01

Printed Copy

\begin{tabular}{cr}
\hline Price Code & Page Range \\
\hline A02 & $1-10$ \\
A03 & $11-50$ \\
A04 & $51-75$ \\
A05 & $76-100$ \\
A06 & $101-125$ \\
A07 & $126-150$ \\
A08 & $151-175$ \\
A09 & $176-200$ \\
A10 & $201-225$ \\
A11 & $226-250$ \\
A12 & $251-275$ \\
A13 & $276-300$ \\
A14 & $301-325$
\end{tabular}

\begin{tabular}{cc}
\hline Price Code & Page Range \\
\hline A15 & $326-350$ \\
A16 & $351-375$ \\
A17 & $376-400$ \\
A18 & $401-425$ \\
A19 & $426-450$ \\
A20 & $451-475$ \\
A21 & $476-500$ \\
A22 & $501-525$ \\
A23 & $526-550$ \\
A24 & $551-575$ \\
A25 & $576-600$ \\
A99 & $601-U p$
\end{tabular}




\title{
Pilot-Scale Testing of In Situ Vitrification of Arnold Engineering Development Center Site 10 Contaminated Soils
}

\author{
C. L. Timmerman \\ M. E. Peterson \\ February 1990 \\ Report Prepared by \\ Pacific Northwest Laboratory \\ P.0. Box 999 \\ Richland, Washington 99352 \\ under Project No. 14384 \\ for \\ HAZWRAP Support Contractor office \\ Oak Ridge, Tennessee 37831 \\ operated by \\ MARTIN MARIETTA ENERGY SYSTEMS, INC. \\ for the \\ U.S. Department of Energy \\ under subcontract DE-AC05-840R21400
}





\section{SUMMARY}

Process verification testing using in situ vitrification (ISV) was successfully performed in a pilot-scale test using soils containing fuel oils and heavy metals from Site 10 Installation Restoration Program (IRP) at the Arnold Engineering Development Center (AEDC) located in the southern portion of middle Tennessee. This effort was directed through the U.S. Department of Energy's Hazardous Waste Remedial Action Program (HAZWRAP) Office managed by Martin Marietta Energy Systems. In situ vitrification is a thermal treatment process that converts contaminated soils and wastes into a durable product containing glass and crystalline phases. During processing, heavy metals or other inorganic constituents are retained and immobilized in the glass structure; organic constituents are typically destroyed or removed and captured by the off-gas treatment system.

The objective of this test is to verify the applicability of the ISV process for stabilization of the contaminated soil at Site 10 . The pilotscale ISV testing results, reported herein, indicate that the AEDC Site 10 Fire Training Area may be successfully processed by ISV. Site 10 is a fire training pit that is contaminated with fuel oils and heavy metals from fire training exercises. Actual site material was processed by ISV to verify its feasible application to those soils. Initial feasibility bench-scale testing and analyses of the soils determined that a lower-melting, electrically conductive fluxing additive (such as sodium carbonate) is required as an additive to the soil for ISV processing to work effectively. The actual Site 10 soils showed a larger degree of compositional variation than the soil used for the bench-scale test. This variation dictates that each vitrification setting should be analyzed to determine the composition as a function of depth and location. This data will dictate the amount (if any) of fluxing additives of sodium and calcium to bring the melt composition to the recommended quantity of 5 wt\% sodium and 5 wt\% calcium oxide. Each variable additive adjustment would result in a vitrification melt composition of $5 \mathrm{wt} \%$ calcium and sodium oxide content.

The pilot-scale operation created a vitrified block weighing 15 metric tonnes $(\mathrm{t})$ and measuring $1.5 \mathrm{~m}(5 \mathrm{ft})$ deep and $2.4 \mathrm{~m}(8 \mathrm{ft})$ on each side. 
The quantity of fluxing additives and the method of placing the fluxing additives in the surface cover soil limited the operating electrical system providing power to the ISV melt. The power limitation created enhanced lateral growth of the block and resulted in a shallower depth. This method of adding fluxes demonstrated that ISV operating efficiency would be greatly improved if the fluxes were injected or mixed with the entire designated vitrification volume. However, the volume vitrified contained a sufficient quantity of hazardous contaminants to allow for an effective verification evaluation of ISV processing of the AEDC Site 10.

Analytical efforts for this project were directed towards evaluating the organic destruction and thermal transport effects of ISV processing on the Site 10 contaminated soil. No thermal transport of hydrocarbon contaminants to the surrounding soil were detected. These results continue to confirm the organic destruction and nontransport mechanisms presented in this report. off-gas releases of the hydrocarbons indicated an 89 wt\% destruction efficiency by the ISV process exclusive of off-gas treatment. The destruction and removal efficiency of the overall ISV system was $99.85 \mathrm{wt} \%$. Leach testing using extraction procedure (EP) toxicity and toxic characteristics leach procedure (TCLP) showed that all metals of concern were below leach testing release limits, indicating that the ISV process produces a nonhazardous product. These favorable results indicate that ISV can be used to effectively treat and remediate the contaminated soils at the AEDC Site 10. 


\section{ACKNOWLEDGMENTS}

The authors gratefully acknowledge Martin Marietta Energy Systems, Inc., and Arnold Engineering Development Center for providing Pacific Northwest Laboratory the opportunity to perform this pilot-scale testing.

Several fellow researchers and technicians contributed to and made this test a success. Listed below are these contributors and their areas of assistance.

J. L. Buelt - Project Support

J. G. Carter - Site Supervision

K. E. Eliason - Test Operation

J. T. Jeffs - Test Preparation and Operation

T. D. Powe11 - Test Preparation and Operation

S. R. Somers - Site Off-Gas Sampling Support

E. D. Smith - Site Off-Gas Sampling Support

F. T. Hara - Inorganic Analytical Support

K. B. 01 sen - Organic Analytical Support

T. J. Gilmore - Site Soil Core Sampling

G. V. Last - Site Soil Core Sampling 



\section{CONTENTS}

SUMMARY

ACKNOWLEDGMENTS ..................... . . . v

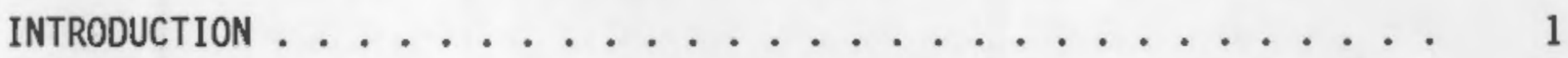

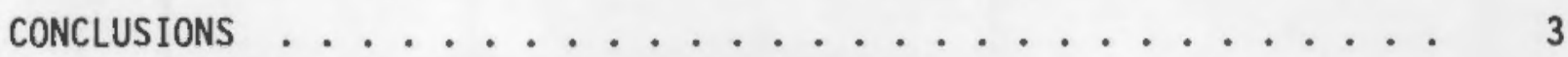

PROCESS DESCRIPTION AND STATUS OF DEVELOPMENT . . . . . . . . . 5

AEDC SITE 10 BACKGROUND ................................. 11

PILOT-SCALE TEST SYSTEM . . . . . . . . . . . . . . . . . 15

POWER SYSTEM DESIGN .......................... 15

OFF-GAS CONTAINMENT AND ELECTRDDE SUPPORT HOOD $\ldots . . . . . . . \quad 16$

OFF-GAS TREATMENT SYSTEM ....................... 18

THEORETICAL BASIS FOR ORGANIC DESTRUCTION BY ISV . . . . . . . . . 25

FATE OF PYROLYSIS PRODUCTS ................. 27

EXPLOSION POTENTIAL . . . . . . . . . . . . . . 28

TEST DESCRIPTION . . . . . . . . . . . . . . . . . . . . . 29

TEST RESULTS AND PERFORMANCE ANALYSIS . . . . . . . . . . . . . 33

POWER SYSTEM .................... 33

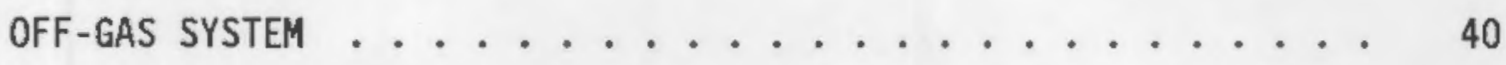

Off-Gas Containment Hood .............. 41

Off-Gas Treatment Equipment ............ 44

Particulate Characteristics ............ 46

Gaseous Characteristics ............. 47

Water Removal .................. 50

Thermal Destruction and Removal Efficiency ........ 51

Product and Surrounding Soil Characterization ...... 53 
REFERENCES ......................... 59

APPENDIX A - ISV ORGANIC DESTRUCTION MECHANISMS . . . . . . A.1

APPENDIX B - AEDC SITE 10 BENCH-SCALE TESTING SOIL ANALYSIS ..... B.1

APPENDIX C - AEDC SITE 10 ORIGINAL SOIL ORGANIC CONCENTRATIONS . . . C. 1 


\section{FIGURES}

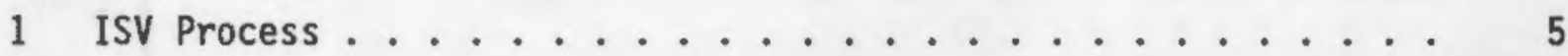

2 ISV Pilot-Scale and Large-Scale Systems ........... 8

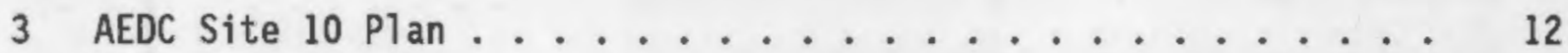

4 Typical Pilot-Scale ISV Hood and Process Trailer Arrangement . . 15

5 Scott-Tee Electrical Connection for the Pilot-Scale ISV

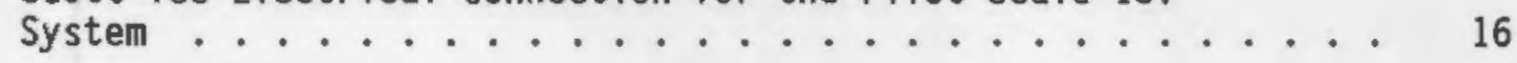

6 Off-Gas Containment and Electrode Support Hood . . . . . . 17

7 Electrode Bus Bar to Hood Seal Insulating Board Connection . . 19

8 Schematic of Off-Gas System for the Pilot-Scale ISV Process . . 20

9 Cutaway View of Pilot-Scale ISV Process Trailer and Hood .... 21

10 Off-Gas System Contaìnment Module ............. 22

11 Tandem Nozzle Hydro-Sonic Scrubber . . . . . . . . . . 23

12 Pilot-Scale System with the Associated Sampling Positions . . . 34

13 Power to Electrode ................. 39

14 Voltage and Current ................ 40

15 Hood Vacuum ....................... 41

16 off-Gas flow Rate .................... 42

17 Off-Gas Temperatures from Hood Plenum to the Process Trailer . . 43

18 Off-Gas Hood Temperatures ............... 43

19 Off-Gas Temperatures from the Venturi-Ejector Outlet to the Heater Inlet .................... 44

20 Off-Gas Temperatures from the Heater Inlet to the Stack . . . 44 45

21 Scrubbing System Differential Pressures ............ 46

22 Filter Differential Pressures . . . . . . . . . 46 
23 Scrub Tank Liquid Volumes................ 47

24 Carbon Dioxide and Carbon Monoxide Concentrations ....... 49

25 0xygen Concentration ................. 49

26 Surface View of ISV Block After Processing ......... 54

27 AECD Site 10 Pretest Soil Analyses ............ 56

28 AECD Site 10 Posttest Soil Analyses ............ 58 


\section{$\underline{\text { TABLES }}$}

1 Testing Units for Developing ISV Technology .........6 6

2 Chronological List of Events During the AEDC Pilot-Scale ISV Test ....................... 31

3 AEDC Site 10 Pilot-Scale Pretest Soil Coring Analyses, normalized $w t \% \ldots \ldots . \ldots . \ldots 35$

4 Particulate Filter Analyses from Hood and Stack Sample Trains, mg/filter................. 48

5 Organic Quantities Released from the Vitrified Volume ...... 52

6 Final Glass Composition of the AEDC Pilot-Scale Product . . . . 55

7 EP Toxicity and TCLP Metal Extract Concentrations: AEDC Vitrified Product .............. 55 



\section{INTRODUCTION}

Pacific Northwest Laboratory (PNL) (a) is developing a remedial action process for contaminated soils that is significant in its application to immobilize and/or destroy these contaminated materials. The process, called in situ vitrification (ISV), was initially developed to demonstrate a potential technology for disposal of soil contaminated with transuranic waste at the Hanford Site in southeastern Washington, although recent tests have shown that many hazardous chemical wastes are also destroyed or immobilized as a result of the treatment. In situ vitrification was originally developed for the U.S. Department of Energy by PNL. This report presents evidence that ISV also has applicability to Arnold Engineering Development Center (AEDC) contaminated soils, which are contaminated with fuel oils and heavy metals from fire training exercises.

In situ vitrification is a thermal treatment process that converts contaminated soils into a chemically inert and stable product composed of glass and crystalline phases. The ISV process could potentially be applied to many contaminated soil sites at AEDC. The processing is performed in place; high temperature destroys or removes organic contaminants, and the glass and crystalline product immobilizes inorganic contaminants. All these functions are performed in one processing step.

This report presents the results of a pilot-scale ISV test conducted for Martin Marietta Energy Systems and AEDC. The primary objective of this study was to verify the applicability of the ISV process to soils contaminated with fuel oils, heavy metals, and other organics. To accomplish this objective, a pilot-scale ISV test was performed on a portion of the Site 10 Fire Training Area soil. Testing results determined the destruction of organics and the retention of inorganics in the vitrified product. Fractional release of contaminants to the off-gas treatment system and leaching characteristics of the vitrified material were also determined.

(a) The Pacific Northwest Laboratory is operated for the U.S. Department of Energy by Battelle Memorial Institute under Contract DE-AC06-76RL0 1830. 
The results of this report on ISV application to a specific site's organic-contaminated soils indicate that ISV can offer a long-term improvement to remediation of AEDC contaminated soil at Site 10. 


\section{CONCLUSIONS}

Verification testing of the ISV process was successfully performed on the Site 10 Fire Training Area at the AEDC site. Analyses of the data from the test provide the following conclusions regarding the performance of the ISV process to AEDC Site 10 soils:

- Processing parameters from pilot- and bench-scale tests demonstrated the feasibility of using ISV to process these contaminated soil types into a more compact and environmentally stable (immobilized) form. However, the AEDC soils require the use of a fluxing additive such as sodium ( $\mathrm{Na}$ ) and/or calcium ( $\mathrm{Ca}$ ) to adjust the soil composition to 5 wt\% content each $\mathrm{Na}$ and $\mathrm{Ca}$ based on oxide composition.

- Fluxing additions are necessary to process AEDC site soils. Fluxing additives administered to the $0.9 \mathrm{~m}(3 \mathrm{ft})$ of cover soil allowed ISV to treat a portion of the Site 10 soil, but did not result in efficient ISV process operations or effective flux mixing with AEDC soils. Therefore, if fluxing additives are required, these fluxing additives should be added to the entire vitrification volume by soil mixing or injection techniques.

- The pilot-scale ISV electrical and off-gas treatment system operated effectively within design constraints throughout the $168-\mathrm{h}$ AEDC pilot-scale test operating period.

- The operation produced a $15-t$ vitrified block measuring $1.5 \mathrm{~m}$ $(5 \mathrm{ft})$ deep and $2.4 \mathrm{~m}(8 \mathrm{ft})$ wide on each side. A greater melt depth was desired, but soil composition variations as a function of depth, the amount and type of fluxing additives, and the method of adding the flux directly affected the depth achieved.

- Inorganic particulate releases from the melt to the off-gas system were minor. The ISV process effectively retained inorganic materials within the melt. Of the small quantities released (127 g), the off-gas treatment system performed a very efficient scrubbing and filtering of the particulates. No detectable particulate releases were measured out the stack after off-gas treatment.

- Organic contaminants were effectively destroyed to an 89 wt\% level for the fuel oil-contaminated Site 10 soil solely by the ISV melt, exclusive of any off-gas treatment. The overall ISV system destruction and removal efficiency (DRE) was $99.85 \mathrm{wt} \%$, which included the off-gas treatment system. Organic release concentrations to the hood were below the National Institute for 
Occupational Safety and Health/Occupational Safety and Health Administration (NIOSH/OSHA) permissible exposure limits for petroleum mixtures.

- Leach testing results for both the extraction procedure (EP) toxicity and toxic characteristics leach procedure (TCLP) leach tests showed that all metals of concern were below leach release limits. This indicates that inorganic contaminants were immobilized to a level that should allow the site to be listed as nonhazardous material according to regulatory criteria.

- The pretest soil samples showed the highest organic concentration in the surface soil samples of the original surface grade position. The posttest analyses showed that the samples in a region close to the block ( $<30 \mathrm{~cm}$ away) displayed a noticeable decrease in the organic concentration between the pre- and posttest samples from the same relative positions. The available data indicate that ISV processing will deplete a zone near the block of organic material but does not thermally transport the organic species away from the vitrification zone.

Pilot-scale testing further demonstrates the potential for ISV treatment of organic-contaminated soils from the Fire Training Area of the AEDC Site 10. Based on the results of the feasibility and pilot-scale verification tests, ISV can be used to effectively treat and remediate the contaminated soils at the AEDC Site 10 Fire Training Area. 


\section{PROCESS DESCRIPTION AND STATUS OF DEVELOPMENT}

In situ vitrification has been developed as a remedial action process for soils contaminated with hazardous chemical wastes and/or radionuclides. Figure 1 illustrates the operation of the ISV process. A square array of four molybdenum (Mo) and graphite electrodes is inserted into the ground to the desired treatment depth. Because soil is not electrically conductive when its moisture has been driven off, a conductive mixture of flaked graphite and glass frit is placed among the electrodes to serve as a starter path. An electrical potential is applied to the electrodes to establish an electrical current in the starter path. The flow of current heats the starter path and surrounding soil to well above the initial soil-melting temperatures of $1100^{\circ} \mathrm{C}$ to $1400^{\circ} \mathrm{C}$. The graphite starter path is eventually consumed by oxidation and the current is transferred to the molten soil, which is processed at temperatures between $1450^{\circ} \mathrm{C}$ and $2000^{\circ} \mathrm{C}$. As the molten or vitrified zone grows, it incorporates or encapsulates any radionuclides and nonvolatile hazardous elements, such as heavy metals, into the glass structure. The high temperature of the process destroys organic components by pyrolysis. The pyrolyzed byproducts migrate to the surface of the

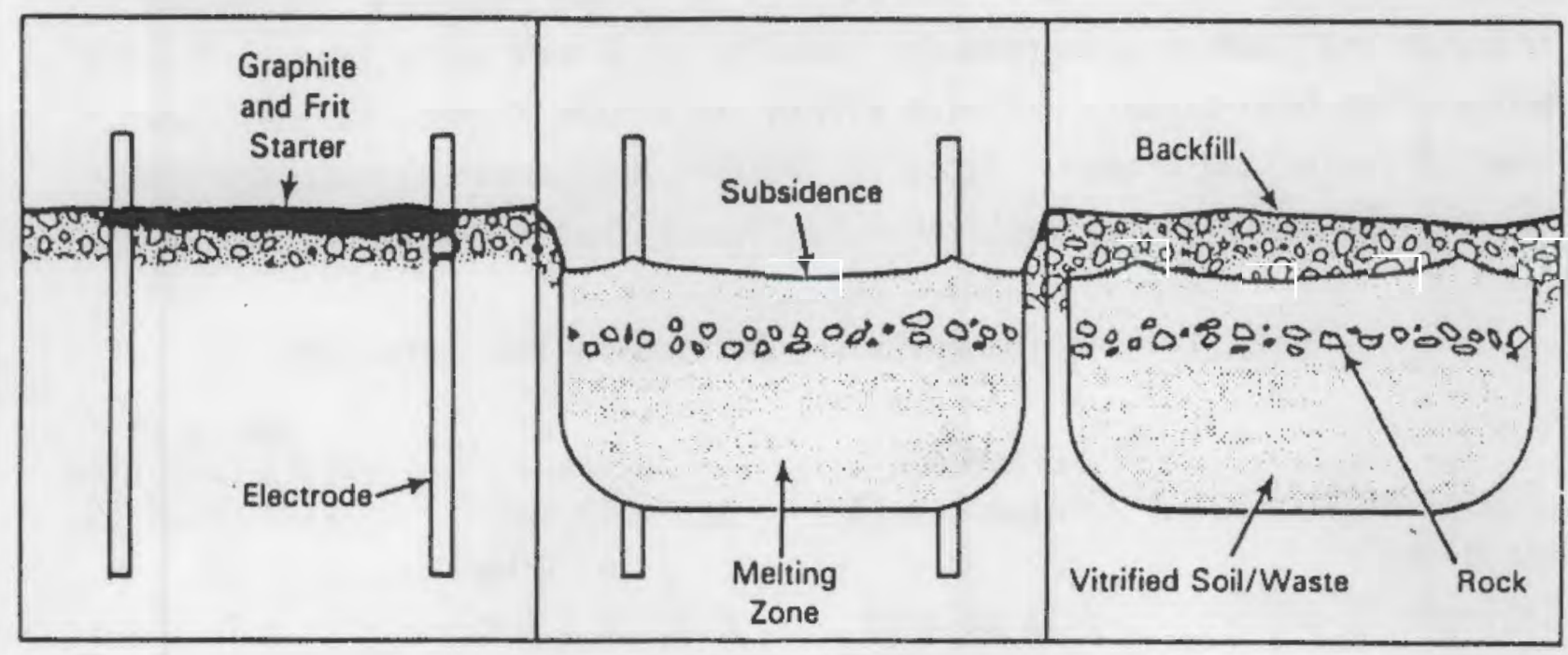

FIGURE 1. ISV Process 
vitrified zone, where they combust in the presence of air. A hood placed over the area being vitrified directs the gaseous effluents to an off-gas treatment system.

The process could also accommodate a staging operation alternative. In this processing alternative, outlying materials are placed on the surface of an area to be vitrified to increase the effective vitrification depth of each setting. Since ISV is a batch operation, this alternative will increase the amount of material vitrified in each batch setting, thereby improving the efficiency of the operation.

Pacific Northwest Laboratory began developing ISV technology in 1980. Since that time, numerous experimental tests under a variety of site conditions and with a variety of waste types have been conducted (Buelt et al. 1987; Timmerman and Oma 1984; Timmerman et al. 1983; 8uelt and Carter 1986a and 1986b; Carter et a1. 1987). Table 1 describes the different scales of testing units that PNL uses in developing and adapting ISV technology. The successfui results of 59 bench-, engineering-, pilot-, and large-scale tests have proven the general feasibility and widespread applications of the process. Also, economic studies have indicated that tremendous economies of scale are attainable with the ISV process (Oma et al. 1983). The ISV technology has been refined to the point that it is now ready for technology transfer and commercialization for specific hazardous waste types. The ISV process has been broadly patented within the United States, Canada, Japan, Great Britain, and France. Battelle, Pacific Northwest Laboratories (BNW) holds a partially exclusive license to those patents; BNW has exclusive

TABLE 1. Testing Units for Developing ISV Technology

\begin{tabular}{|c|c|c|c|}
\hline Equipment Size & $\begin{array}{c}\text { Electrode } \\
\text { Separation, m }\end{array}$ & $\begin{array}{l}\text { Block } \\
\text { Size }\end{array}$ & $\begin{array}{c}\text { Number of } \\
\text { Tests Completed } \\
\text { as of } 1 / 26 / 90\end{array}$ \\
\hline Bench-scale & 0.11 & 1 to $10 \mathrm{~kg}$ & 19 \\
\hline Engineering-scale & 0.23 to 0.36 & 0.05 to $1.0 \mathrm{t}$ & 33 \\
\hline Pilot-scale & 0.9 to 1.5 & 10 to $50 \mathrm{t}$ & 17 \\
\hline Large-scale & 3.5 to 5.5 & 400 to $800 t$ & 5 \\
\hline
\end{tabular}


worldwide rights to all ISV technology except for U.S. governmental applications of ISV to radioactive waste. Battelle recently transferred these licensing rights to Geosafe Corporation.

The decision to proceed with the design, fabrication, and testing of a large-scale unit was made on the basis of the extensive database developed as a result of engineering- and pilot-scale tests. The pilot-scale unit demonstrated the process using radioactively spiked soils and provided support for the decision to design and fabricate the large-scale system. Subsequent tests have been conducted with the bench-, engineering-, and pilot-scale units to determine processing behavior using various types of waste and to develop improved operating techniques.

The large-scale process equipment for transuranic (radioactive) contaminated soils has been fabricated and tested (Figure 2). The large-scale testing culminated in successful operation of the large-scale radioactive test on an actual radioactively contaminated soil site at Hanford in Washington State.

The extensive technical data for the ISV process establish the performance of the system and product, economics and safety, and waste site applications for radioactive and hazardous chemical wastes. These aspects of the process are summarized as follows:

- The estimated processing depth limit, independent of moisture content, of the large-scale ISv system is $10 \mathrm{~m}$ in Hanford soils. Depths up to $5 \mathrm{~m}$ have been demonstrated.

- Radionuclides and heavy metals are effectively retained within the me1t, and nitrates and organics are destroyed during processing.

- Generally, environmental regulations do not allow the direct evolution of the small percentage of heavy metals and organics that escape from the vitreous mass during processing. Therefore, an off-gas treatment system is included in the process to remove the contaminants from the gaseous effluents.

- A reference electrode design has been established for future ISV applications. This design employs a Mo and graphite combination to promote subsidence of the surface of the melt below the original soil grade. Oxidation of Mo during processing is prevented by the graphite collar, plus a fused coating of MoSi ${ }_{2}$ on the Mo electrode core. 


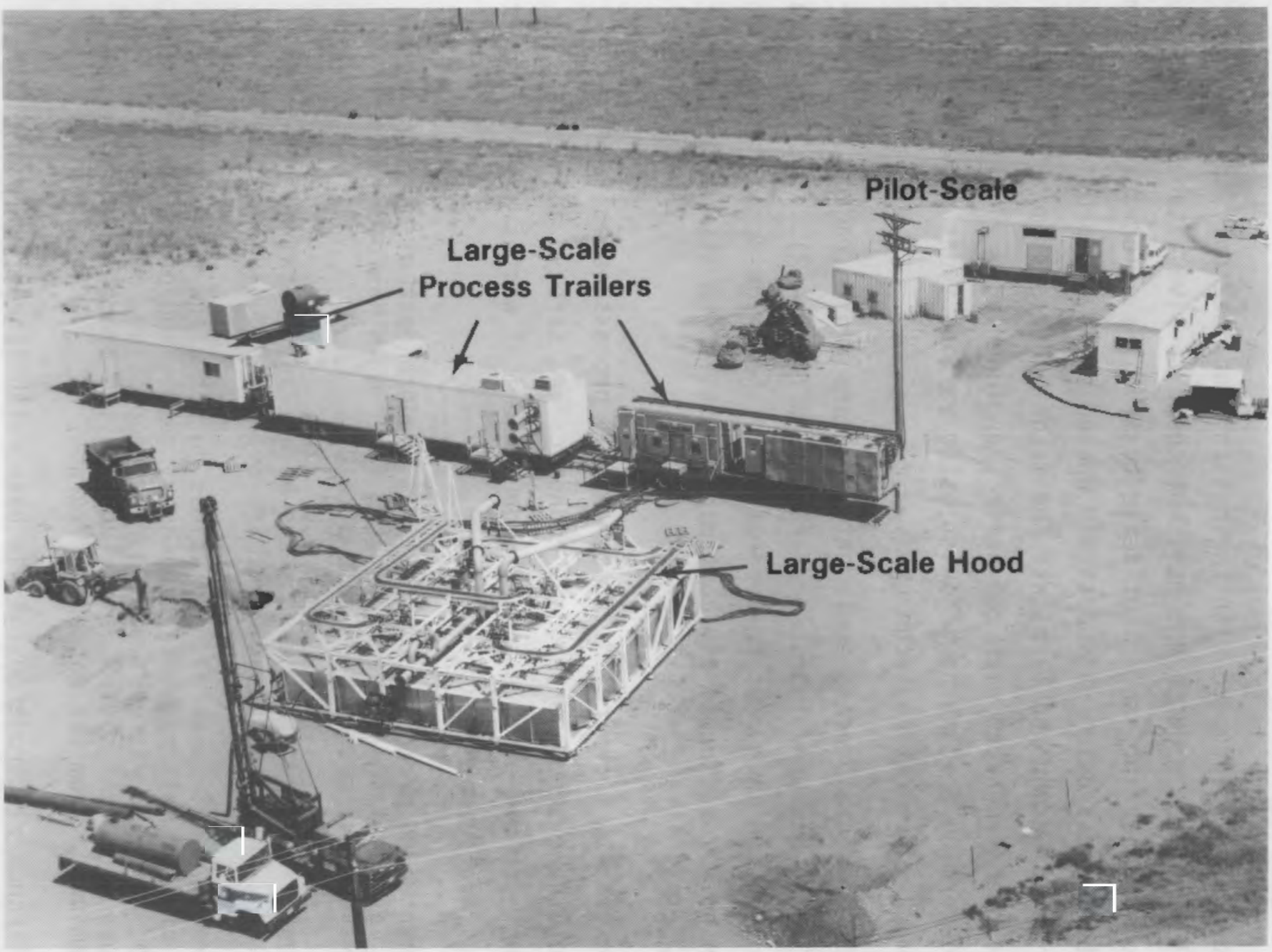

FIGURE 2. ISV Pilot-Scale and Large-Scale Systems 
- Metal inclusions do not significantly affect the ISV process unless a full electrical short circuit is approached.

- Cement inclusions are completely dissolved within the glass product.

- In situ vitrification is capable of processing various soil types throughout the United States. Soils from nine different U.S. locations were found to be similar in the properties that could affect the ISV process. Similar ISV processing capacity is anticipated for other worldwide soil types.

- The ISV product is expected to surpass established and proposed toxicity tests. Leachability of vitrified soil has been measured to establish and confirm these conditions.

- Soil moisture generally increases the time and power required to vitrify a waste site; however, the effect of moisture on the maximum attainable depths of ISV is small. Industrial sludges with a total moisture content (amount of water in the soil) as high as $70 \mathrm{wt} \%$ have been vitrified by ISV. 



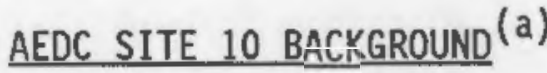

The AEDC is part of the Arnold Air Force Base located in southcentral Tennessee, southeast of Nashville and northwest of Chattanooga. The AEDC reservation occupies approximately 40,000 acres of 1 and and includes a 30,000-acre wild life management area operated by the Tennessee Wildlife Resources Agency. The majority of the Air Force activity on the reservation occurs within a 7,000 -acre fenced area.

Geologically, AEDC is located in the outcrop area of Quaternary-age sediments and Mississippian- and Devonian-age rocks (CH2M Hill 1989). A small southeastern portion of the installation is underlain at the surface by alluvial deposits. A much larger northern portion is underlain by the St. Louis and Warsaw limestones. One area along Spring Creek and Rollins Creek is underlain by the Ft. Payne and Chattanooga formations. The alluvial deposits are composed of unconsolidated sand, silt, and clay, whereas the St. Louis, Warsaw, Ft. Payne, and Chattanooga units are composed of consolidated rocks. The St. Louis is a dolomitic limestone; the Warsaw a bioclastic limestone, and the Ft. Payne is a cherty limestone. The Chattanooga unit is a shale. The lithologic types of rocks underlying AEDC are a determining factor on the ground-water occurrences and movement.

Site 10 is located within the fenced area and comprises approximately 14.5 acres, which include Landfill No. 1, Fire Training Area No. 2, and Burn Area No. 1, as shown in Figure 3. Site 10 is located in the northern portion of the fenced area, northwest of Building No. 451 (Model Shop) and northeast of Gate No. 5. The Fire Training Area No. 2 was constructed in 1973 and was the site for the pilot-scale ISV test.

Landfill No. 1 served as a disposal site for many wastes including refuse, garbage, construction debris, and shop wastes. The shop wastes were generally placed in a trench located at or near Landfill No. 1 and burned (this area is known as Burn Area No. 1). Some of the shop wastes include

(a) This section was adapted from a CH2M Hill Site 10 analytical report (CH2M Hill 1989). 


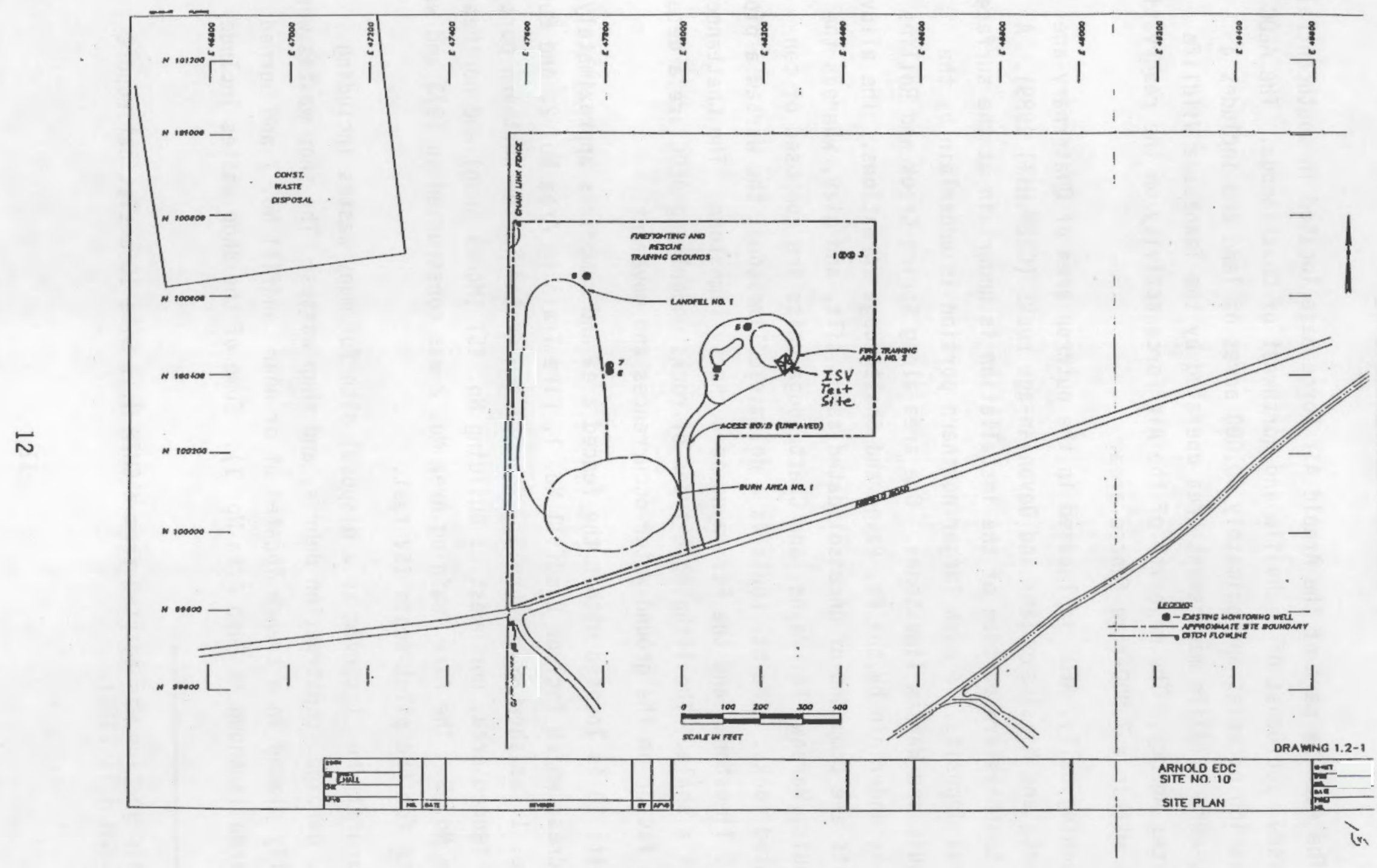

FIGURE 3. AEDC Site $10 \mathrm{Plan}$ 
waste oils, contaminated fuels, solvents, thinners, and other combustible wastes. Along the western edge of Landfill No. 1 is a bermed area that contains fly ash from when the AEDC power plant burned coal. In the eastern and northern portion of Site 10 , metal shop wastes, such as metal scraps and turnings, were buried. Materials visible along the edges of the site indicate that concrete and other construction debris may also have been buried in this landfill (CH2M Hill 1989).

Fire Training Area No. 2 consists of an unlined gravel burning area, with drains connected to a small overflow pond. During the burn procedures, water is first applied to the surface of the burning area, followed by application and ignition of the combustible fuel. Materials beneath Fire Training Area No. 2 have been contaminated by petroleum fuels and fuel filters, waste oils, thinners, solvents, some propellants, and the products of incomplete combustion. The latest materials burned have consisted primarily of JP-4 fuel and some sodium-potassium (NaK) alloys. Approximately 1900 to $2300 \mathrm{~L}$ (500 to $600 \mathrm{ga} 7$ ) of fuels were consumed during a burn. Normally 20 to 21 burns per year are conducted. The Fire Training Area has not been used since April 1988. The contaminants identified above were the constituents of concern for the ISV test. 



\section{PILOT-SCALE TEST SYSTEM}

The pilot-scale test system at AEDC used four electrodes with $0.9 \mathrm{~m}$ ( $3 \mathrm{ft}$ ) separation and consisted of a power control unit, an off-gas containment hood over the test site, and an off-gas treatment system housed in a portable semi-trailer (see Figure 4). Prior to the AEDC test, this same system had been used on 11 pilot-scale tests at the Hanford Site and 1 test at the Oak Ridge, Tennessee site.

\section{POWER SYSTEM DESIGN}

The pilot-scale power system uses a Scott-Tee connection to transform a 3-phase input to a 2-phase secondary load on diagonally opposed electrodes in a square pattern. The $500-\mathrm{kW}$ power supply may be either voltage or current regulated. The aiternating current primary is rated at $480 \mathrm{~V}, 600 \mathrm{~A}$, 3-phase, and $60 \mathrm{~Hz}$. This 3-phase input feeds the Scott-Tee connected transformer (see Figure 5), providing a 2-phase secondary. The transformer has four separate voltage tap settings--1000 V, $650 \mathrm{~V}, 430 \mathrm{~V}$, and $250 \mathrm{~V}$. Each voltage tap has a corresponding amperage rating of $250 \mathrm{~A}, 385 \mathrm{~A}, 580 \mathrm{~A}$, and $1000 \mathrm{~A}$ per phase, respectively. The amount of 3-phase input power delivered

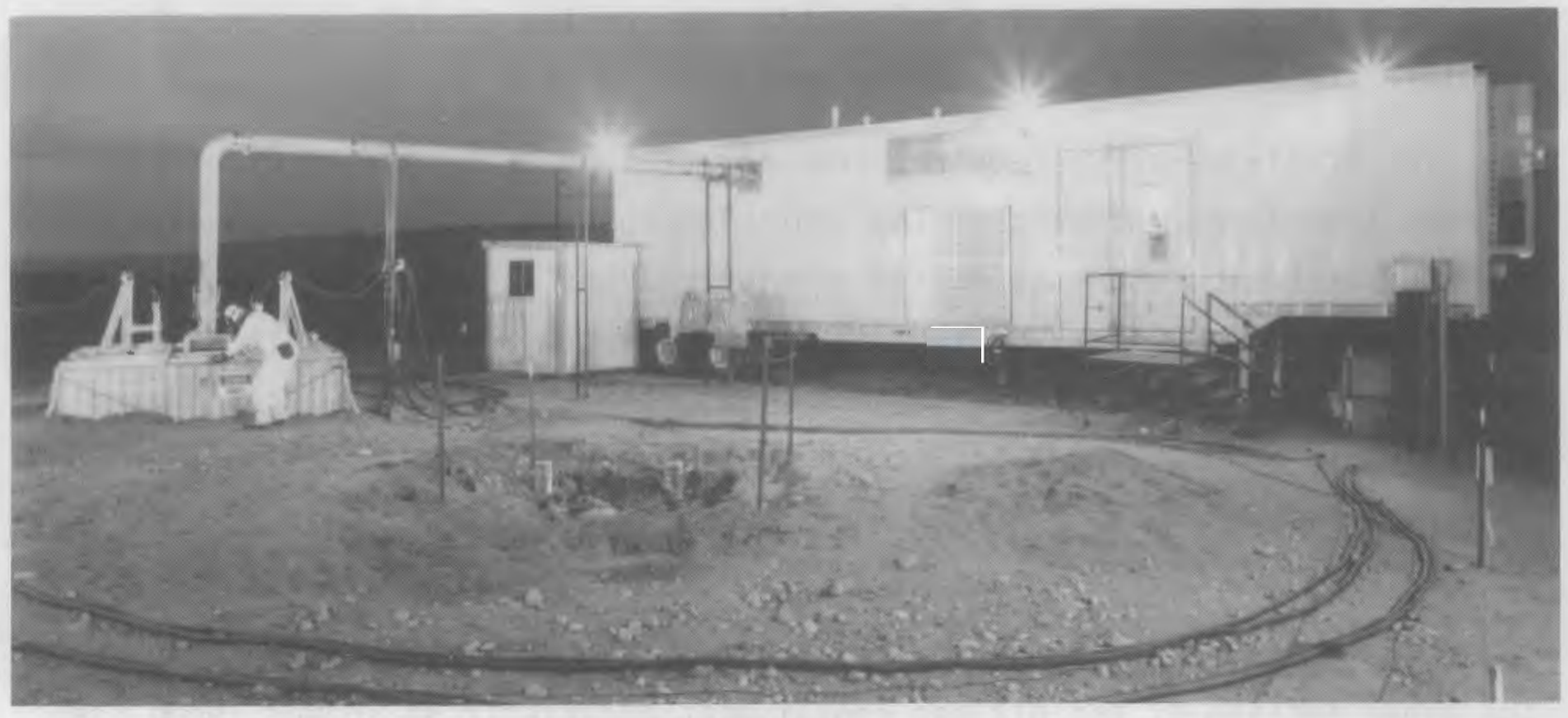

FIGURE 4. Typical Pilot-Scale ISV Hood and Process Trailer Arrangement 


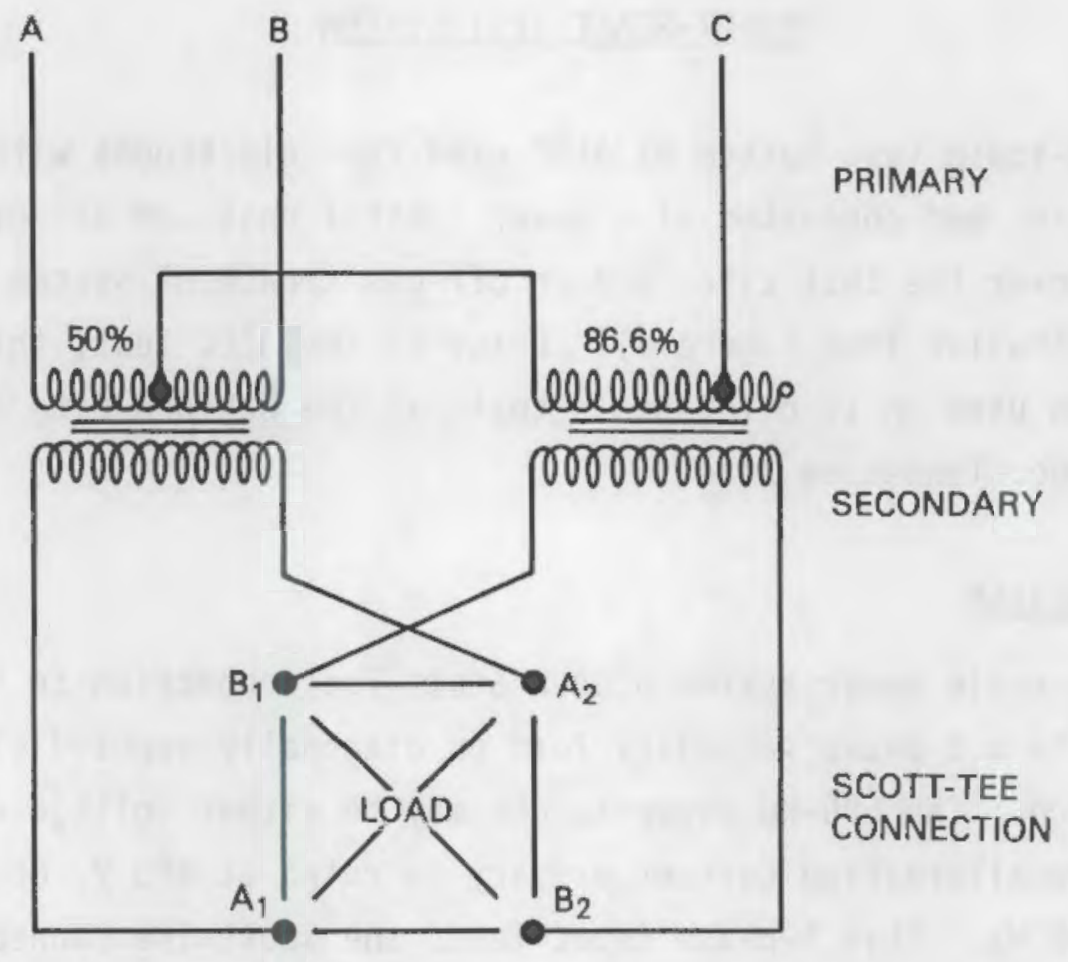

FIGURE 5. Scott-Tee Electrical Connection for the Pilot-Scale ISV System

to the transformer is controlled by adjusting the conduction angle of the thyristor switches located in each of the three input lines. These switches, in conjunction with selectable taps on the transformer secondary, regulate the amount of output power delivered to both secondary phases.

The Scott-Tee setup requires transformer taps at 50 and $86.6 \%$ of the primary transformer windings. The Scott-Tee connection provides an even power distribution when the molten zone approaches a uniform resistance load. The primary and secondary current is balanced for a Scott-Tee system when a balanced load exists. During the AEDC test, this power system proved very effective in maintaining a balanced load to the electrodes.

\section{OFF-GAS CONTAINMENT AND ELECTRODE SUPPORT HOOO}

Constructed from 7 panels of 20 -gauge stainless steel bolted together, the upper section of the off-gas containment and electrode support hood (see Figure 6) is $3.05 \mathrm{~m}(10 \mathrm{ft})$ wide by $5.5 \mathrm{~m}(18 \mathrm{ft})$ long. The lower portion of 


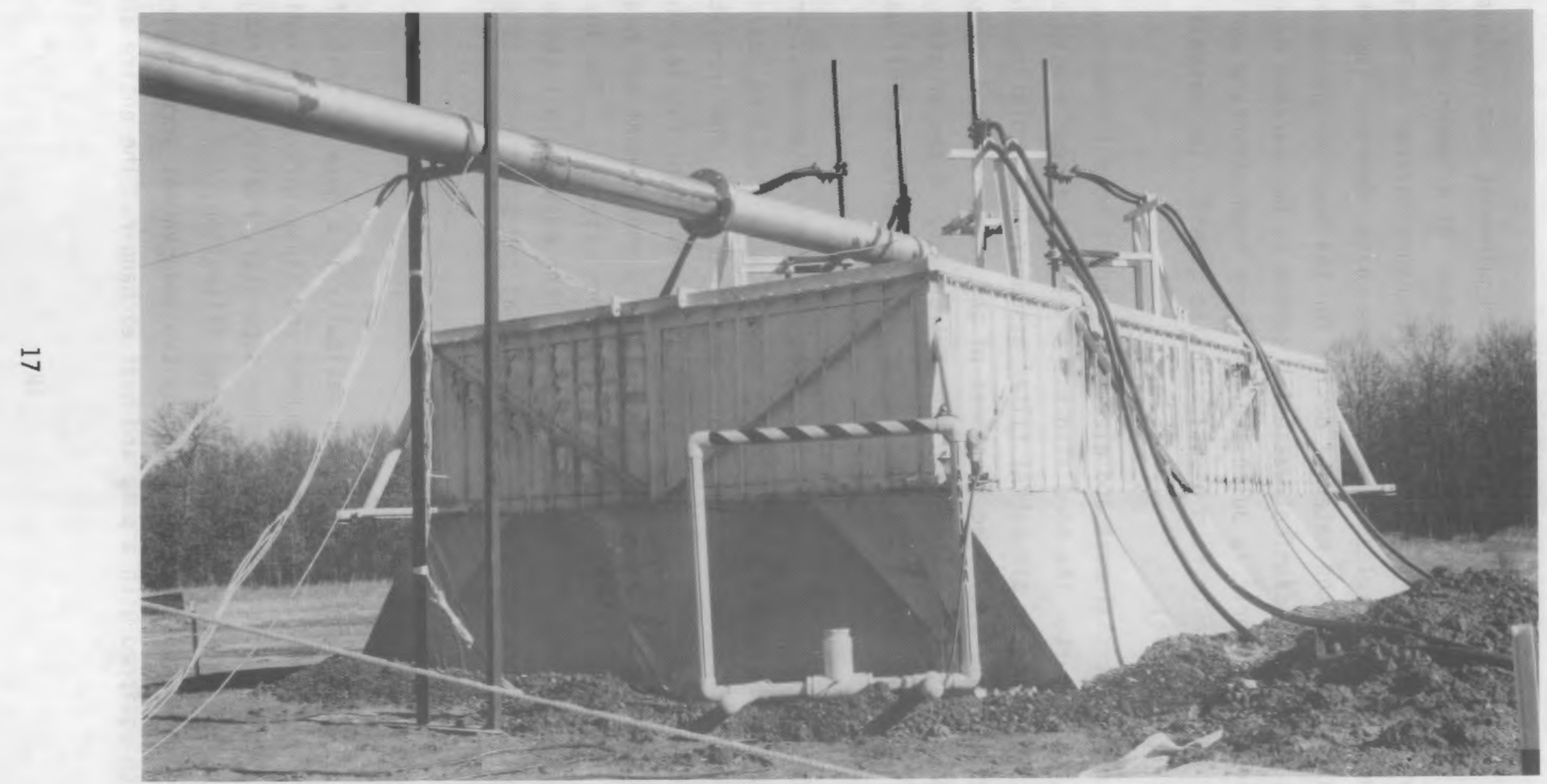

FIGURE 6. Off-Gas Containment and Electrode Support Hood 
the hood is the result of a system upgrade requirement that expanded the capacity of the hood, which minimized the impact of a sudden gas release. This lower structure is simply a support structure covered and sealed with high-temperature, fiberglass-based, silicone-coated fabric. The choice of fabric was based upon the material design for the hood on the recently constructed hazardous chemical waste ISV system to be operated by Geosafe Corporation. The fabric is bolted to the upper hood structure and covered with soil at the base to form a seal with the ground. The overall hood height is $1.8 \mathrm{~m}(6 \mathrm{ft})$.

The off-gas containment and electrode support hood includes a viewing port and access port. The hood also has a seal pot assembly with a highefficiency particulate air (HEPA) filter assembly for regulating the vacuum on the hood and for providing treatment of any gases released during a hood pressurization prior to release to the environment. A center off-gas port allows direct coupling of the hood to the processing van and off-gas treatment system.

Electrical bus bars, consisting of Mo electrode extensions, protrude through the hood and are surrounded by electrically insulated boards that allow adjustment of the electrode position (Figure 7). The insulating boards seal to the hood and the same high-temperature-resistant fabric, which was used for the lower section of the hood, forms a containment and heat seal from the insulating boards to the electrode bus extension. The insulators are designed to withstand movement of the molten mass against the electrodes from convective currents and the gravitational and buoyant forces exerted on the electrodes.

\section{OFF-GAS TREATMENT SYSTEM}

The off-gas system is shown schematically in Figure 8 . The off gas passes through a venturi-ejector scrubber and separator, Hydro-Sonic scrubber, separator, condenser, another separator, heater, one stage of HEPA filtration, one stage of activated carbon filtration, and a blower. Liquid to the two wet scrubbers is supplied by two independent scrub recirculation tanks, each equipped with a pump and heat exchanger. The entire off-gas 


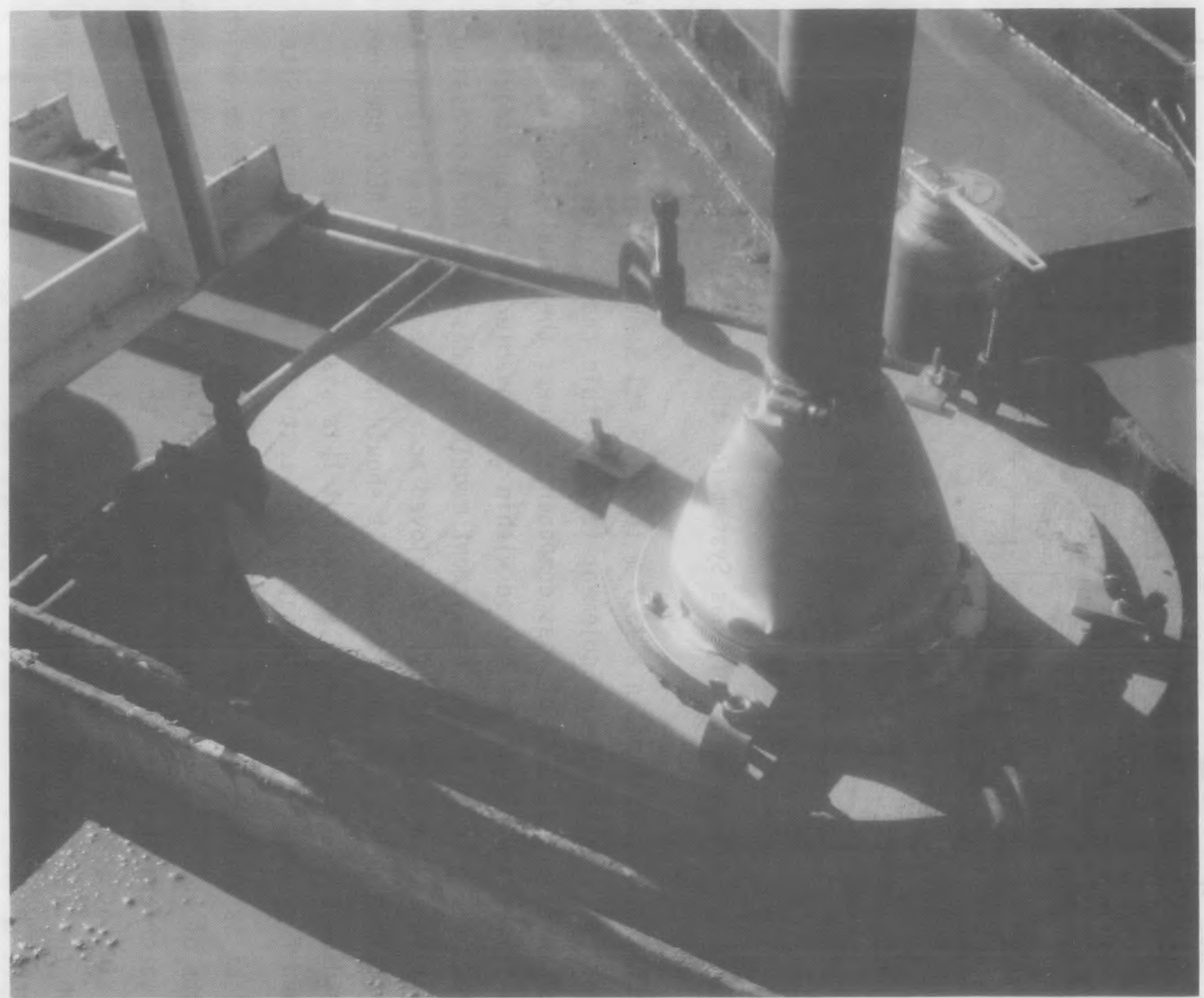

FIGURE 7. Electrode Bus Bar to Hood Seal Insulating Board Connection 


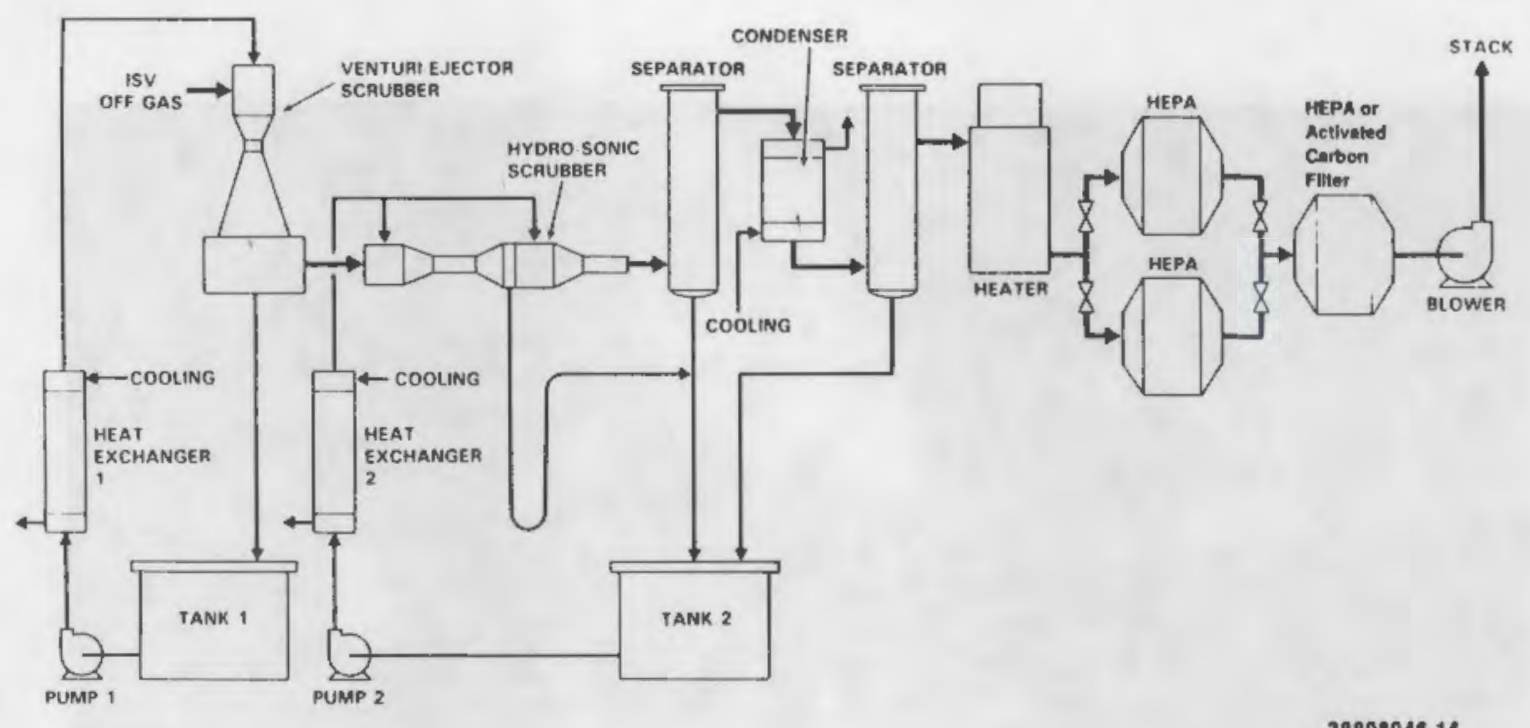

38808046.14

FIGURE 8. Schematic of Off-Gas System for the Pilot-Scale ISV Process

system has been installed in a $13.7-\mathrm{m}-1$ ong ( $45 \mathrm{ft}$ ) semi-trailer to facilitate transport to a waste site. Equipment layout within the trailer is illustrated in Figure 9. All off-gas components except the final-stage activated carbon filter and blower are housed within a removable containment module pictured in Figure 10. The containment module was designed for processing radioactive-contaminated soils, has gloved access for remote operations, and is maintained under a slight vacuum. It should be noted that AEDC does not have radioactively contaminated soils, but this system was originally designed for radioactive-contaminated soil testing at the DOE Hanford Site.

Heat is removed from the off gas by a closed loop cooling system, which consists of an air/liquid heat exchanger, a coolant storage tank, and a pump. A 50\% water/ethylene glycol mix is pumped from the storage tank through the shell side of the condenser and the two scrub solution heat exchangers, then through the air/liquid exchanger, where heat is removed from the coolant and discharged back to the air.

The venturi-ejector scrubber serves both as a quencher and high-energy scrubber. The second scrubber is a two-stage Hydro-Sonic scrubber (tandem nozzle scrubber), as illustrated in Figure 11. The first section condenses 


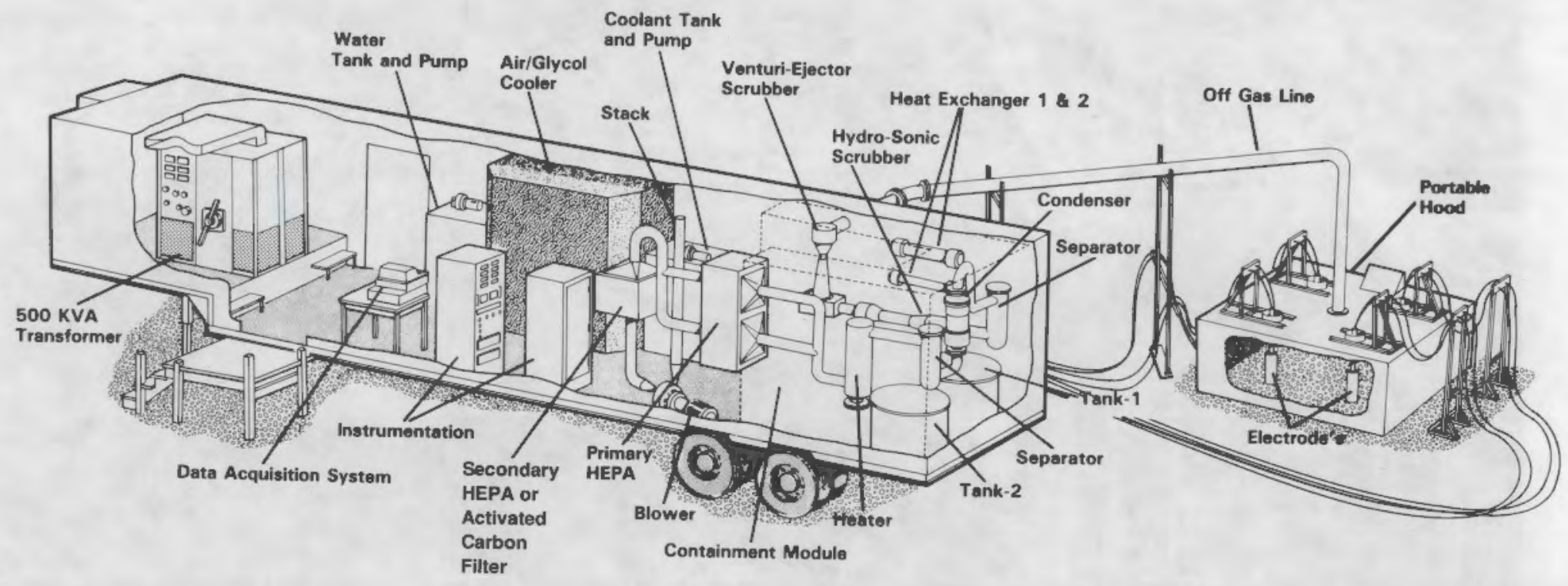

38911054.2

FIGURE 9. Cutaway View of Pilot-Scale ISV Process Trailer and Hood 


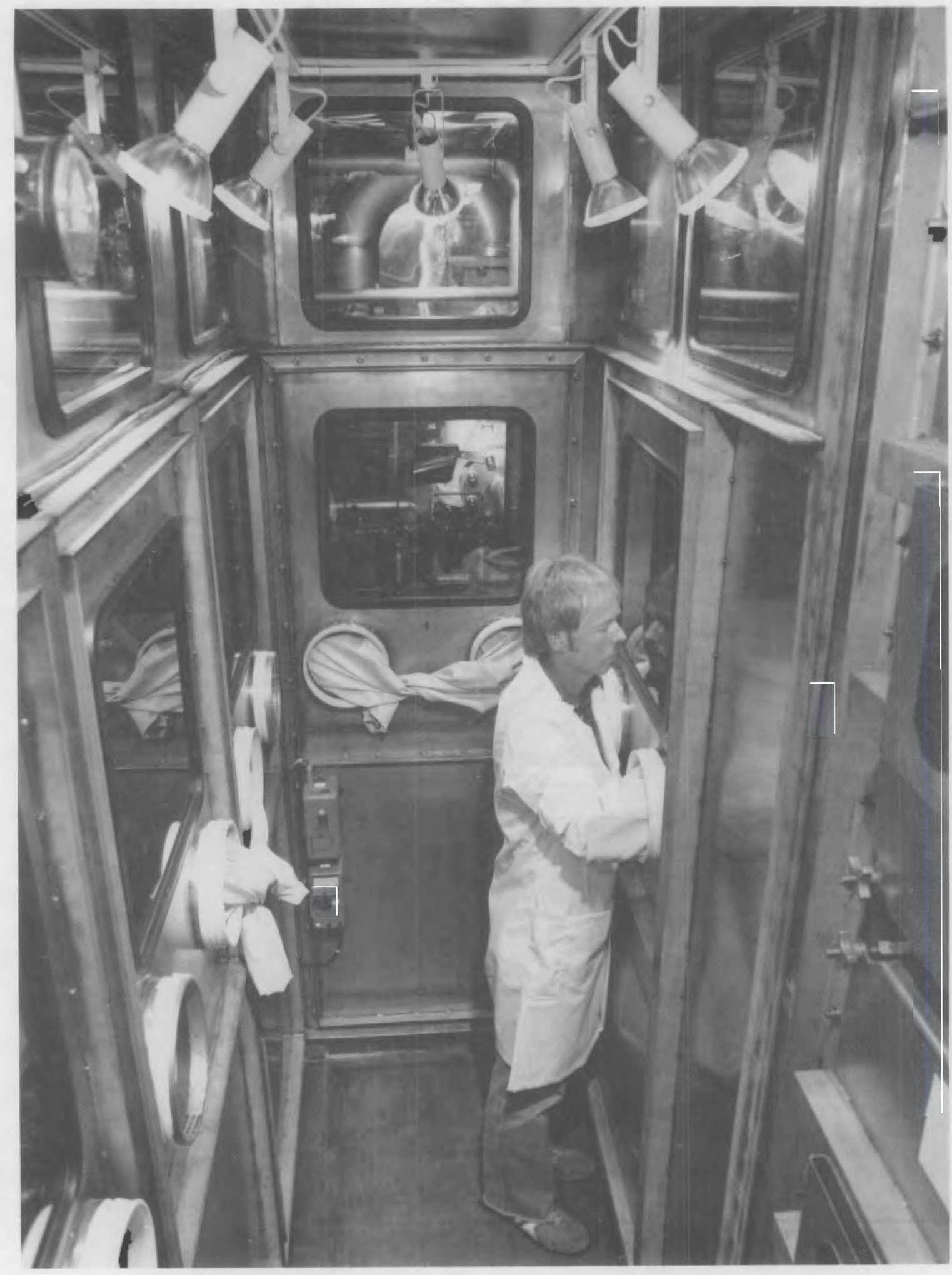

FIGURE 10. Off-Gas System Containment Module 


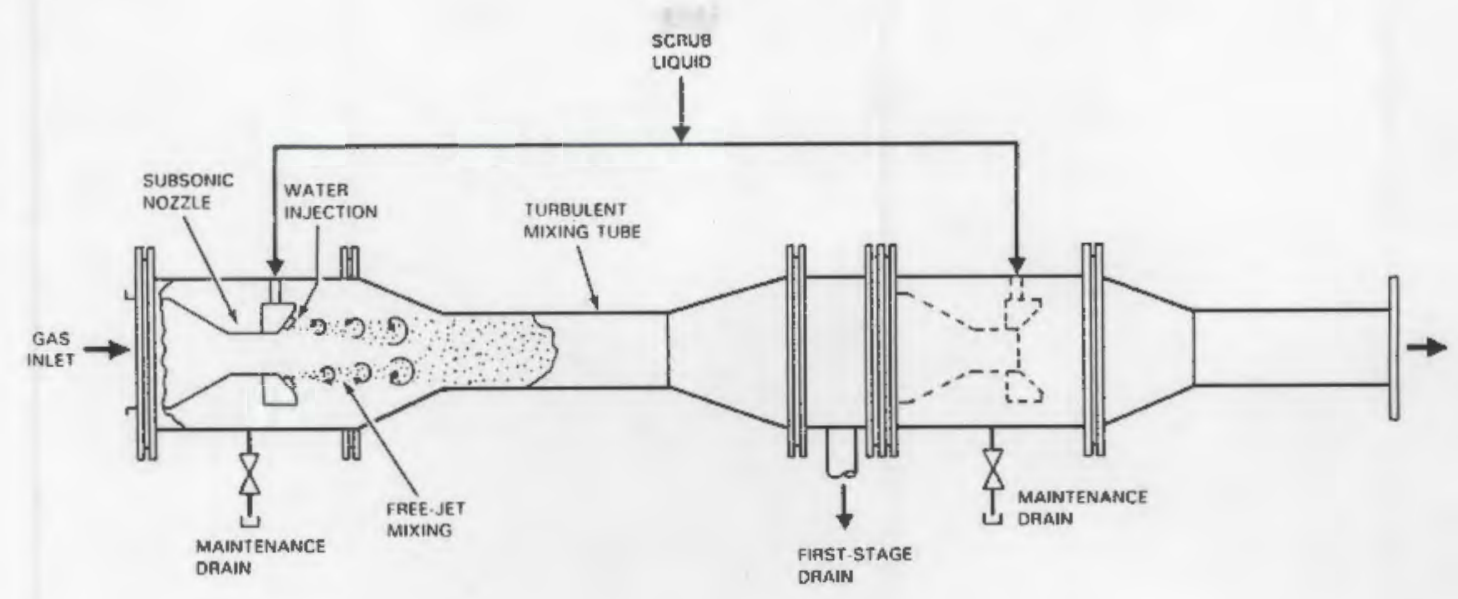

36100006.17

FIGURE 11. Tandem Nozzle Hydro-Sonic Scrubber (Hydro-Sonic Systems, Dallas, Texas)

vapors, removes larger particles, and initiates growth of the finer particles so that they are more easily captured in the second stage. Particulate is captured when the gas is mixed with fine water droplets produced by spraying water into the exhaust of the subsonic nozzle. Mixing and droplet growth continue down the length of the mixing tube. Large droplets containing the particulate are then removed by a vane separator and drained back into the scrub tank. The unit is designed to remove over $90 \%$ of all particulates greater than $0.5 \mu \mathrm{m}$ in diameter when operated at a differential pressure of $127-\mathrm{cm}$ (50 in.) water. Removal efficiency increases with an increase in pressure differential.

Additional water is removed from the gas system by a condenser having a heat exchange area of $8.9 \mathrm{~m}^{2}\left(96 \mathrm{ft}^{2}\right)$ and a final separator. The gases are then reheated $25^{\circ} \mathrm{C}$ above the dew point in a $30-\mathrm{kW}$ heater to prevent condensate carryover to the filters.

The first stage of filtration consists of two $61 \times 61 \times 29-\mathrm{cm}(24 \times 24 \times$ 11.5-in.) HEPA filters in parallel. During operation, one filter is used and the other remains as a backup in case the generating filter becomes loaded. The primary filter can be changed out during operation without process shutdown. The second-stage filter is an activated carbon filter that provides organic removal capabilities plus acts as a backup particulate filter in case a first-stage filter fails. 



\section{THEORETICAL BASIS FOR ORGANIC DESTRUCTION BY ISV}

The behavior of organics during ISV processing is controlled by several interrelated mechanisms. These mechanisms include: 1) molecular diffusion; 2) carrier gas transport; 3) capillary forces; 4) flow resistance in the soil column; 5) sorption of the liquid and vapor phase onto the soil; and, 6) pyrolysis (Battelle Northwest 1988). A discussion of these mechanisms is summarized in Appendix A. Pyrolysis affects the destruction of organics as the organics move upward through the melt and adjacent to the molten mass where the processing temperature is above the pyrolysis temperature of organics. The other five mechanisms affect the movement of organics in the vicinity of the melt. A numerical value is not available to define the relative effectiveness of each mechanism for the spectrum of contaminant concentrations and soil types encountered. However, it is important to understand the effect of each mechanism, how the mechanisms interrelate, and their scientific validity.

It is not uncommon, when first encountering ISV technology, to think that organics may be driven outward by the heating process into the surrounding soil. However, the aforementioned mechanisms support experimental observations made during the development and demonstration of the ISV process that the opposite effect occurs. Experimental data consistently demonstrate that the majority of organics are destroyed or removed from the contaminated soi1. Destruction up to $99.9985 \%$ has been observed for a spectrum of organics with attendant DREs of $>99.9999 \%$. Residual amounts of organics remaining in the soil not treated by ISV after processing have ranged from nondeductible residuals up to $2.9 \%$ of the original contaminants remaining in the surrounding soil after ISV treatment (the higher value resulted from an incomplete test that was shutdown for other reasons prior to complete vitrification of the contaminated soi1). These data support the conclusions that the controlling mechanisms enhance destruction/removal and not thermal transport.

Additional compelling evidence of the validity of the mechanisms affecting the DRE for the ISV process is provided in a recent paper (Dev et al. 1988). This paper describes the results of a radio frequency (RF) 
heating field test on a site contaminated with spilled jet fuel. The contaminants involved were volatile aromatics and aliphatics and semi-volatile aliphatics. While the temperatures and temperature gradients were not as significant as in the ISV process, all of the mechanisms discussed above were observed during the field test.

During this field test, thermal transport into and out of the heated zone was assessed by injecting tracers and by sampling the soil in the zone immediately outside the heated soil volume. Halon, a mobile tracer injected $1.2 \mathrm{~m}(4 \mathrm{ft})$ outside the heated zone at a depth of $1.8 \mathrm{~m}(6 \mathrm{ft})$, was detected in the off-gas stream being collected from the heated zone. A new reduction of 70 to 76 wt\% organics was observed in the immediate area outside the heated zone, with no measurable outward thermal transport of organics. The authors of this RF heating paper concluded, based on the test results, that there was no thermal transport of contaminants from the heated area to the surrounding soil.

During ISV processing, there is a steep thermal gradient that advances at a rate of 2 to $7 \mathrm{~cm} / \mathrm{h}(1$ to $3 \mathrm{in.} / \mathrm{h})$. The outward thermal gradient is typically 70 to $100^{\circ} \mathrm{C}$ per $\mathrm{cm}$ soil. Therefore, the $100^{\circ} \mathrm{C}$ isotherm is usually within 22 to $30 \mathrm{~cm}$ ( 9 to $12 \mathrm{in.)}$ of the melt during the processing operation. The relationship of the mechanisms can best be visualized by comparing the ISV process to the consumption of wax as a candle burns (Battelle Northwest 1988).

First, in the candle, molten wax is drawn up the wick toward the heat of the flame. This occurs because capillary forces draw the wax up the wick to replace wax vaporized at the top by the flame. Similarly, in the ISV process, water and liquid organics are drawn by capillary forces toward a region near the melting soil that is being dried by the evaporation of water.

Second, in the candle, vaporized wax is swept into the flame by the convection of air along the wick. Similarly, in the ISV process, soil moisture is converted to steam and the attendant pressurization forces steam into the melt, or upward along the boundary of the melt, as is evident from the virtually complete recovery of soil moisture in the ISV off-gas system 
(Battelle Northwest 1988). The steam flow sweeps vaporized organics along the same path, either into the melt or alongside the molten region to the off-gas collection hood.

Finally, in the candle, some vaporized wax condenses back on the wick, since the wick is much cooler than the flame. However, consumption of wax by pyrolysis in the base of the flame creates a concentration gradient that "pulls" the vapor into the flame by diffusion. Similarly, in the ISV process, the very high temperature of the molten soil $\left(1400\right.$ to $2000^{\circ} \mathrm{C}$ ) causes organics to be consumed by pyrolysis, creating a concentration difference between the melt and the region where organics are volatilized. This concentration gradient "pulls" vapor toward the melt by diffusion. Vapors also diffuse away from the molten soil and condense; however, the evaporation of organics and their thermal transport to a region of condensation is reversible, while the loss of organics by pyrolysis or by the steam flow is irreversible. Consequently, in the course of the ISV process, pyrolysis and steam transport are dominant mechanisms, resulting in the observed efficient destruction of organics.

As the organic vapors move through the molten soil or in the dry soil region toward the off-gas hood, they pyrolyze in the absence of oxygen (0). Specifically, polychlorinated biphenyls (PCBs) are calculated to be exposed in the pyrolysis region for a minimum retention time of $5 \mathrm{sec}$ at temperatures up to $1600^{\circ} \mathrm{C}$. These conditions exceed the 2-sec retention time (dwell time) required by the Toxic Substances Control Act (TSCA) for incinerators. The calculated residence time is conservatively estimated based on vitrifying soils with 25 wt\% moisture and on the assumption that all the moisture and organic vapors travel to the off-gas hood through the 15-cm-thick dry soi? region. In actual tests, a significant portion of the gases have been observed to be released through the molten soil, which results in even greater destruction efficiencies.

\section{FATE OF PYROLYSIS PRODUCTS}

During pyrolysis of PCBs in the dry soil region or molten soil, fumes of chlorides and combustible products such as methane and hydrogen $(\mathrm{H})$ are 
released into the hood. The combustible products are converted to $\mathrm{CO}_{2}$ and $\mathrm{H}_{2} \mathrm{O}$ when they meet air introduced into the hood. The chlorides are scrubbed out in the wet scrubber of the off-gas treatment system as $\mathrm{HCl}$. Caustic is periodically added to the scrubber solution to neutralize the $\mathrm{HCl}$, producing nonhazardous $\mathrm{NaCl}$ and water as follows:

$$
\mathrm{NaOH}+\mathrm{HCl} \longrightarrow \mathrm{NaCl}+\mathrm{H}_{2} \mathrm{O}
$$

\section{EXPLOSION POTENTIAL}

There is no threat of explosion in the hood because the air sweep through the hood keeps the maximum estimated methane concentration at a factor of 5 below the lower explosion 1 imit and the maximum hydrogen concentration at a factor of 10 below its lower explosion limit (Sax and Lewis 1987). In addition, the high temperature of the gases emanating from the melt and the 0-rich atmosphere in the hood ensures that combustibles are oxidized immediately upon contact with air in the hood. Measurements have shown negligible concentrations $\left(5 \times 10^{-3}\right.$ vol\%) of combustibles exiting the hood (Oma, Farnsworth, and Timmerman 1984). 


\section{IEST DESCRIPTION}

The primary objective of the AEDC pilot-scale test was to confirm the bench-scale feasibility testing results (Timmerman 1989) on the actual site 10 Fire Training Area contaminated soils. The testing evaluated the effectiveness of process operations and off-gas behavior of volatile or entrained materials. As determined from the bench-scale feasibility testing, AEDC soils require a fluxing additive (e.g., sodium carbonate) to increase the electrical conductivity to allow ISV processing. The bench-scale analyses completed in 1988 had shown that not enough alkali fluxing material (0.3 wt\% $\mathrm{Na}_{2} \mathrm{O}$ ) was present in the Site 10 soil. Typically, an ISV melt requires 3 to 5 wt\% alkali oxide content in the melt for proper operation. Therefore, this earlier testing effort determined the need to add fluxes to the pilot-scale test soils.

The additives were placed differently in the pilot-scale test than they were in the initial bench-scale test. The smaller test allowed total blending of the fluxing additive $\left(\mathrm{Na}_{2} \mathrm{CO}_{3}\right)$ with the entire soil volume. This original recommended method of mixing the fluxing additive with the entire pilot-scale test volume to be vitrified was revised because of the client's desire to determine if effective depths could be achieved without disturbing the contaminated soil. Consequently, a higher fluxing additive concentration (27 wt\%) was mixed with the clean surface cover soil placed over the contaminated soil site to be vitrified. Besides providing a fluxing additive volume, the cover soil also serves to enhance the process destruction efficiency of the organic contaminants by ISV. The cover soil allows ISV to establish a molten zone of soil prior to contacting the organic contaminants. This thermal inertia mass of molten soil achieves pyrolysis of the organics as opposed to volatilizing the organics if ISV were started at the contaminated soil surface. The cover soil/additive mixture was positioned

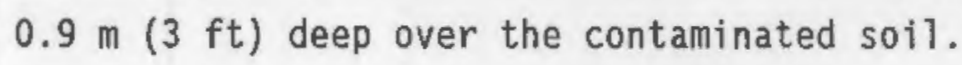

Four $5 \mathrm{~cm}$ ( 2 in.) in diameter cores with $15 \mathrm{~cm}$ ( 6 in.) in diameter graphite collar electrodes were placed to the $3.05 \mathrm{~m}(10 \mathrm{ft})$ depth from the cover soil surface. The electrodes were positioned on a $0.9-\mathrm{m}(3 \mathrm{ft})$ square separation. Two of the electrodes had fiber optic, depth-monitoring 
transmitters (Buelt et al. 1987) attached to them. These depth-monitoring systems were intended to track the depth progress of the ISV me1t.

The test was performed on the southern edge of the Fire Training Area. This site was chosen to allow application of ISV to an actual portion of the contaminated site and to allow thermal transport monitoring to the clean surrounding soil. To assess the effects of ISV processing on the soil, pretest and posttest soil core sampling was performed to obtain before and after soil profiles. Pretest samples were taken at various depths to $4.27 \mathrm{~m}(14 \mathrm{ft})$ at the center and around the four sides of the projected vitrification zone. Posttest samples were taken on two sides of the produced block at various distances away and at one angled core to obtain surrounding soil data below the vitrified block. The performance results associated with this and other testing aspects are presented in the next section.

The AEDC pilot-scale test was successful in destroying or containing the contaminants within the vitrified product or off-gas treatment system. An organic destruction efficiency (DE) of 89 wt\% was achieved with the ISV process alone. Coupling the off-gas treatment system with a single activated carbon filter to the DE yields an overall DRE of $99.85 \mathrm{wt} \%$ for the entire ISV operation. The pilot-scale test proved to be an effective test for verifying the ISV process applicability to the Site 10 Fire Training Area soils. Analysis of the ISV system performance is tied to certain test events or processing conditions that could affect interpretation of the data. Table 2 lists the significant test events and their time of occurrence. Specific system performance and testing results of the AEDC test and their relation to these test events are presented in the next section. 
IABLE 2. Chronological List of Events During the AEDC Pilot-Scale ISV Test

\begin{tabular}{|c|c|c|c|}
\hline Date & $\begin{array}{l}\text { Actual } \\
\text { Time }\end{array}$ & $\begin{array}{c}\text { Run Time, } \\
\mathrm{h} \\
\end{array}$ & Event Description \\
\hline $2 / 2$ & $\begin{array}{l}1430 \\
1733 \\
1935 \\
2150 \\
2230\end{array}$ & $\begin{array}{l}0.0 \\
3.1 \\
5.1 \\
7.3 \\
8.0\end{array}$ & $\begin{array}{l}\text { Startup. Power transformer on } 650-V \text { tap } \\
\text { Power transformer switched to } 430-V \text { tap } \\
\mathrm{CO}^{-} \mathrm{CO}_{2} \text { generation increasing } \\
\text { Vacuum fluctuations } \\
\text { B-phase amperage beginning to decrease }\end{array}$ \\
\hline \multirow[t]{3}{*}{$2 / 3$} & 0217 & 11.8 & \multirow{3}{*}{$\begin{array}{l}\text { Transformer varistor failed (power-phase } \\
\text { imbalance) } \\
\text { Varistor failed again } \\
\text { Varistor failed again } \\
\text { Lost B-phase, power off } \\
\text { Laid new starter path } \\
\text { Restart. Power back on ( } 650-V \text { tap) with new } \\
\text { starter path } \\
\text { Power transformer switched to } 430-V \text { tap and } \\
\text { current control }\end{array}$} \\
\hline & $\begin{array}{l}0635 \\
0750 \\
1425 \\
1800 \\
2014\end{array}$ & $\begin{array}{l}16.1 \\
17.3 \\
23.9 \\
27.5 \\
29.7\end{array}$ & \\
\hline & 2320 & 32.8 & \\
\hline $2 / 4$ & $\begin{array}{l}0502 \\
1619 \\
1625\end{array}$ & $\begin{array}{l}38.5 \\
49.8 \\
49.9\end{array}$ & $\begin{array}{l}0.6 \mathrm{~m}(2 \mathrm{ft}) \text { depth reached } \\
\text { Transformer switched to } 250-V \text { tap } \\
0.9 \mathrm{~m}(3 \mathrm{ft}) \text { depth reached }\end{array}$ \\
\hline $2 / 5$ & $\begin{array}{l}2138 \\
2200\end{array}$ & $\begin{array}{l}79.1 \\
79.5\end{array}$ & $\begin{array}{l}\text { Removed shunts on voltage meters } \\
1.2 \mathrm{~m}(4 \mathrm{ft}) \text { depth projected }\end{array}$ \\
\hline \multirow[t]{2}{*}{$2 / 6$} & 0019 & 81.8 & \multirow{2}{*}{$\begin{array}{l}\text { Lateral growth to } 0.3 \mathrm{~m}(1 \mathrm{ft}) \text { outside } \\
\text { electrodes }\end{array}$} \\
\hline & $\begin{array}{l}0209 \\
1740\end{array}$ & $\begin{array}{l}83.7 \\
99.2\end{array}$ & \\
\hline $2 / 7$ & 0605 & 111.6 & $\begin{array}{l}\text { Lateral growth to } 0.6 \mathrm{~m}(2 \mathrm{ft}) \text { outside } \\
\text { electrodes }\end{array}$ \\
\hline $2 / 8$ & $\begin{array}{l}0305 \\
1130\end{array}$ & $\begin{array}{l}132.6 \\
141.0\end{array}$ & $\begin{array}{l}\text { Power at } 150 \mathrm{~kW} \\
\text { Rod measurement of glass depth } 1.52 \mathrm{~m}(5 \mathrm{ft})\end{array}$ \\
\hline \multirow[t]{2}{*}{$2 / 9$} & 0915 & 162.8 & \multirow{3}{*}{$\begin{array}{l}\text { Rod measurement of glass depth } 1.57 \mathrm{~m} \\
(5 \mathrm{ft} 2 \text { in.) } \\
\text { Power off--total energy } 18,300 \mathrm{kWh} \\
\text { Finish tank flushing } \\
\text { Equipment demobilized and trailers prepared } \\
\text { for shipment. }\end{array}$} \\
\hline & $\begin{array}{l}1355 \\
2123\end{array}$ & 167.4 & \\
\hline $2 / 10$ & & & \\
\hline
\end{tabular}





\section{IEST RESULTS AND PERFORMANCE ANALYSIS}

Performance of the ISV process is based on the equipment operation and the ability of the system to stabilize and contain the contaminants present in the soil. Three primary areas of performance are addressed: 1) power system, 2) off-gas system, and 3) product characterization. Sampling positions relating to the analysis of the off-gas system and product are illustrated in Figure 12.

\section{POWER SYSTEM}

The power system performed as designed during the AEDC pilot-scale test. Early in the test, disruption of the melt path between the B-phase electrodes led to a phase imbalance on the secondary of the transformer. The loss of B-phase was attributed to gas releases from the water vapor created from the soil moisture or the decomposition of the sodium carbonate additive. This imbalance caused circuitry protection varistors to fail when experiencing voltage or amperage spikes. The imbalance caused the electrical system to be shut down, a new starter path to be laid, and a balanced restart of the system. After the restart, the electrical system functioned within its capabilities with no problems.

The additives placed in the cover soil proved to be a limiting factor to the power system. The soil turned out to be too conductive to get enough resistive energy into the melt to grow at an effective rate. A contributing factor to the additive adjustment to the AEDC soil was a compositional difference between the bench-scale test soil and the actual Site 10 soil vitrified during the pilot-scale test. The bench-scale analyses completed in August 1988 had shown that not enough alkali fluxing material $\left(0.3 \mathrm{wt}_{\mathrm{N}} \mathrm{Na}_{2} \mathrm{O}\right)$ was present in the Site 10 soil. Typically, an ISV melt requires 3 to $5 \mathrm{wt} \%$ flux content in the melt for proper operation. The recent pilot-scale Site 10 soil corings showed the $\mathrm{Na}_{2} \mathrm{O}$ content varied between 0.3 to $20.6 \mathrm{wt} \%$ in the original soil. The typical $\mathrm{Na}_{2} \mathrm{O}$ content was between 1 and $2 \mathrm{wt} \%$. All elemental oxide analyses for the pilot-scale pretest soil corings are presented by sample position and depth in Table 3. All elements (e.g., Al, C, Si) influencing melt behavior properties (melt temperature, viscosity, etc.) 


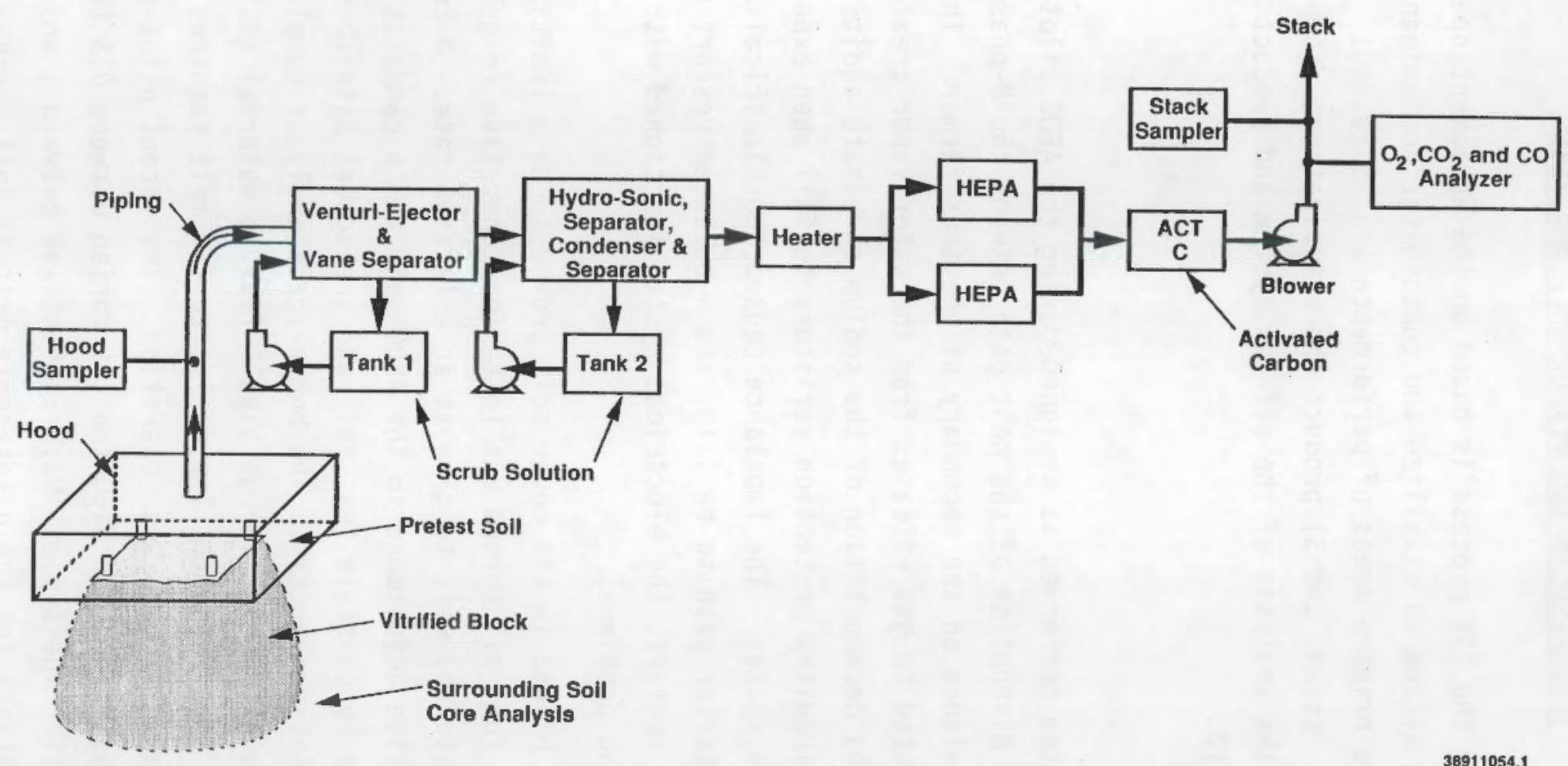

FIGURE 12. Pilot-Scale System with the Associated Sampling Positions 
TABLE 3. AEDC Site 10 Pilot-Scale Pretest Soil Coring Analyses, normalized wt\%

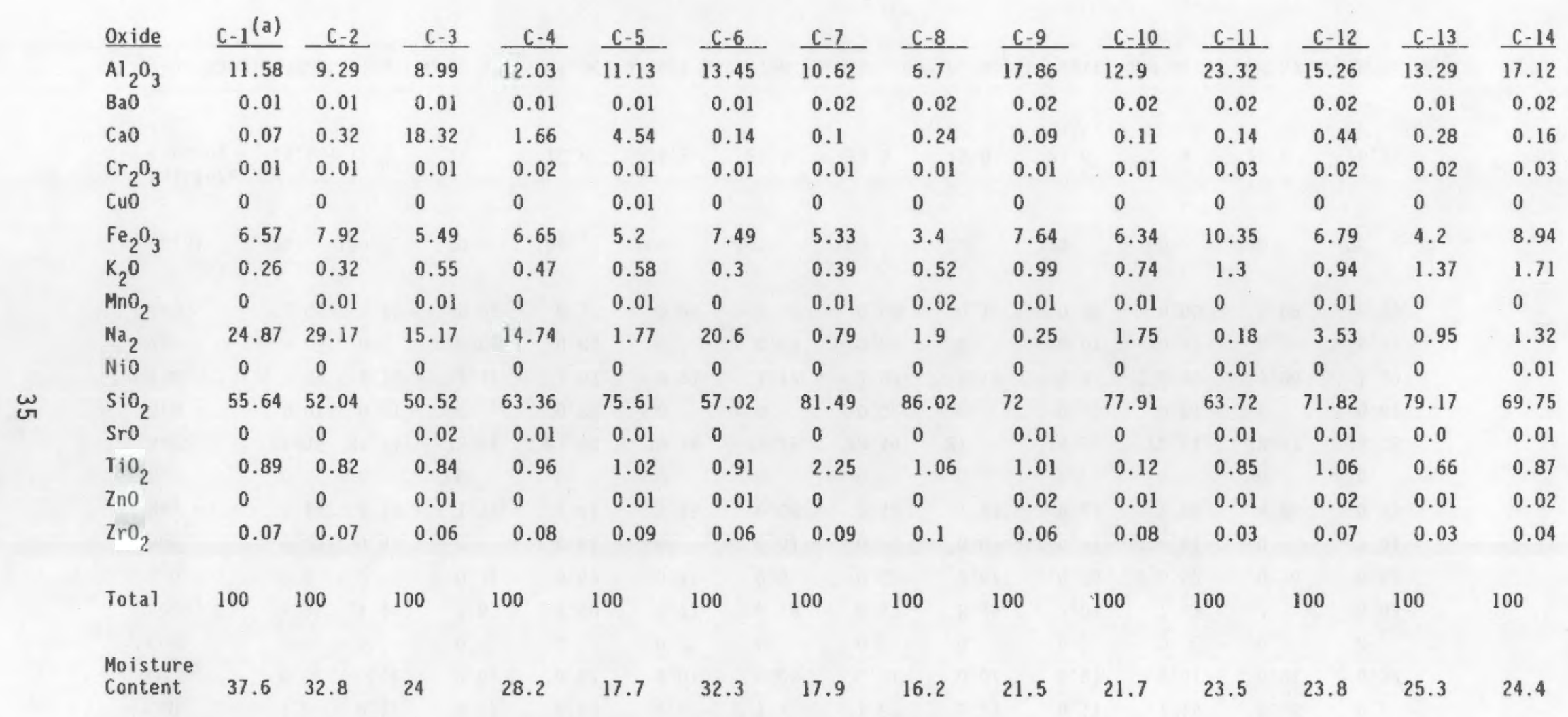

(a) Sample identification is by pilot-scale test position (center, north, south, east, and west) and by depth in feet. 
TABLE 3. (contd)

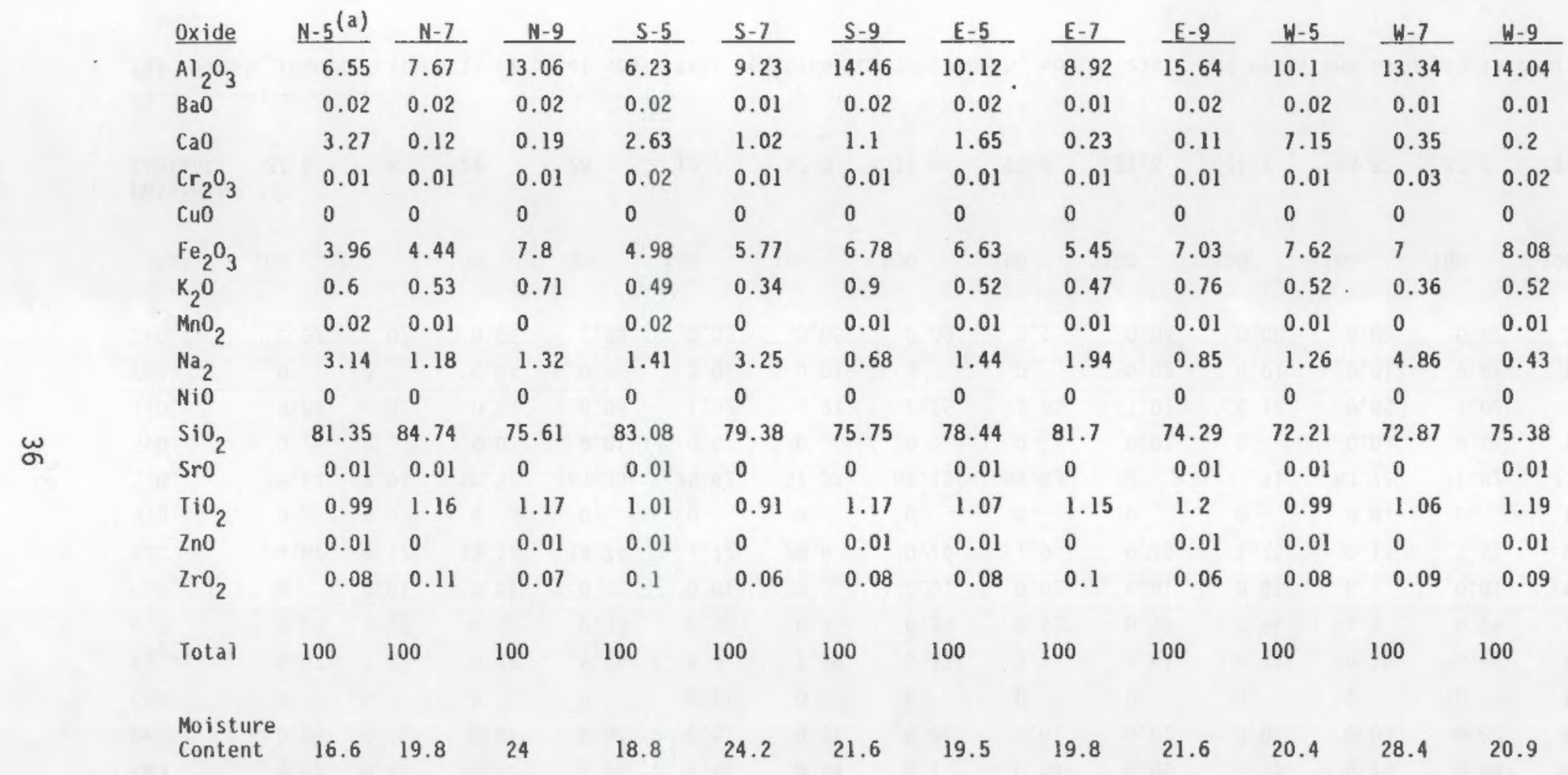

(a) Sample identification is by pilot-scale test position (center, north, south, east, and west) and by depth in feet. 
exclusive of sodium ( $\mathrm{Na}$ ) are in the same relative concentration as the benchscale data (see Appendix $\mathrm{B}$ ); thus $\mathrm{Na}$ is the only element of significant soil composition variation between the two tests.

The actual site vitrified for the pilot-scale test had a significantly higher concentration of fluxing material in the soil than the bench-scale test soil: $1.5 \mathrm{wt} \%$ versus $0.3 \mathrm{wt} \%$, respectively. This higher concentration of $\mathrm{Na}$ coupled with the amount of $\mathrm{Na}$ added to the cover soil, which was based on the bench-scale testing sample analyses, caused the molten soil to be too conductive (or not resistive enough). This increased conductivity pushed the pilot-scale electrical system below its effective operating resistive heating range $(0.5$ to $1.5 \mathrm{ohm}-\mathrm{m})$ and reduced the power input into the melt-- $150 \mathrm{~kW}$ versus $400 \mathrm{~kW}$. The lower power input (about $1 / 3$ power) caused a slower melt rate and contributed to increased lateral growth of the pilot-scale block. Therefore, the differing soil compositions contribute directly to the low power input, ultimate depth achieved, and lateral growth of the block. A better-defined soil composition profile prior to each large-scale vitrification setting is recommended so that the appropriate amount of fluxing additive can be added. The use of $\mathrm{Ca}$ as a fluxing additive to replace approximately half of the $\mathrm{Na}$ needed is recommended to prevent electrical system amperage limitations by having the soil become too conductive. Existing ternary-phase diagrams (Buelt et al. 1987) show that replacing half of the $\mathrm{Na}_{2} \mathrm{O}$ fluxing additive with $\mathrm{CaO}$ yields a melt temperature equivalently lowered, yet the electrical resistivity effectively doubled. The compositional data obtained thus far indicate that ISV is applicable to the AEDC soils, but each vitrification setting's compositional data will determine the necessary fluxing additive amount required for each Site 10 area setting. As a guideline, it is recommended that the soils processed by ISV have a 5 wt\% content of each $\mathrm{Na}_{2} \mathrm{O}$ and $\mathrm{CaO}$. This will require differing amounts and compositional mixes of fluxing additives based on the soil variable composition at Site 10 .

The technique of adding fluxes used in this test also contributed to the limitations on the power system and the eventual shallower depth achieved. The recommended method of mixing the fluxing additives with the entire volume to be vitrified was revised because of the client's desire to 
determine if effective depths could be achieved without disturbing the contaminated soil. Consequently, a higher flux concentration was mixed with the surface cover soil placed over the site to be vitrified. This increased the fluxing content in the startup vitrification volume, which decreased this surface melt region's operating temperature and electrical resistivity. The decreased resistivity caused the electrical system to be power 1 imited and operate at a lower power input as discussed above. Decreasing both the glass temperature and melt resistivity slows the fluxing additive mixing process with the underlying original soil and promotes lateral growth. Thus, to ensure success for a large-scale remediation of Site 10, full vitrification depth injection or mixing of the adjusted amount of fluxing additives is recommended prior to vitrification.

Recent posttest modeling of the AEDC pilot-scale test using the actual test data and its correspondingly low resistivity predicted a vitrified block $\sim 1.8$ to $2.1 \mathrm{~m}$ ( 6 to $7 \mathrm{ft}$ ) deep and $2.4 \mathrm{~m}(8 \mathrm{ft})$ wide within the time and power consumption parameters of the test operation. This is closer to the actual block created than the previous modeling predicted. The actual vitrified block was $1.5 \mathrm{~m}(5 \mathrm{ft})$ deep and $2.4 \mathrm{~m}(8 \mathrm{ft})$ wide on each side. The previous modeling was performed using an order of magnitude higher resistivity which would increase the melt rate and produce a narrower and deeper block over the same period of time. Because of heavy rains before the test, the high moisture present at this site (20 to $30 \mathrm{wt} \%$ ) consumed a significant amount of energy that is normaliy devoted to melting soil, which may have also contributed to a shallower depth achieved. Proper soil composition readjustments to the site would result in higher power levels, allowing the ISV process to be implemented on the Site 10 soils even at the high soil moisture content. With these appropriate adjustments to the additives and injection or mixed distribution of the additives into the site, large-scale processing operations should be able to achieve a depth of 3.1 to $4.6 \mathrm{~m}$ (10 to $15 \mathrm{ft}$ ) with no complications. [Melt depths of $5 \mathrm{~m}(16 \mathrm{ft}$ ) have already been demonstrated on two separate occasions with the Targe-scale unit.] Because of the variability of soil composition likely to be present across Site 10, it is recommended to obtain soil coring analyses as a function of depth to determine the appropriate amount of additives needed for 
each ISV large-scale setting. Based on this compositional variability, it is recommended to use approximately $5 \mathrm{wt} \%$ each of $\mathrm{Na}$ and $\mathrm{Ca}$ on an oxide basis as the operating quantities for ISV processing. This means that variable additions or no additives may be required depending on the site compositional data.

The above information aids in explaining why a shallower depth and increased lateral growth were obtained during the AEDC pilot-scale ISV test. The same information and evaluation also provide added confidence that largescale remediation operations can be successfully implemented at the AEDC Site 10 Fire Training Area.

With the increased melt conductivity, the Scott-Tee transformer system was power limited, as discussed, but performed to expectations, providing a balanced supply of power to the melt after the restart. The operating data for power, voltage, and amperage for the AEDC pilot-scale test are illustrated in Figures 13 and 14 . These plots show the lower power input created by the lower melt resistivity, which led to the high amperage (1000 amp/ phase) and low voltage ( $75 \mathrm{~V} /$ phase) conditions that existed throughout the majority of the test. A vitrified block was produced that weighed

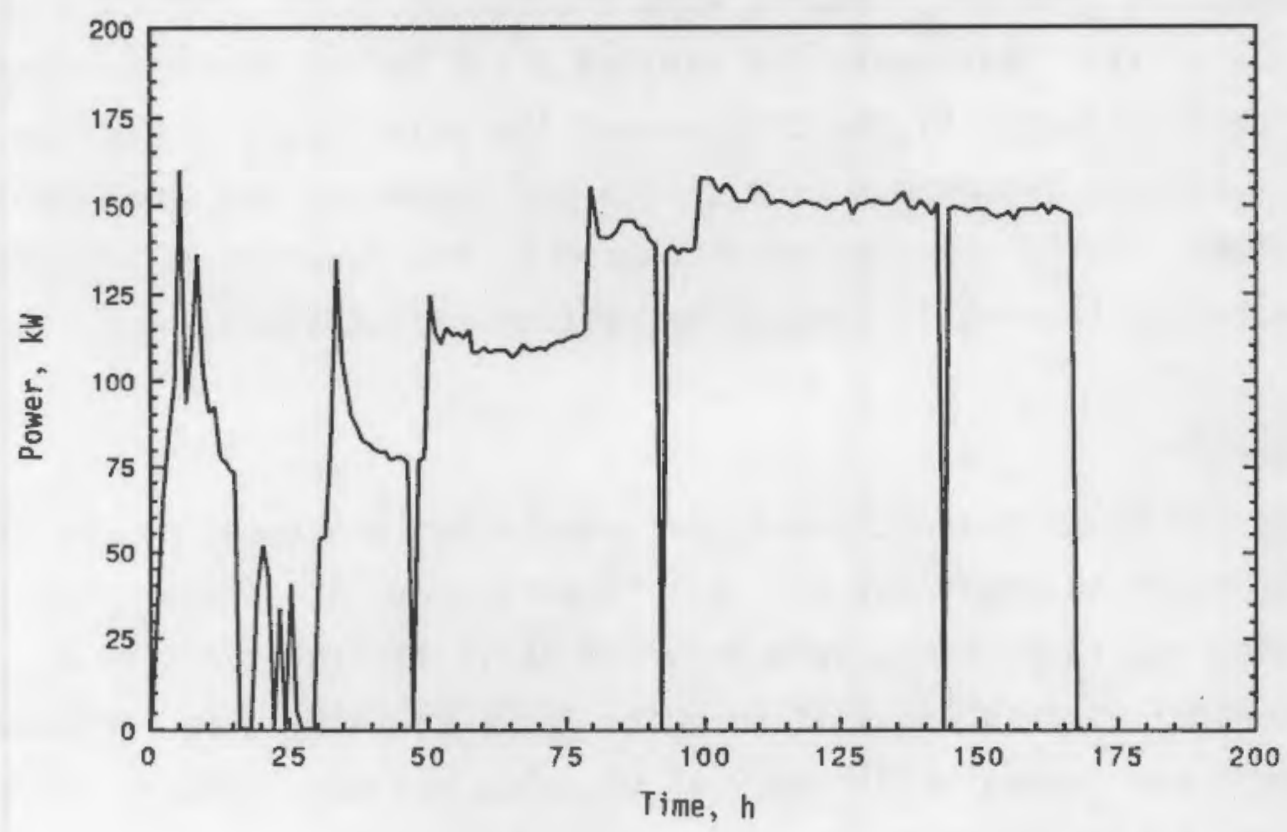

FIGURE 13. Power to Electrode 


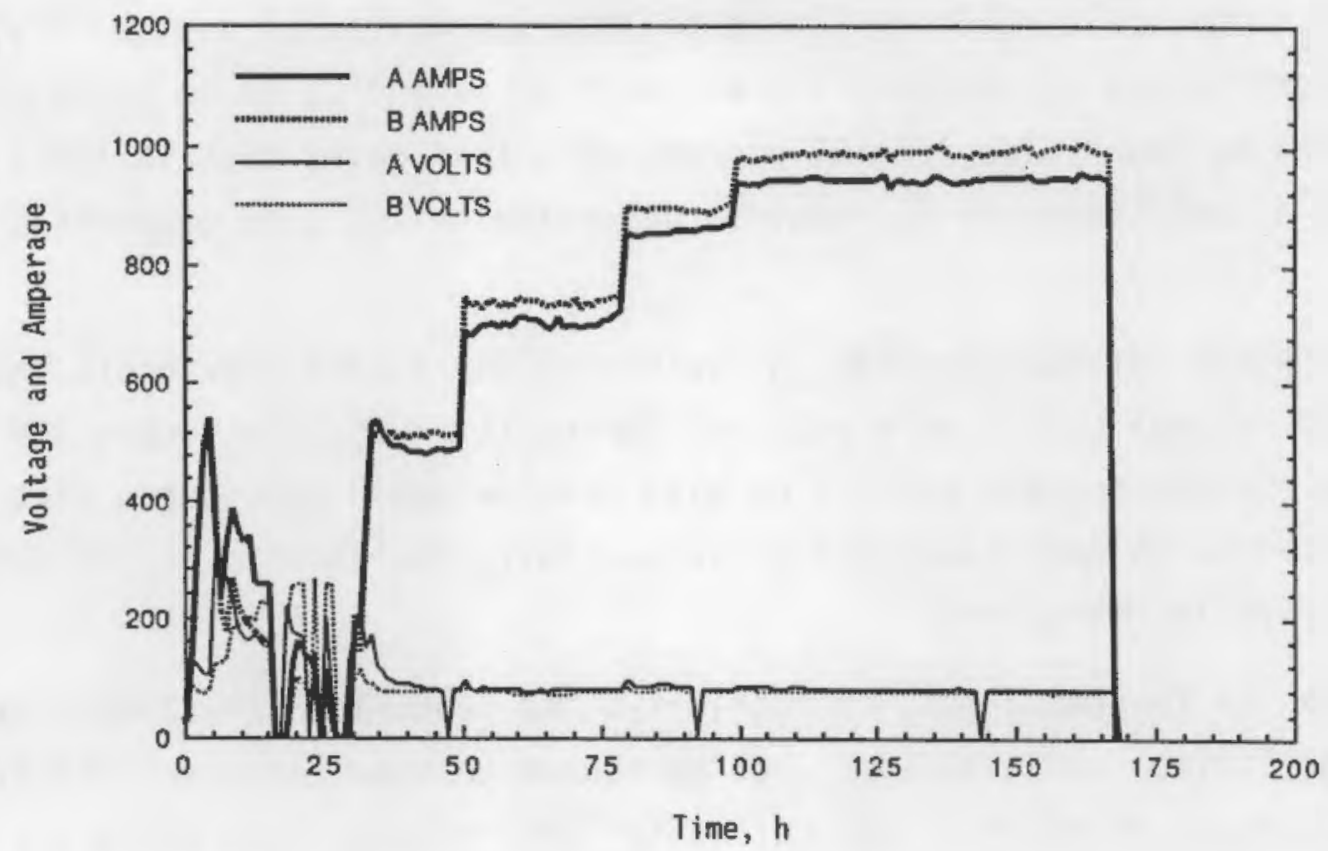

FIGURE 14. Voltage and Current

approximately $15 \mathrm{t}$ and measured $1.57 \mathrm{~m}$ (5 ft $2 \mathrm{in.}$ ) deep from the original cover soil grade. The block melted laterally to $2.4 \mathrm{~m}(8 \mathrm{ft})$ wide on a side. Energy consumption of $17,500 \mathrm{kWh}$ was utilized over the $138 \mathrm{~h}$ of continuous operation from the restart, with a total of $168 \mathrm{~h}$ of operation from the original start. This operation yielded a $1.2 \mathrm{kWh} / \mathrm{kg}$ energy-to-mass ratio, which is slightly higher than normal ISV pilot-scale operations (0.8 to $1.1 \mathrm{kWh} / \mathrm{kg}$ ) (Timmerman et a1. 1983 and Timmerman and Oma 1984). This slightly higher energy consumption is caused by the lower operating efficiency created by the highly conductive surface soil mixture.

\section{OFF-GAS SYSTEM}

During the test, the equipment performance was monitored by the extensive use of field instrumentation. All temperatures, pressures, flows, gas compositions, and tank levels were recorded at 10 -min intervals by a computer-controlled data acquisition unit. Data pertaining to performance of the equipment and removal efficiency of organics and particulates are presented in the following sections. 


\section{Off-Gas Containment Hood}

The hood covering the vitrification zone maintained a slight vacuum over the molten area at all times during the test. Brief moments $(<1 \mathrm{sec})$ of reduced vacuum fluctuations were experienced early in the test due to gas generation from the soil moisture or decomposition of the sodium carbonate flux. The hood maintained an effective operating vacuum throughout the test.

Structurally, the hood maintained its integrity through all the tests. The pilot-scale hood was designed to withstand a $5-\mathrm{cm}(2-i n$.$) water vacuum.$ A HEPA filtered air inlet system with a seal pot was connected to the hood to ensure that the plenum vacuum never exceeded the hood's structural limitations and to provide filtered pressure relief in case of a hood pressurization.

The hood vacuum averaged between $1.3-$ and $5.1-\mathrm{cm}(0.5-$ and $2.0-\mathrm{in}$. water during the test, as shown in Figure 15 . The vacuum fluctuations

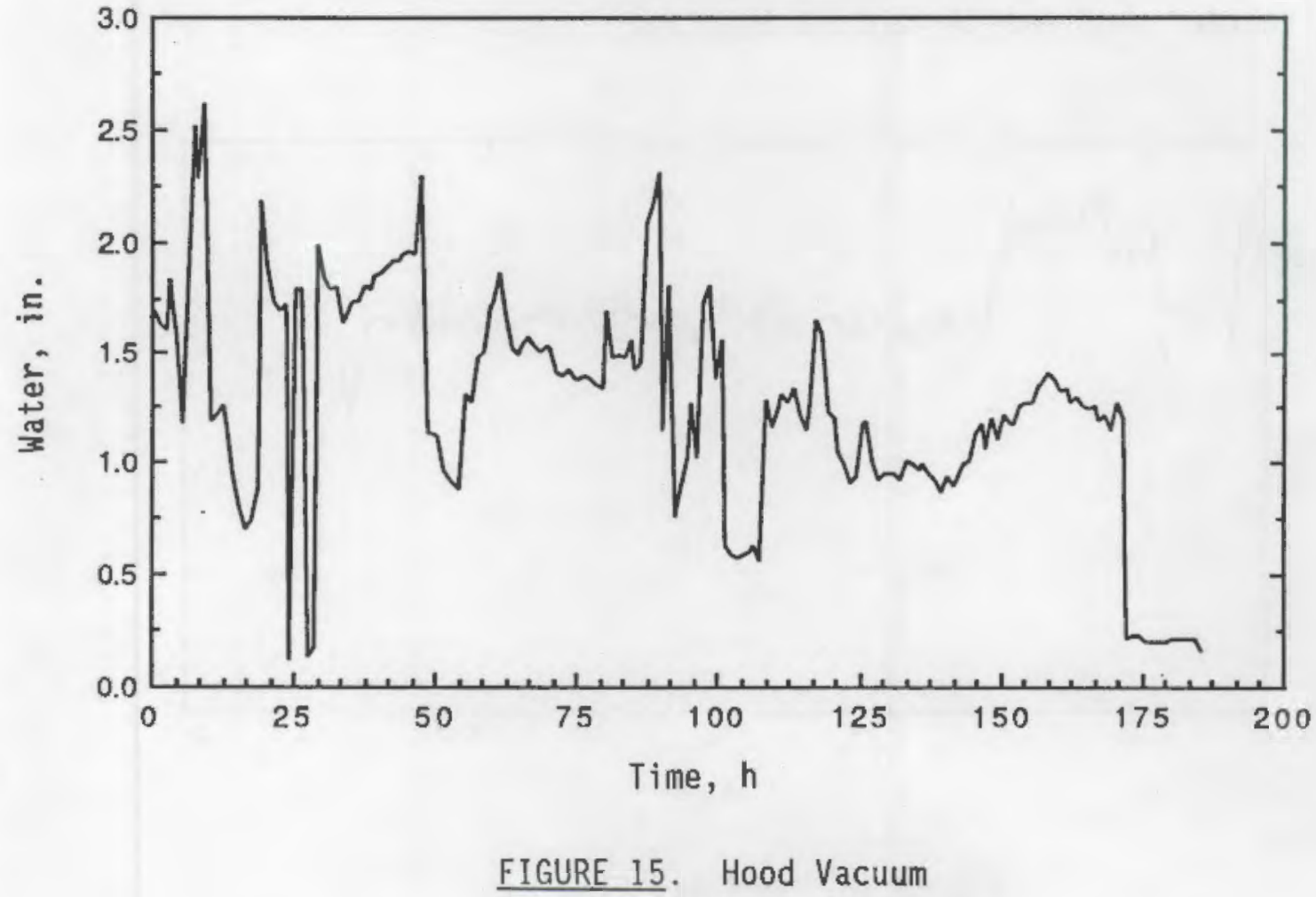


earlier in the test were created by the gas generation and laying of a new starter path. The vacuum was maintained within the desired safe operating range throughout the remainder of the test.

The actual relative off-gas flow rate was relatively steady at $17 \mathrm{~m}^{3} / \mathrm{min}\left(600 \mathrm{ft}^{3} / \mathrm{min}\right)$ after the restart at about $30 \mathrm{~h}$ (see Figure 16). This corresponds to a calibrated flow of $10 \mathrm{dry}$ standard $\mathrm{m}^{3} / \mathrm{min}$ ( $350 \mathrm{dscfm}$ ). The higher flow values earlier in the test were created by flow adjustments and an open hood during relaying of the starter path.

off-gas temperatures from the hood plenum to the process trailer are presented in Figure 17 . The hood plenum temperature ranged from 100 to $175^{\circ} \mathrm{C}$ later in the test. The temperature of the hood metal itself did not exceed $110^{\circ} \mathrm{C}$ (see Figure 18). The hood wall and roof tracked approximately the same thermal profile relative to the plenum temperature. The hood metal and fabric maintained its integrity and showed no weak points due to stresses imposed by thermal cycling or the vacuum. This was the first operational test for the hood fabric material. The fabric effectively maintained hood vacuum and its ground surface seal. The fabric experienced no structural or thermal-related problems throughout the test.

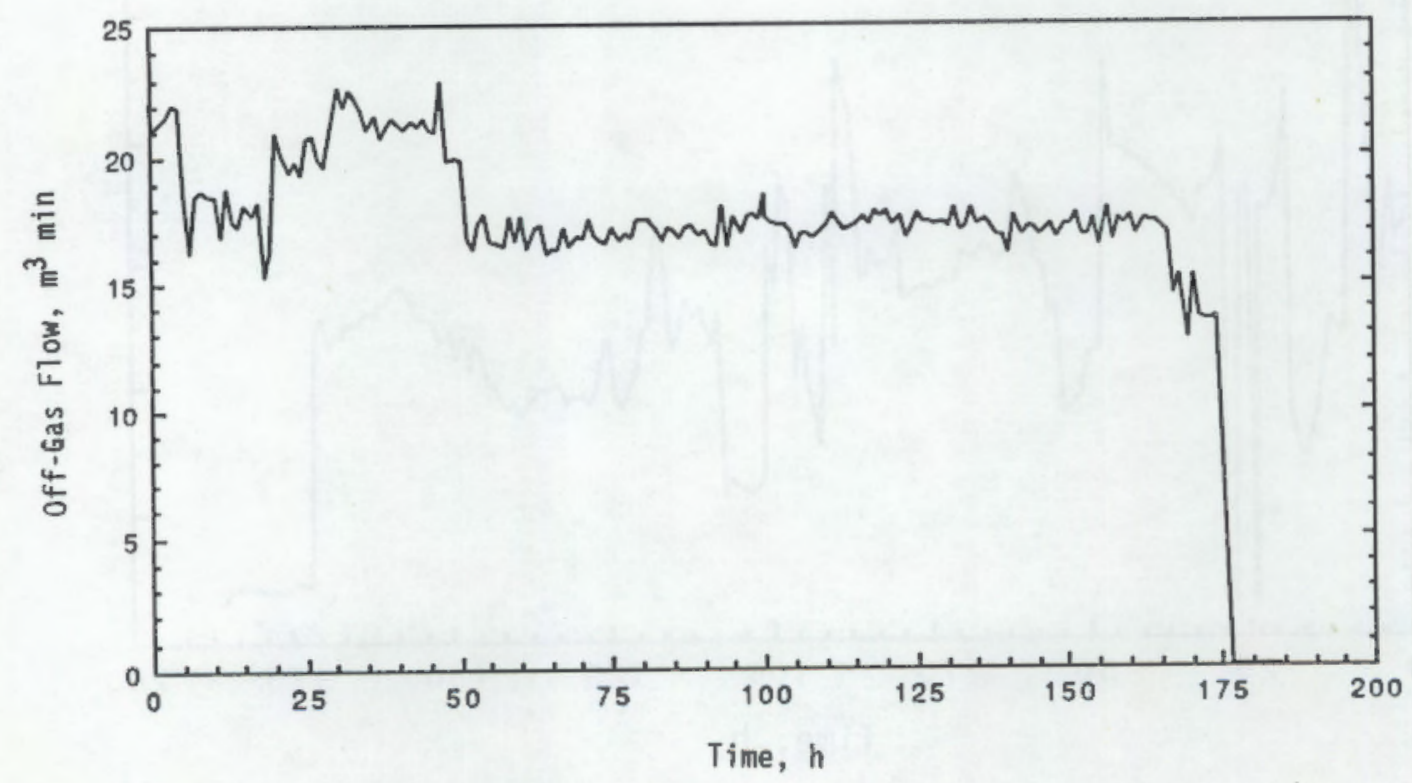

FIGURE 16. Off-Gas Flow Rate 


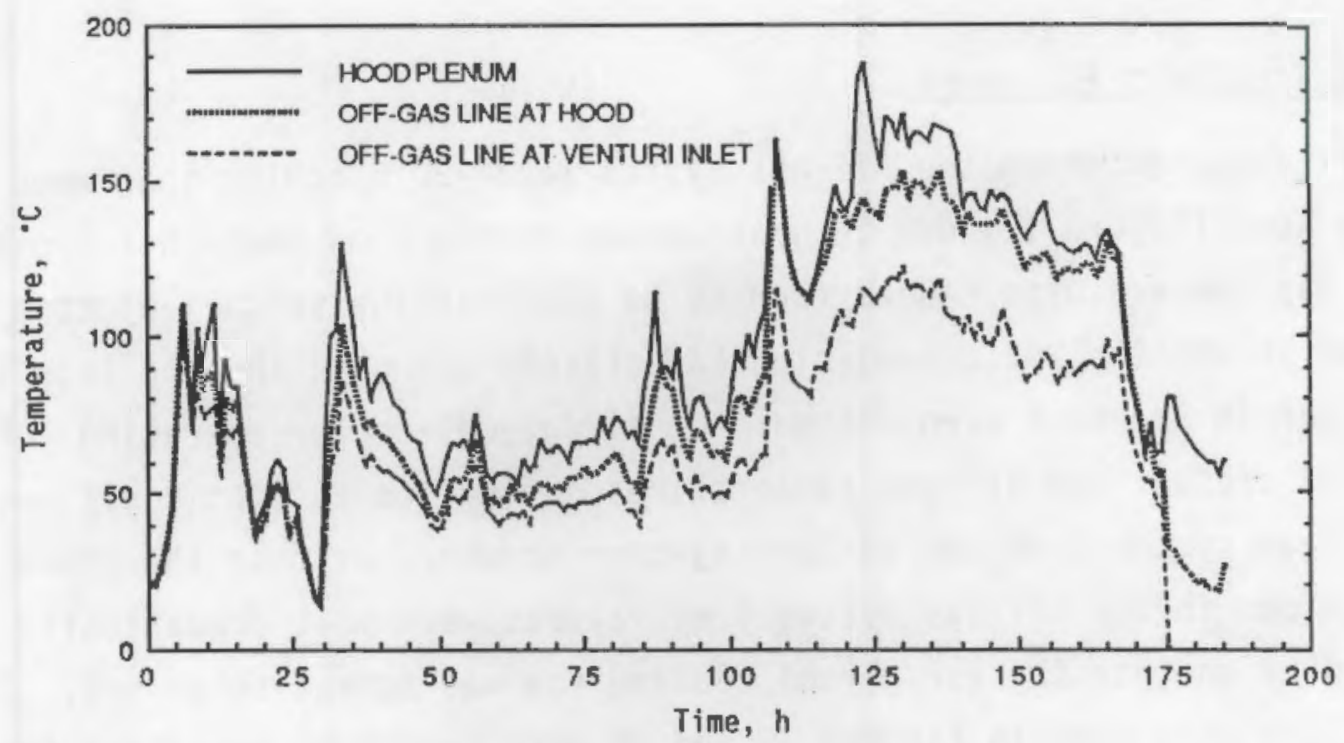

FIGURE 17. Off-Gas Temperatures from Hood Plenum to the Process Trailer

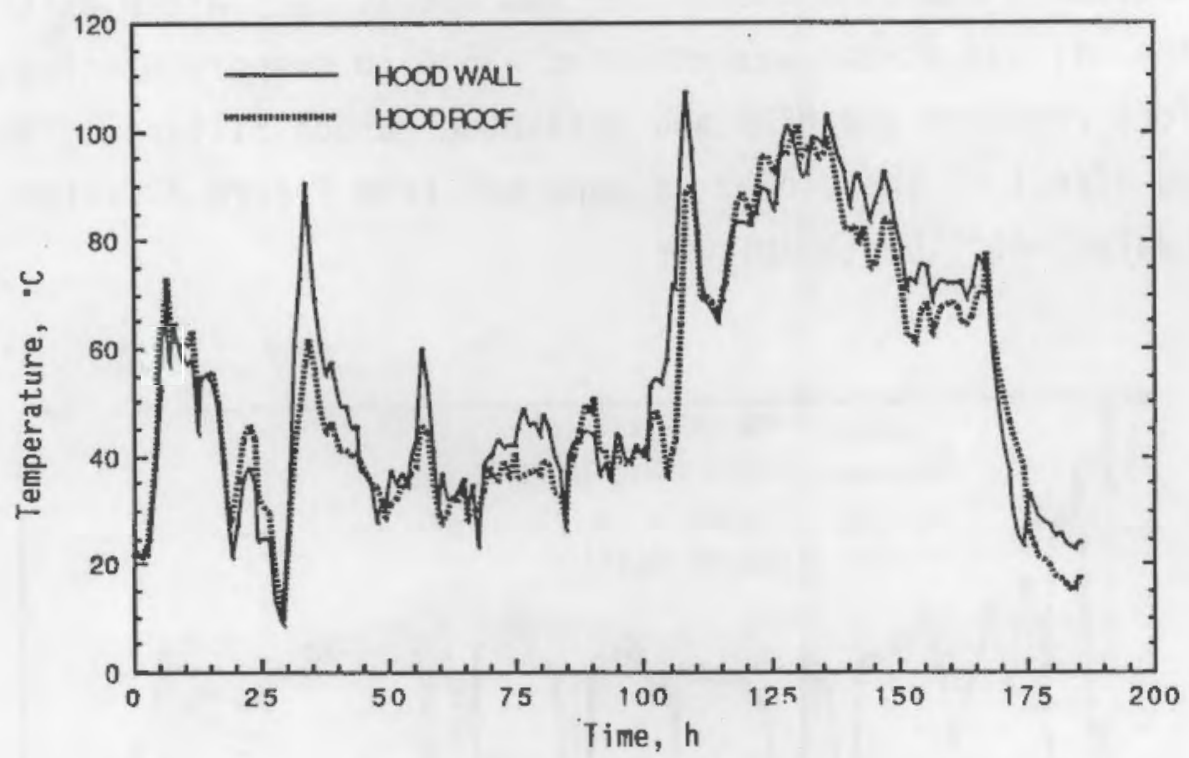

FIGURE 18. Off-Gas Hood Temperatures

The hood effectively contained off gases from the melt and supported the electrodes. This effective containment was demonstrated throughout the AEDC pilot-scale test, in which no containment releases were observed, thus effectively controlling environmental containment of potentially hazardous off-gas releases. 


\section{Off-Gas Treatment Equipment}

Off gases entering the off-gas system were $-30^{\circ} \mathrm{C}$ cooler than when exiting the hood (Figure 17) due to heat losses during flow through the off-gas 1ine. Gas temperatures ranged from 50 to $125^{\circ} \mathrm{C}$ at the venturi-ejector scrubber inlet; the venturi-ejector effectively quenched them to less than $50^{\circ} \mathrm{C}$ later in the test even without the air/g1ycol cooler operating. Figures 19 and 20 present the off-gas temperatures during the test at positions in the off-gas system from the venturi-ejector scrubber exit to the stack. The fluctuations in the off-gas system temperatures were most dramatically affected by whether the air/glycol cooling fan was operating or not. The temperature dips seen in Figures 19 and 20 were caused by operating the cooling fan to reduce evaporation of the scrubber solution. As seen in Figure 19, the Hydro-Sonic scrubber and condenser both cooled the gases one additional increment when the cooler fan was operating. After exiting the condenser, the off-gas stream was reheated $\sim 25^{\circ} \mathrm{C}$ to evaporate entrained moisture before reaching the HEPA and activated carbon filters. The adiabatic heating effect of the blower is apparent from Figure 20, since the off gases were heated $\sim 45^{\circ} \mathrm{C}$ by the blower.

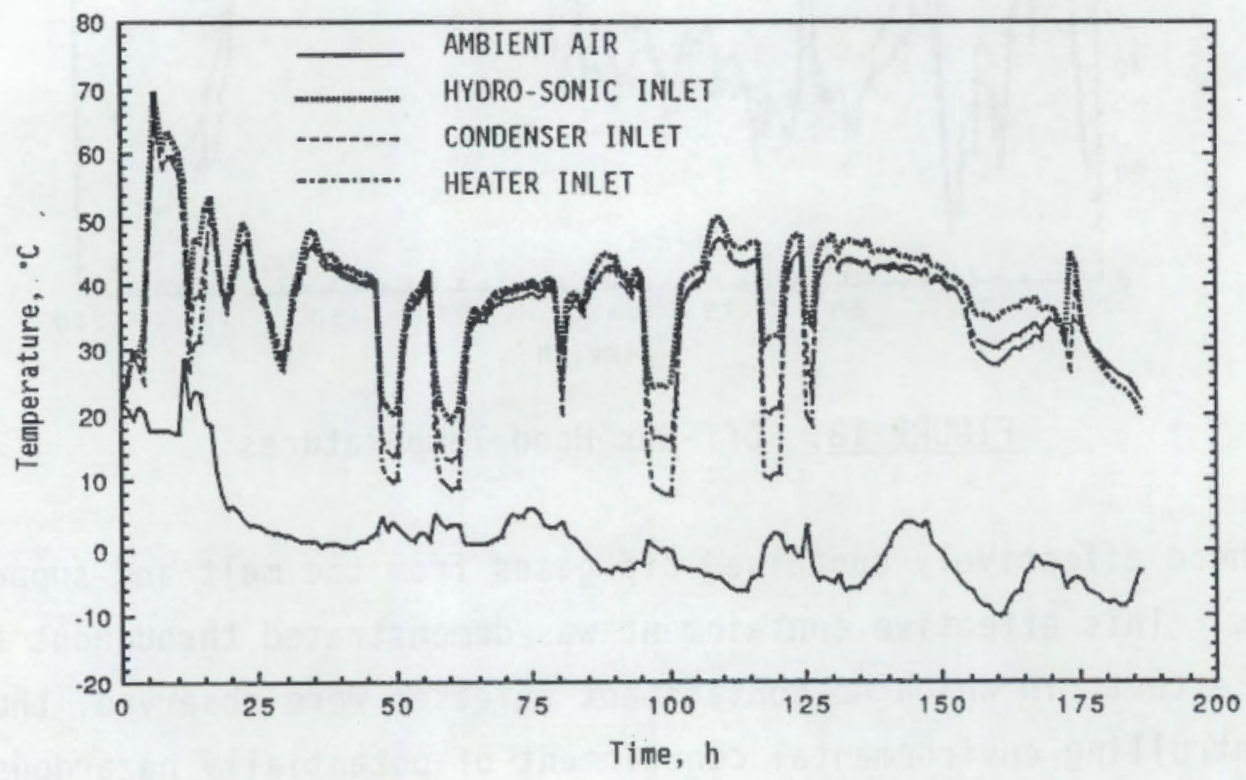

FIGURE 19. Off-Gas Temperatures from the Venturi-Ejector Outlet to the Heater Inlet 


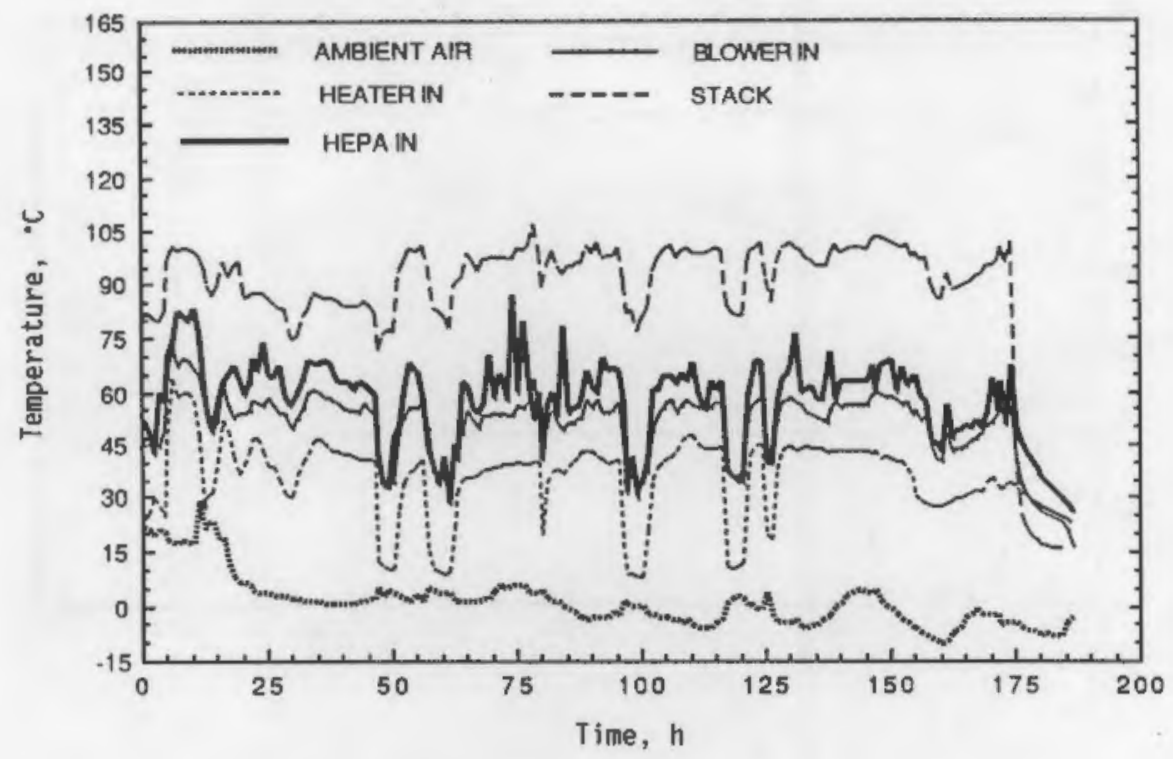

FIGURE 20. Off-Gas Temperatures from the Heater Inlet to the Stack

The off-gas system scrubber performance was monitored by the operating differential pressure across the individual scrubbers. As can be seen from Figure 21, the differential pressure on all the scrubbing and condensing equipment was maintained at a relatively constant operating setting throughout the test. The drop in the venturi differential pressure between 20 to $30 \mathrm{~h}$ into the test was caused by a freezing and plugging of the line to the transducer, which provided inaccurate readings during that time.

The HEPA and activated carbon filters gave no significant increase in flow resistance resulting from particulate or organic loading, as indicated by differential pressure data (see Figure 22). The differential pressures averaged $10.2 \mathrm{~cm}$ ( 4 in.) water column (W.C.) across the HEPA filter during the continuous power-on part of the operation. The activated carbon differential pressure averaged $4.3 \mathrm{~cm}$ (1.7 in.) W.C. during the same test operational period.

Scrub solution was gradually carried over from the venturi-ejector scrub tank to the Hydro-Sonic scrub tank due to evaporation followed by recondensation throughout the test. In addition, evaporation from the scrub tank 


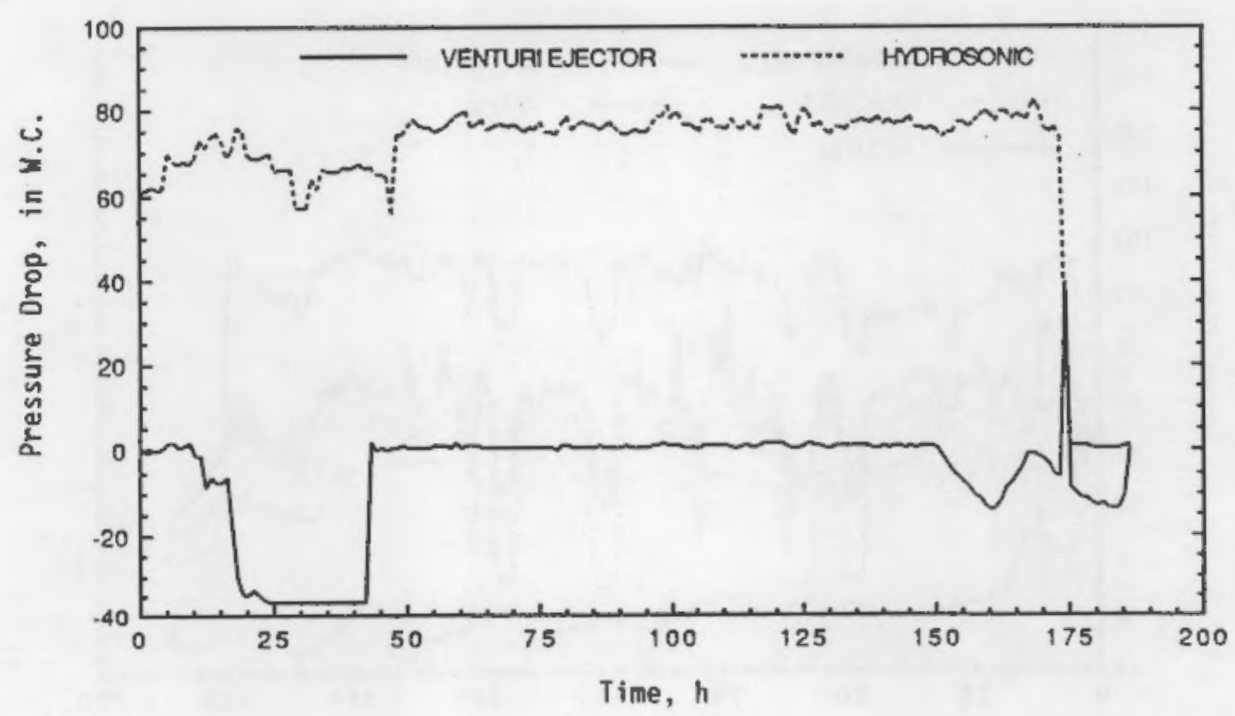

FIGURE 21. Scrubbing System Differential Pressures

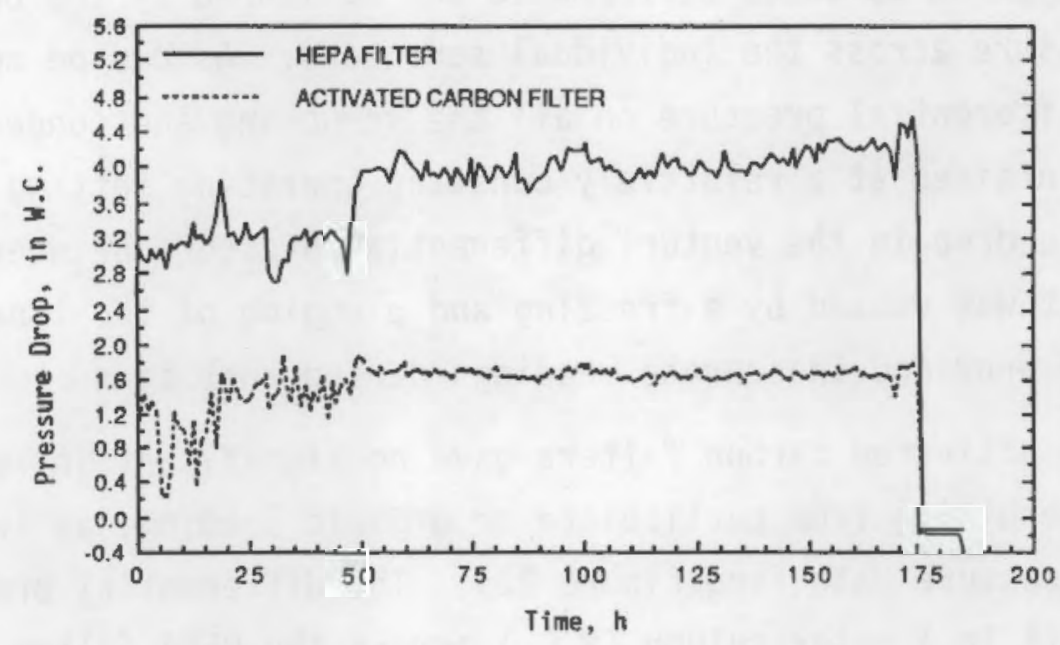

FIGURE 22. Filter Differential Pressures

solution occurred when the cooler fan was not operating. As seen in Figure 23 , both scrub tanks were maintained at an operating volume of $\sim 200 \mathrm{~L}$. Particulate Characteristics

For the AEDC pilot-scale test, particulate filtering was performed on both of the sample trains--one at the hood piping inlet to the trailer and 


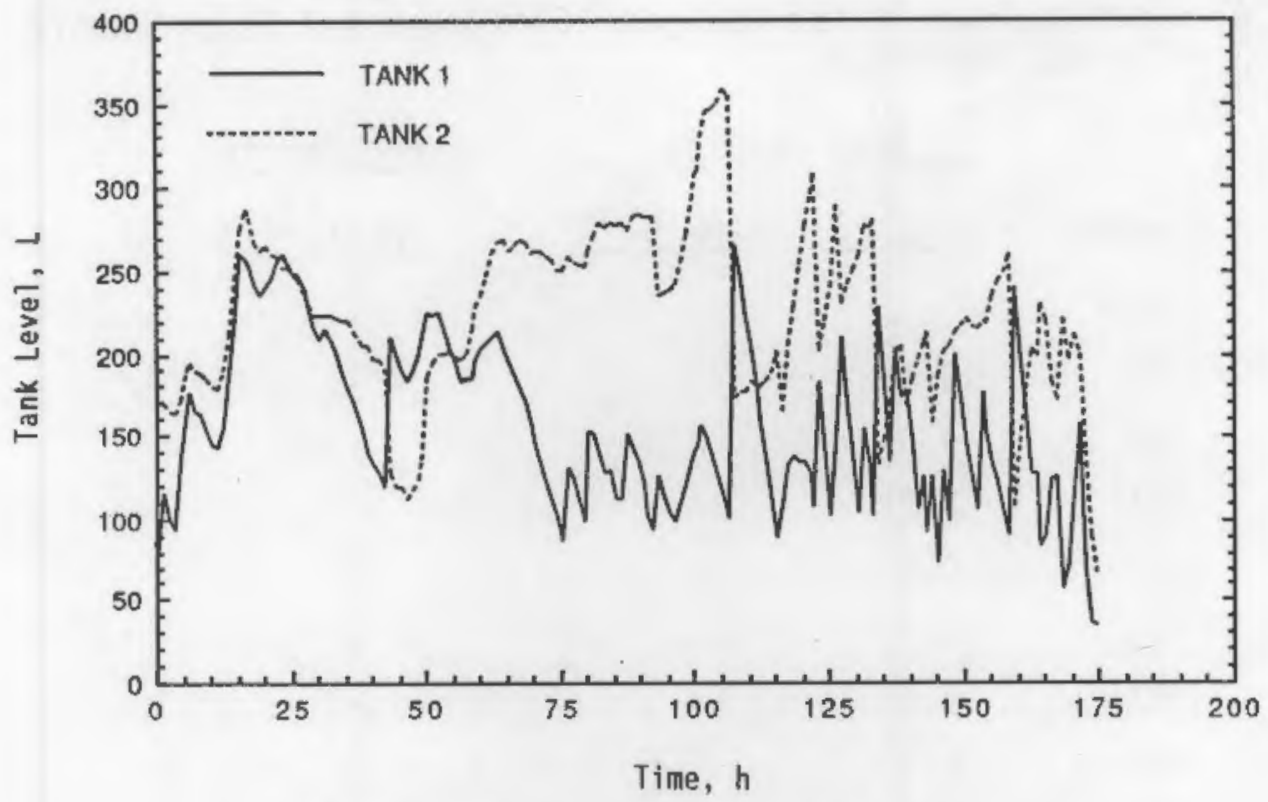

FIGURE 23. Scrub Tank Liquid Volumes

one at the stack exit. These hood and stack filters were analyzed for elemental release. The results of these analyses are provided in Table 4 . As Table 4 strongly shows, no particulate loading was detected at the stack of the ISV off-gas system and only small quantities $(127 \mathrm{~g})$ were released from the melt. This demonstrates that the off-gas treatment system performs a very efficient scrubbing and filtering of particulates, and the ISV process effectively retains most of the particulate-generating elements. Of the natural soil constituents released to the off gas and detected at the hood, only arsenic (As) and lead ( $\mathrm{Pb}$ ) are in high enough concentrations to create any secondary waste (scrub solution and filter loading) concerns, which could be recycled into the next vitrification setting(s) during actual remediation operations.

\section{Gaseous Characteristics}

Gases were analyzed for $\mathrm{O}_{2}, \mathrm{CO}$, and $\mathrm{CO}_{2}$ at a point downstream from the off-gas blower (see Figure 12). The $\mathrm{O}_{2}$ analysis was performed by a coulometric process whereby the gas sample was passed through an electrochemical cel1. Both the $\mathrm{CO}$ and $\mathrm{CO}_{2}$ analyses were performed using a nondispersive infrared monitoring technique. 
TABLE 4. Particulate Filter Analyses from Hood and Stack Sample Trains, mg/filter

\begin{tabular}{|c|c|c|c|}
\hline \multirow[b]{2}{*}{ Element } & \multicolumn{2}{|c|}{ Hood Samples } & \multirow{2}{*}{$\frac{\text { Stack Samples }}{\mathrm{PF}-1^{(\mathrm{c})}}$} \\
\hline & $\underline{P F-C^{(a)}}$ & $\underline{P F-D^{(b)}}$ & \\
\hline A1 & -. & - & -. \\
\hline As & 13.4 & -- & -- \\
\hline $\mathrm{Ca}$ & 4.0 & 3.4 & -- \\
\hline Cd & 0.2 & -- & -- \\
\hline $\mathrm{Fe}$ & 0.9 & -. & .. \\
\hline K & 5.7 & -. & -- \\
\hline $\mathrm{Mg}$ & 0.3 & $\cdots$ & -- \\
\hline Mo & 0.3 & 0.4 & - \\
\hline $\mathrm{Na}$ & 96.6 & 11.4 & - \\
\hline $\mathrm{Pb}$ & 19.3 & 20.3 & -. \\
\hline$S b$ & 0.7 & -- & - \\
\hline Si & -. & -. & -- \\
\hline $\mathrm{Zn}$ & 14.7 & 39.4 & -- \\
\hline $\mathrm{Zr}$ & 0.2 & -- & -- \\
\hline
\end{tabular}

NOTE: No particulate sampling data were collected during vitrification of the cover soil (run time 0 to $50 \mathrm{~h}$ ).
(a) Particulate filter $\mathrm{C}$ at the hood, run time 51 to $119 \mathrm{~h}$.
(b) Particulate filter $D$ at the hood, run time 120 to $170 \mathrm{~h}$.
(c) Particulate filter 1 at the stack, run time 51 to $170 \mathrm{~h}$.

Figure 24 presents the $\mathrm{CO}$ and $\mathrm{CO}_{2}$ concentrations as a function of runtime. The higher $\mathrm{CO} / \mathrm{CO}_{2}$ concentrations at the beginning of the test and at about $30 \mathrm{~h}$ into the test corresponds to the periods of most active combustion of the graphite/frit startup path. The $\mathrm{CO}_{2}$ level after the startup periods can be explained by graphite electrode oxidation due to heating from the molten zone plus combustion byproducts from the organic contaminants in the soil. 


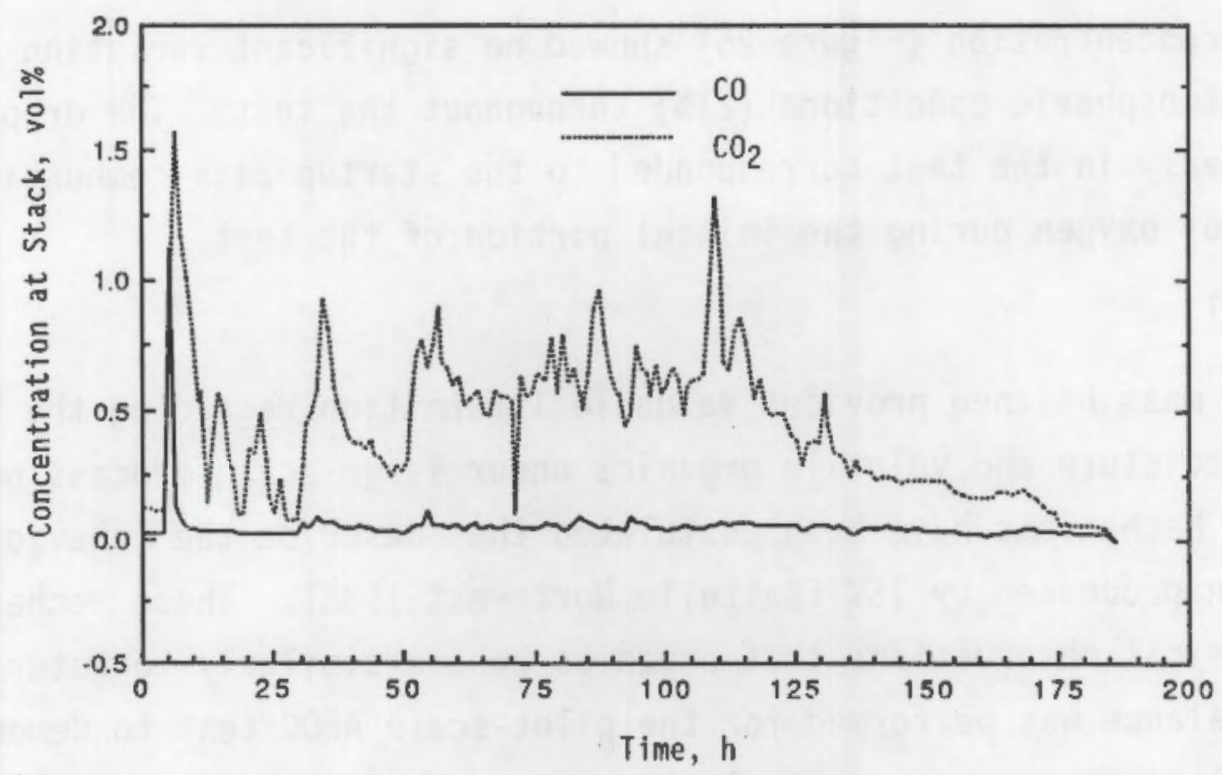

FIGURE 24. Carbon Dioxide and Carbon Monoxide Concentrations

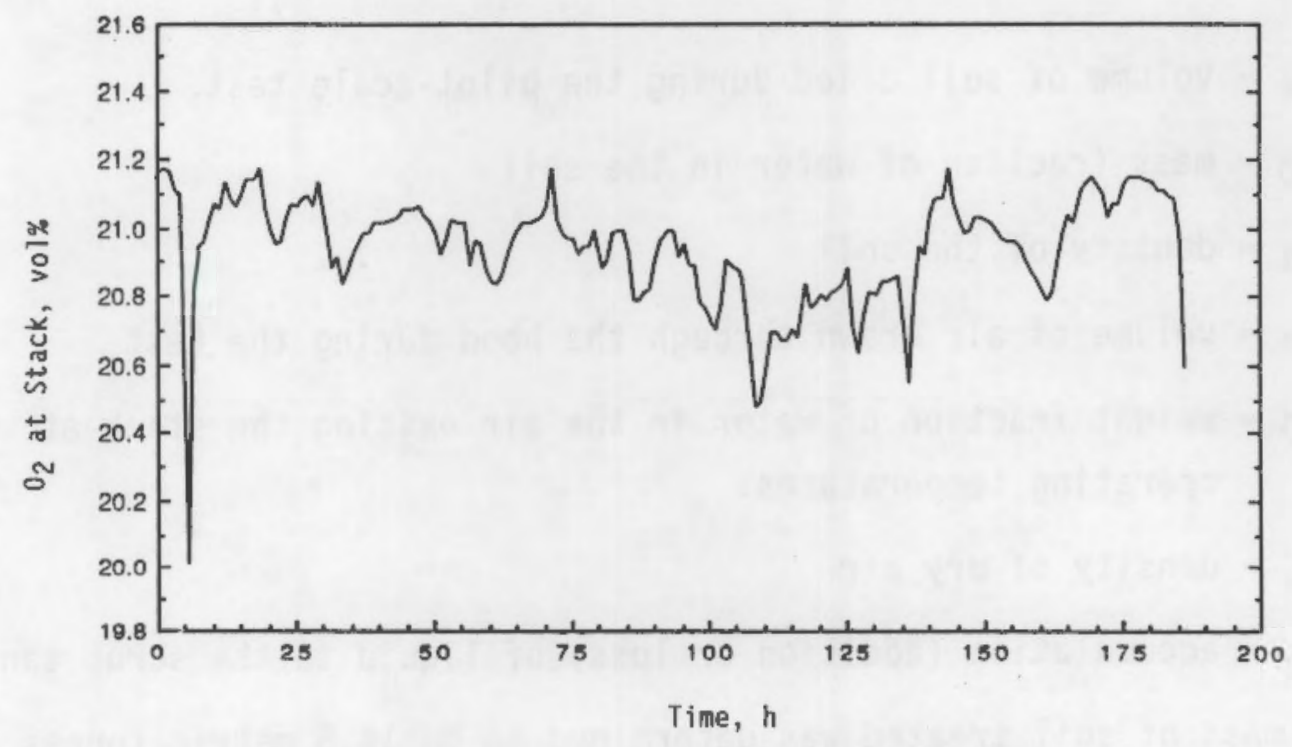

FIGURE 25. Oxygen Concentration 
The $\mathrm{O}_{2}$ concentration (Figure 25) showed no significant variation from the normal atmospheric conditions (21\%) throughout the test. The drop noticeable early in the test corresponded to the startup path combustion consumption of oxygen during the initial portion of the test.

\section{Water Removal}

A water mass balance provides valuable information regarding the behavior of soil moisture and volatile organics under large-scale processing conditions. Mechanisms have been postulated that describe the behavior of organics when processed by ISV (Battelle Northwest 1988). These mechanisms support empirical observations that organics behave similarly to water. A water mass balance was performed for the pilot-scale AEDC test to demonstrate that the soil moisture was completely removed by the ISV process. The water mass balances are achieved by the following:

$$
V_{S} \cdot \rho_{S} \cdot X_{H_{2} O}+\Delta V_{1 i q}=V_{a i r} \cdot X_{e_{2} O} \cdot \rho_{d a}
$$

where $V_{S}=$ volume of soil dried during the pilot-scale test, $L$

$$
\begin{aligned}
& X_{\mathrm{H}_{2} \mathrm{O}}=\text { mass fraction of water in the soil } \\
& \rho_{S}=\text { density of the soil } \\
& V_{\text {air }}=\text { volume of air drawn through the hood during the test } \\
& \mathrm{X}_{\mathrm{eH}_{2} \mathrm{O}}=\text { weight fraction of water in the air exiting the stack at } \\
& \text { operating temperatures. } \\
& \rho_{\mathrm{da}}=\text { density of dry air } \\
& \Delta V_{1 i q}=\text { accumulation (addition or loss) of liquid to the scrub tanks. }
\end{aligned}
$$

The mass of soil treated was determined to be 14.5 metric tonnes of vitrified soil, plus $23 \mathrm{~cm}$ (9 in.) of dry soil (5.4 metric tonnes) surrounding the vitrified block (which is typically measured in ISV tests), for a total of $19.9 \mathrm{t}$. The moisture content in the soil was calculated based on the moisture in the pretest soil samples (Table 3 ). The pretest soil samples were obtained at $1-\mathrm{ft}$ intervals in the center of the test site and the moisture content varied from 17.7 to 37.6 wt\% water among these samples. 
Based on previous ISV test data, it was assumed that the moisture was removed from the soil within $23 \mathrm{~cm}$ ( 9 in.) of the vitrified zone. Within $23 \mathrm{~cm}$ (9 in.) of the block, the soil temperature was $100^{\circ} \mathrm{C}$ and the water in the soil was vaporized. The moisture in the soil totaled $5700 \mathrm{~kg}$.

The amount of water added to the scrub tanks accounts for a $\Delta V_{1 \text { iq }}$ of $670 \mathrm{~L}$. Since a humidity meter was not located on the stack, $\mathrm{Xe}_{\mathrm{H}_{2} \mathrm{O}}$ was determined based on $100 \%$ saturation at the exit of the scrub system's condenser. The temperature at this point ranged from $8^{\circ} \mathrm{C}$ to $60^{\circ} \mathrm{C}$. The amount of water exhausted from the stack was $6740 \mathrm{~L}$. Since the left and right sides of the mass balance equation are less than $10 \%$, we conclude that water associated with the area being treated is removed and treated by the process before being released to the atmosphere. Also, organics that may be associated with the soil being vitrified are expected to be removed to the same degree as water with no significant outward migration, as indicated by this water balance. This conclusion is reasonably conservative because it does not account for destruction of organics by pyrolysis.

Thermal Destruction and Removal Efficiency

Therma1 DRE represents the fractional amount of contaminant destroyed and/or removed from the contaminated matrix. The DRE is defined for incinerators that burn hazardous waste in 40 CFR 264, and is determined from the following equation [40 CFR 264.343 (a)(1)]:

$$
\text { DRE }=\frac{(\text { Win }- \text { Wout })}{\text { Win }} \times 100 \%
$$

where Win $=$ mass feed rate of the principal hazardous constituent in the waste stream feeding the incinerator (or mass of constituent in the waste to be treated)

Wout $=$ mass emission rate of the principal hazardous constituent in exhaust emissions prior to release to the atmosphere (or mass of constituent released in the off gas).

Table 5 lists the sampling quantities of organics that were released to the off-gas system and to the atmosphere out of the stack. The stack sampler 
TABLE 5. Organic Quantities Released from the Vitrified Volume

\begin{tabular}{|c|c|c|c|}
\hline $\begin{array}{r}X A D-2 \\
\text { Sample } \\
\end{array}$ & $\begin{array}{l}\text { Sample Concentration, } \\
\mathrm{mg} / \mathrm{g} \text { resin }\end{array}$ & $\begin{array}{c}\text { Off-Gas } \\
\text { Concentration, } \\
\mathrm{mg} / \mathrm{m} 3\end{array}$ & Total Release, $\mathrm{g}$ \\
\hline Hood-A & 22.0 & 16.6 & 654 \\
\hline Hood-C & 5.9 & 13.0 & 125 \\
\hline Hood-D & 4.3 & 7.1 & 104 \\
\hline Hood-E & 0.4 & 3.6 & 6 \\
\hline Hood-Total & -- & 14.8 & 889 \\
\hline Stack-B & 0.6 & 0.18 & 21 \\
\hline Bl ank & 0.1 & -- & -- \\
\hline
\end{tabular}

required only one XAD-2 resin sampler tube, while the hood sampler required the sampler tube to be changed four times. The sampling was started when the melt approached the $0.9-\mathrm{m}(3-\mathrm{ft})$ depth contaminated soil zone. The data show a decline in the organic off-gas concentration as a function of operating time and a very low release of organic material from the stack. The OSHA exposure limit for petroleum distillates is $2000 \mathrm{mg} / \mathrm{m}^{3}$, while the NIOSH 1 imit is $350 \mathrm{mg} / \mathrm{m}^{3}$ (NIOSH/OSHA 1978). As can be seen from the data, all these concentration releases are below the permissible exposure limits for petroleum mixtures.

The DE obtained for the ISV process was $89 \%$ based on the off-gas releases shown in Table 5 and the original soil concentrations provided in Appendix $C$. The DE value represents the amounts of hydrocarbon organics not released to the off-gas system and actually destroyed by the ISV melt. The $\% D E$, as calculated for the ISV process, does not include the removal efficiency of the off-gas treatment system. The ISV soil-to-off-gas \%DRE based on the stack release values was $99.85 \%$. The off-gas treatment system contributed to an approximate $99 \%$ removal efficiency of the organics. This is slightly lower than expected since a single-stage activated carbon filter is stated to have a $99.9 \%$ organic removal efficiency (Charcoal Services Corporation). Contributing factors such as filter residence time, revolatilization, and operating parameters may have lowered our operating efficiency; however, the releases to the environment were acceptably low. 


\section{Product and Surrounding Soil Characterization}

Analyses of the vitrified ( $g l a s s$ ) product showed no detectable amounts of organics in the final product. A surface view of the ISV block with electrodes still protruding is provided in Figure 26 . The final glass composition is shown in Table 6 . This average glass composition shows the final $\mathrm{Na}$ content to be high by a factor of 2 to 3 . Greater depth would have diluted this $\mathrm{Na}$ content to the predicted final value; however, the lower power input due to the increased electrical conductivity did not allow the greater depth to be reached within a reasonable period of operating time with the pilot-scale unit.

A sample of the vitrified product was subjected to leach testing using the EP toxicity test and TCLP. The EP toxicity test and TCLP results for metal concentrations in the leachate and maximum concentration 1 imits established by the U.S. Environmental Protection Agency (EPA) in the leachate are given in Table 7. As shown, the concentrations of regulated metals in the leach extract are well below the regulatory limits for the vitrified product.

The pretest organic analyses of the Site 10 vitrification region are presented in Figure 27 and show concentrations as a function of position and depth. There were 5 initial soil corings: one in the center and four (north, south, east, and west) around the outer periphery, $1.4 \mathrm{~m}(4.5 \mathrm{ft}$ ) equidistant from the center line. Therefore, the north and south data presented in Figure 27 are shown with the correct depth, but are actually positioned perpendicular to the page in each direction to the $1.4-\mathrm{m}(4.5-\mathrm{ft})$ distance. The pretest samples show higher concentrations in the 0.3- to $1.2-\mathrm{m}(1-$ to $4-\mathrm{ft})$ depth, which is to be expected below $0.9 \mathrm{~m}(3 \mathrm{ft})$. The cause of the higher concentration $(2.4 \mathrm{mg} / \mathrm{g}$ ) in the $0.3-$ to $0.6-\mathrm{m}(1-$ to $2-\mathrm{ft}$ ) center zone is unknown since the upper $0.9 \mathrm{~m}(3 \mathrm{ft})$ of soil was a clean cover soil. Another higher concentration is detected at the 3.0-m$(10-\mathrm{ft})$ deep center sample, which may correspond to an organic concentration migration to just above the impermeable clay layer at the site. All pretest samples show an organic concentration range of 0.1 to $2.5 \mathrm{mg} / \mathrm{g}$, depending on soil position. 


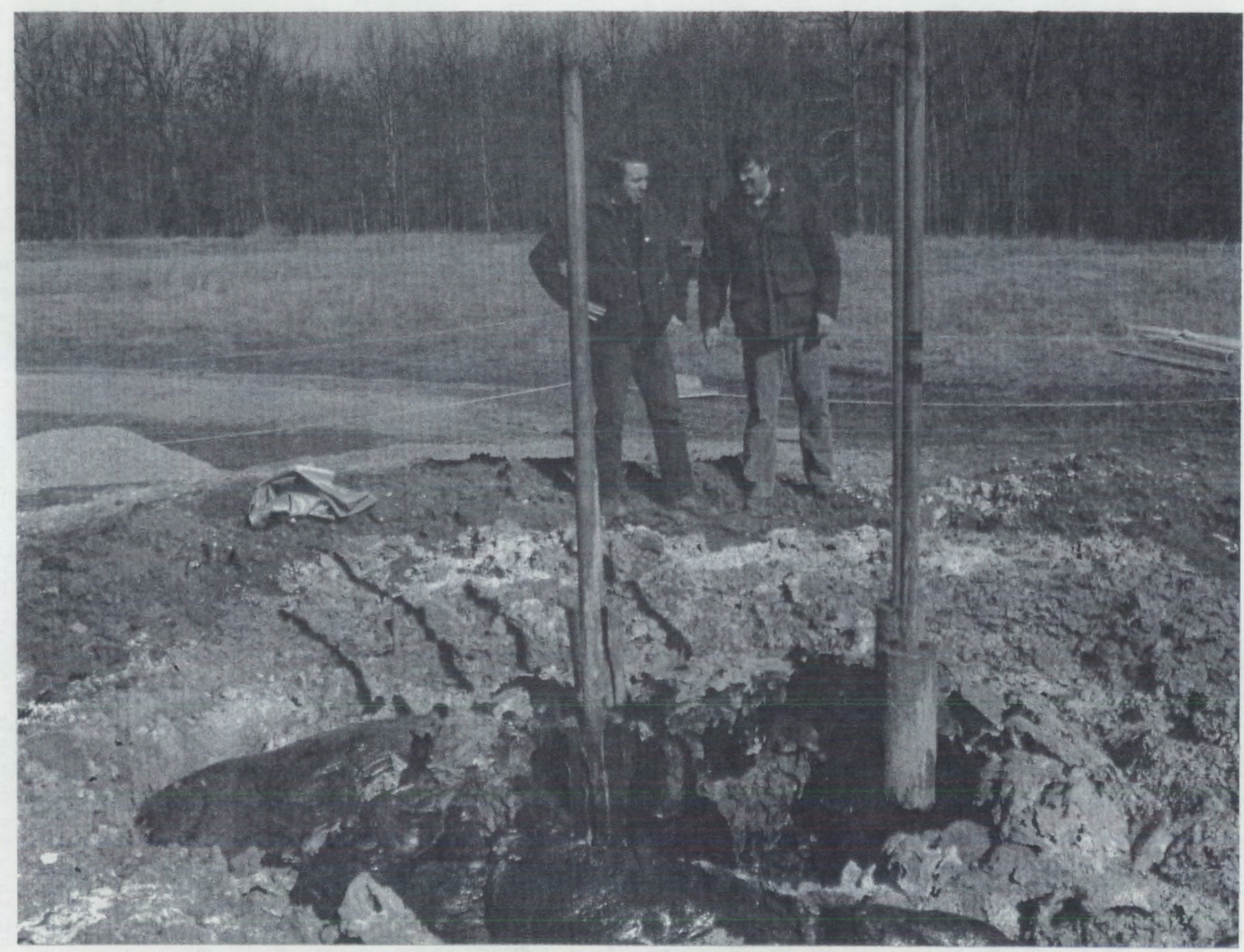

FIGURE 26. Surface View of ISV Block After Processing 
TABLE 6. Final Glass Composition of the AEDC Pilot-Scale Product

\begin{tabular}{lcc}
\multicolumn{1}{c}{ Oxide } & wt\% \\
$\mathrm{Al}_{2} \mathrm{O}_{3}$ & & 8.1 \\
$\mathrm{~B}_{2} \mathrm{O}_{3}$ & & 0.1 \\
$\mathrm{BaO}$ & & 0.01 \\
$\mathrm{CaO}$ & 5.5 \\
$\mathrm{Fe}_{2} \mathrm{O}_{3}$ & & 4.3 \\
$\mathrm{~K}_{2} \mathrm{O}$ & & 0.5 \\
$\mathrm{MgO}$ & 0.43 \\
$\mathrm{MnO}_{2}$ & & 0.01 \\
$\mathrm{Na}_{2} \mathrm{O}$ & & 15.3 \\
$\mathrm{SiO}_{2}$ & 64.3 \\
$\mathrm{SrO}$ & 0.01 \\
$\mathrm{TiO}_{2}$ & 0.77 \\
ZrO & 0.10 \\
Total & 99.7 \\
Density & $2.8 \mathrm{~g} / \mathrm{cc}$
\end{tabular}

IABLE 7. EP Toxicity and TCLP Metal Extract Concentrations: AEDC Vitrified Product

\begin{tabular}{|c|c|c|c|}
\hline Metal & $\begin{array}{c}\text { Maximum } \\
\text { Concentration, } \\
\mathrm{mg} / \mathrm{L}\end{array}$ & $\begin{array}{l}\text { Vitrif } \\
\text { EP Tox }\end{array}$ & $\frac{\mathrm{mg} / \mathrm{L}}{\mathrm{TCLP}}$ \\
\hline As & 5.0 & $<1$ & $<1$ \\
\hline $\mathrm{Ba}$ & 100.0 & $<1$ & $<1$ \\
\hline $\mathrm{Cd}$ & 1.0 & $<1$ & $<1$ \\
\hline $\mathrm{Cr}$ & 5.0 & $<1$ & $<1$ \\
\hline $\mathrm{Pb}$ & 5.0 & $<1$ & $<1$ \\
\hline $\mathrm{Hg}$ & 0.2 & $<0.03$ & $<0.03$ \\
\hline $\mathrm{Se}$ & 1.0 & $<0.01$ & $<0.01$ \\
\hline $\mathrm{Ag}$ & 5.0 & $<0.1$ & $<0.1$ \\
\hline $\mathrm{Ni}$ & 5.0 & $<1$ & $<1$ \\
\hline
\end{tabular}


organic concentration $(\mathrm{mg} / \mathrm{g})$

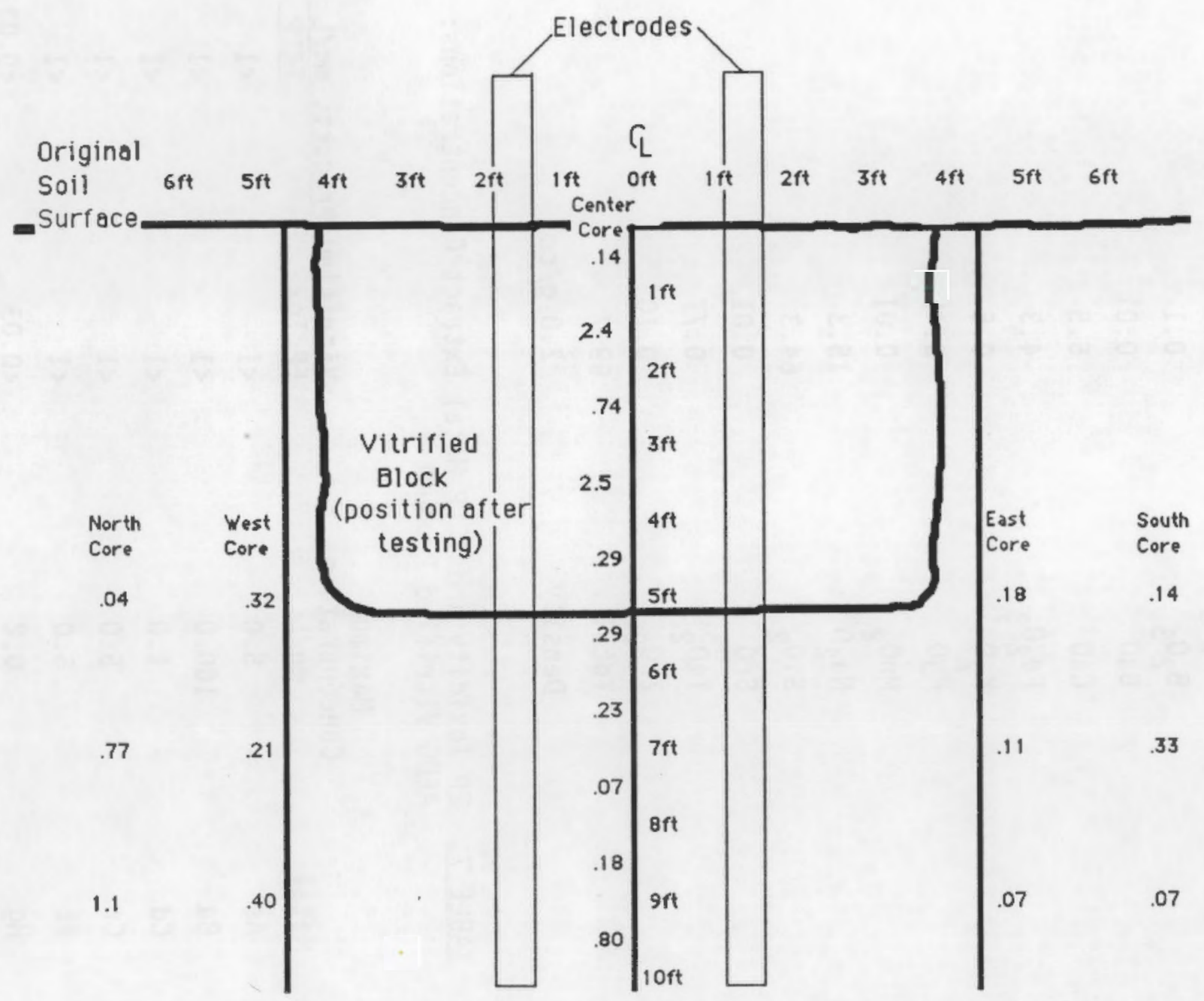

FIGURE 27. AECD Site 10 Pretest Soil Analyses 
The posttest organic analyses of the three soil corings (two adjacent to the vitrified block and one angled to obtain samples beneath the block) are presented in Figure 28. Again the shown concentrations indicate position and depth. The east and west corings are in the same position as the pretest east and west corings. These particular corings show the effects of vitrification on the soils surrounding the zone, especially in the region close $(<1 \mathrm{ft})$ to the vitrified block. In this close region to the block, a noticeable decrease in the organic concentration is generally detected between the pre- and posttest samples from the same relative positions. Insufficient positional sampling was performed to quantify the extent of the organic depression around the block created by the ISV processing. However, the available data indicate that ISV processing will deplete a zone near the block of organic material but does not thermally transport the organic species away from the vitrification zone as would be evidenced by a detectably higher concentration outside this depleted region. Therefore, the organic material in this affected zone surrounding the block is pyrolyzed or released to the off-gas system for capture and treatment. The proposed transport of the organics is described by the mechanisms identified in Appendix A. Again the extent of destruction or release in this zone cannot be quantitatively evaluated due to limited data, but no selective thermal transport away from the vitrification zone was detected. 
orgenic concentration (mg/g)

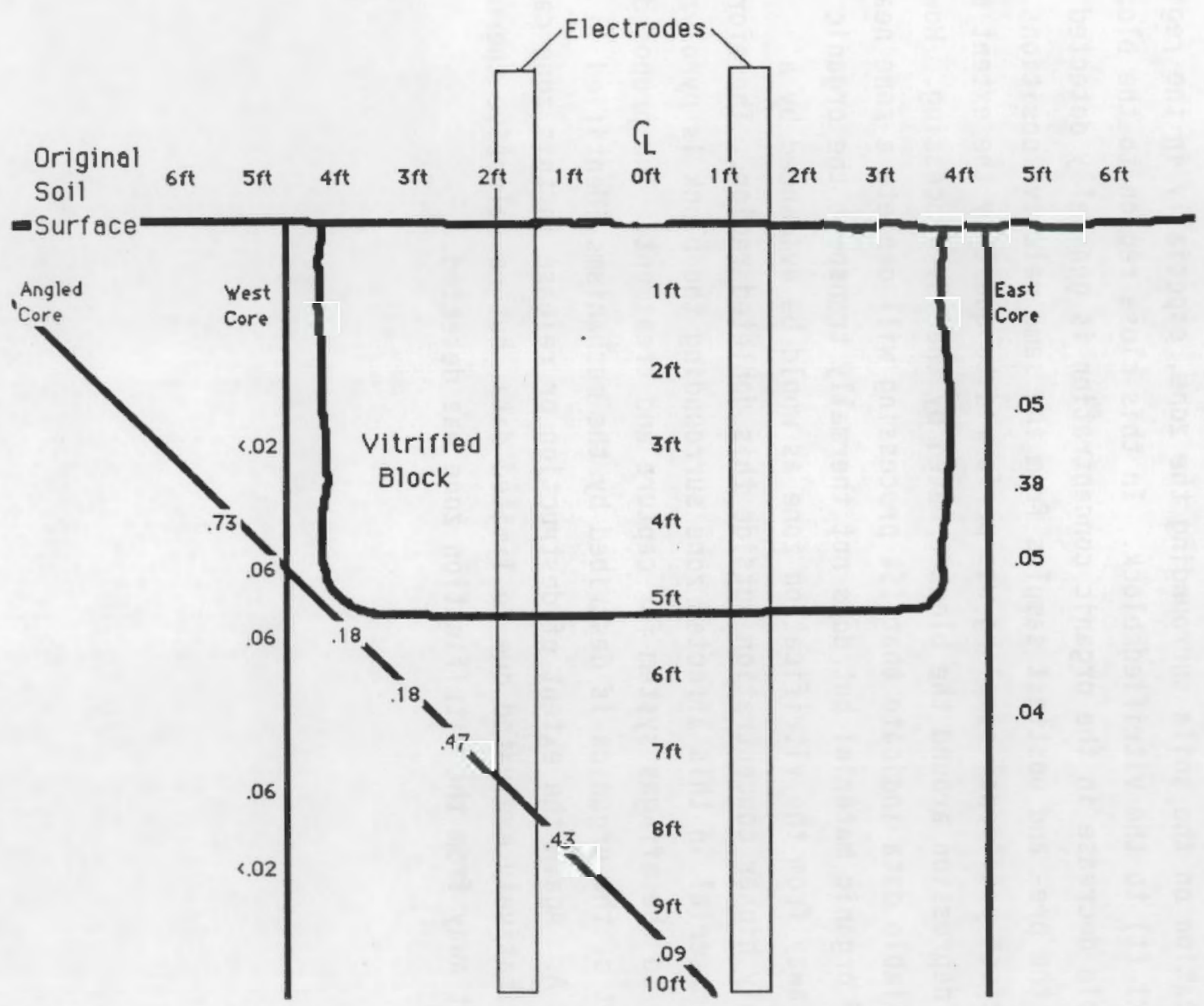

FIGURE 28. AEDC Site 10 Posttest Soil Analyses 


\section{REFERENCES}

Battelle Northwest. 1988. Application of In Situ Vitrification to OrganicContaminated Soils and Sludges. PNWD-1264, Battelle, Pacific Northwest Laboratories, Richland, Washington.

Buelt, J. L., and J. G. Carter. 1986a. Description and Capabilities of the Large-Scale In Situ Vitrification Process. PNL-5738, Pacific Northwest Laboratory, Richland, Washington.

Buelt, J. L., and J. G. Carter. 1986b. In Situ Vitrification Large-Scale Operational Acceptance Test Analysis. PNL-5828, Pacific Northwest Labortory, Richland, Washington.

Buelt, J. L., C. L. Timmerman, K. H. Oma, V. F. FitzPatrick, and J. G. Carter. 1987. In Situ Vitrification of Transuranic Waste: An Updated Systems Evaluation and Applications Assessment. PNL-4800 Supp1. 1, Pacific Northwest Laboratory, Richland, Washington.

Carter, J. G., S. 0. Bates, and G. D. Maupin. 1987. In Situ Vitrification of Oak Ridge National Laboratory Soil and Limestone. PNL-6174, Pacific Northwest Laboratory, Richland, Washington.

40 CFR 264.343(a)(1). "Standards for Owners and Operators of Hazardous Waste Treatment, Storage, and Disposal Facilities." U.S. Code of Federal Regulations.

CH2M Hi11. 1989. Task 2.7, Baseline Analytical Report. USAF IRP, Phase IV Remedial Design for Site 10, Arnold Engineering Development Center, Hazardous Waste Remedial Actions Program, Oak Ridge National Laboratory, Oak Ridge, Tennessee.

Charcoal Services Corporation. High Efficiency Gas Adsorbers, Bulletin No. 283A, Charcoal Services Corporation, Bath, North Carolina.

Dev et al. 1988. Field Test of the Radio Frequency In Situ Soil Decontamination Process, presented at Superfund '88, Washington, D.C.

EPA. 1979. Further Characterization of Sorbent Resins for Environmental Sampling. EPA.600/7-79-216, U.S. Environmental Protection Agency.

NIOSH/OSHA Pocket Guide to Chemical Hazards. 1978. U.S. Government Printing Office, Washington, D.C.

Oma, K. H., D. R. Brown, J. L Buelt, V. F. FitzPatrick, K. A. Hawley, G. B. Mellinger, B. A. Napier, D. J. Silviera, S. L. Stein, and C. L. Timmerman. 1983. In Situ Vitrification of Transuranic Wastes: Systems Evaluations and Applications Assessment. PNL-4800, Pacific Northwest Laboratory, Richland, Washington. 
Oma, K. H., R. K. Farnsworth, and C. L. Timmerman. 1984. "Characterization and Treatment of Gaseous Effiuents from In Situ Vitrification." Radioactive Waste Management and the Nuclear Fuel Cycle 4(4):319-341. Harwood Academic Publishers, New York.

Reimus, M.A.H. 1988. Feasibility Testing of In Situ Vitrification of New Bedford Harbor Sediments. Prepared for Ebasco Services, Incorporated, Arlington, Virginia, under Contract 2311113449.

Sax, N. I., and R. J. Lewis. 1987. Hazardous Chemicals Desk Reference. Van Nostrand Reinhold Company, Inc., New York.

Timmerman, C. L. 1986. In Situ Vitrification of PCB-Contaminated Soils. EPRI CS-4839, Electric Power Research Institute, Palo Alto, California.

Timmerman, C. L. 1989. Feasibility Testing of In Situ Vitrification of Arnold Engineering Development Center Contaminated Soils. PNL-6780, Pacific Northwest Laboratory, Richland, Washington.

Timmerman, C. L., R. A. Brouns, J. L. Buelt, and K. H. Oma. 1983. "In Situ Vitrification: Pilot-Scale Development." Nuclear and Chemical Waste Management $4: 267$.

Timmerman, C. L., and K. H. Oma. 1984. An In Situ Vitrification Pilot-Scale Radioactive Test. PNL-5240, Pacific Northwest Laboratory, Richland, Washington. 


\section{APPENDIX A}

\section{ISV ORGANIC DESTRUCTION MECHANISMS}


APPENDIX A

\section{ISV ORGANIC DESTRUCTION MECHANISMS}

The following sections summarize interrelated mechanisms that govern organic destruction by ISV processing.

\section{MOLECULAR DIFFUSION}

When organics are vaporized as the vitrification zone advances downward, the motion of the gaseous molecules is described by random motion. The molecules are free to move in any direction, including around or through the molten soil, where they pyrolyze (decompose), move to the surface, and are captured in the off-gas collection hood. The portion of the organics that diffuse outward condense or adsorb onto the soil at their vapor point isotherm. The organics are then revaporized by the advancing vitrification zone and again become free to diffuse around and through the molten soil, where they pyrolyze. Hence, molecular diffusion does not promote escape of organics into the surrounding soil, but rather promotes pyrolysis around and through the vitrification zone. Figure A.l depicts this mechanism.

\section{CARRIER GAS TRANSPORT}

Transport of contaminants by carrier gas is assisted by another material/phase in the soil, such as water vapor. Repeated ISV tests have demonstrated that water vapor moves upward to the soil surface where it is captured in the hood and treated by the off-gas treatment system. Material balance measurements during ISV field tests have confirmed this behavior. Organic contaminants are carried into the pyrolysis zone by this water vapor, which accounts for the fact that 96 to $99.9985 \%$ of the organic species tested are destroyed by ISV. Figure A.2 depicts this mechanism. 

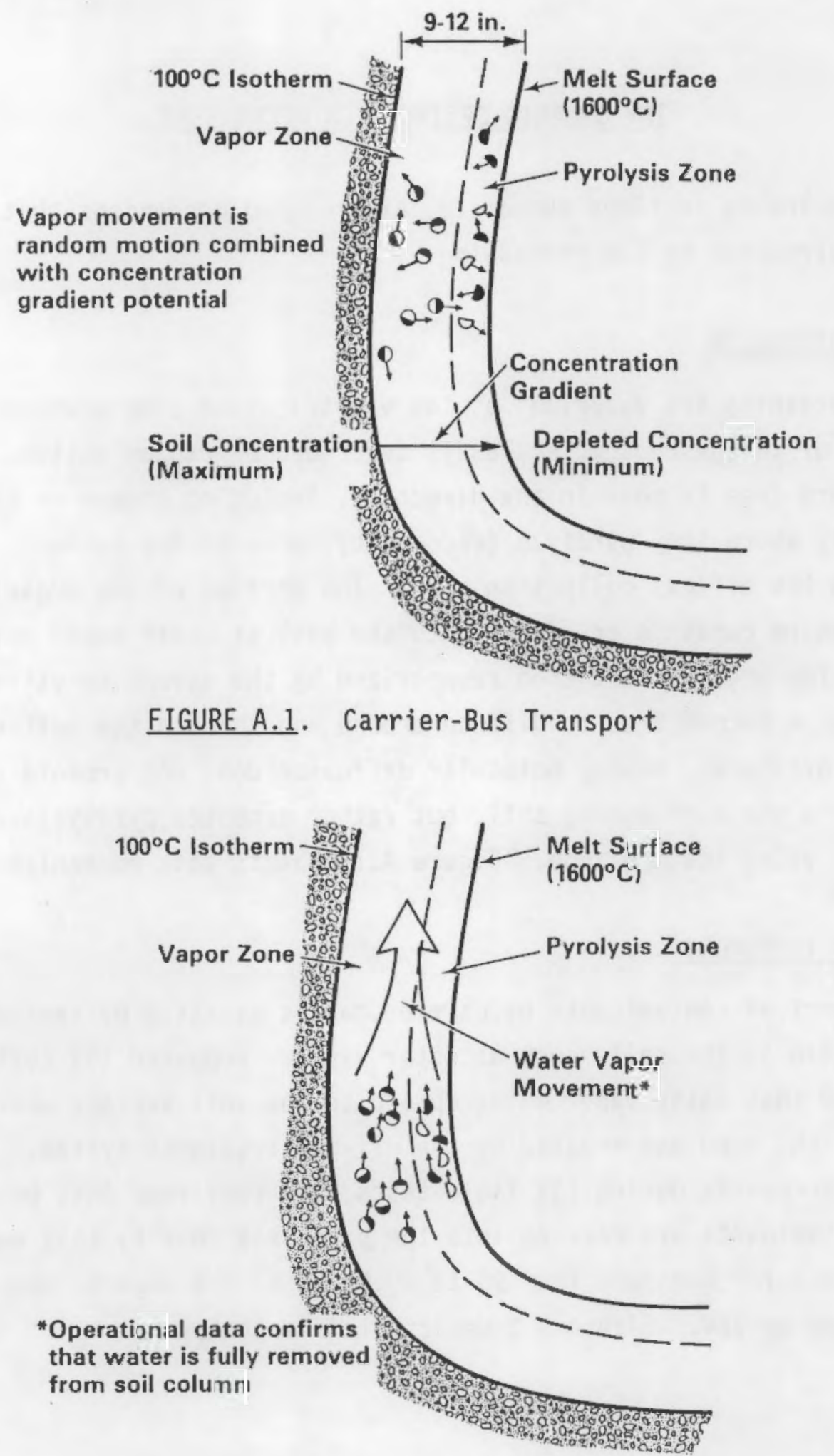

FIGURE A.2. Carrier-Gas Transport 


\section{CAPILLARY FORCES}

For any given soil, capillary forces act on liquid phases, such as water and organic contaminants, to pull the liquid from a wet region to a dryer region. Since the ISV block is surrounded by a 9- to 12-in.-thick dry zone, capillary action draws contaminants in the liquid phase into this zone and toward the ISV molten pool until they are vaporized or decomposed. This mechanism helps explain the observed complete water recovery and high degree of organic destruction.

\section{FLOW RESISTANCE IN THE SOIL COLUMN}

The mobility of both the gas and liquid phases is influenced by the ability of the material to move through the soil column. That is, movement occurs along the path of least resistance. Due to the absence of interstitial moisture, flow resistance is lower in the dry soil region between the vitreous zone and the $212^{\circ} \mathrm{F}$ isoband. Fluids that tend to move preferentially along the path of least resistance move parallel to the vitreous mass and, therefore, upward through the soil along the edges of the block and into the hood. Vapors also move upward through the molten mass into the hood. The graphite electrodes act as gas release vents, allowing preferential flow of contaminants through the molten soil. Like water on wax, molten glass does not wet the surface of graphite, thereby allowing a path for the release of vaporized water and organics to the hood. Another potential path for volatilized organics is directly through the molten glass. Like the electrode route, this path ensures complete destruction of organics. Measurements during field tests have demonstrated that $100 \%$ of the water is recovered. These data strongly support the transport behavior and destruction mechanisms described above. Figure A.3 depicts this mechanism.

\section{SORPTION OF LIQUID AND VAPOR PHASE ONTO THE SOIL}

Sorption of liquids and their vapors onto the soil has yet to be fully evaluated, but because of its known influence at low temperatures, it can be reasonably postulated that a significant degree of sorption exists at high temperatures. Sorption is the mechanism by which a chromatograph works. 


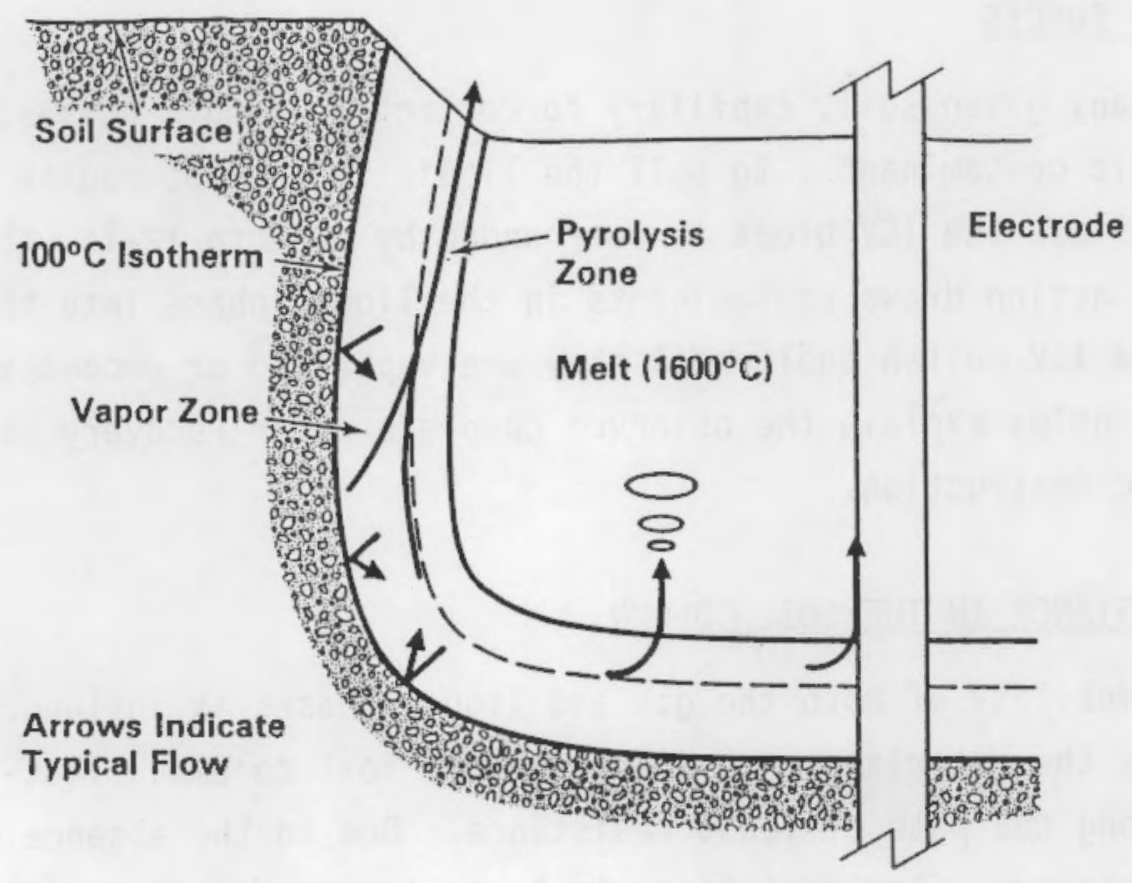

FIGURE A.3. Vapor Flow Resistance

Selective sorption retards the movement of chemicals, which helps account for the ability of the ISV process to pyrolyze and destroy organic contaminants as the molten mass advances through the soil. 
APPENDIX B

AEDC SITE 10 BENCH-SCALE TESTING SOIL ANALYSIS 
TABLE B.1. AEDC Site 10 Bench-Scale Testing Sampling Identification and Location

\section{Identification}

AS $-10-1$

AS-10-2

AS $-10-3$

AS $-10-4$

AS $-10-5$

AS $-10-6$

AS $-10-7$

AS $-10-8$

AS-10-9

\section{Location}

Test sludge

Test clean soil

Upper burn pit - left wing of mock airplane

Lower overflow pond - east side

Lower overflow pond - west side

Clean soil - surface clay

Clean soil - subsurface layer

Run-off area surface soil

Subsurface soil - east coffer 
IABLE B.2. AEDC Site 10 Sample Analyses Originating from the Bench-Scale Test, wt\%

\begin{tabular}{|c|c|c|c|c|c|c|c|c|c|}
\hline Oxide & AS-10-1 & $A S-10-2$ & AS-10-3 & AS-10-4 & AS-10-5 & AS $-10-6$ & AS $-10-7$ & AS-10-8 & $A S-10-9$ \\
\hline $\mathrm{Al}_{2} \mathrm{O}_{3}$ & 6.25 & 10.4 & 3.39 & 5.31 & 4.80 & 9.08 & 11.4 & 9.51 & 5.77 \\
\hline $8 a 0$ & 0.022 & 0.044 & 0.024 & 0.012 & 0.013 & 0.019 & 0.059 & 0.020 & 0.017 \\
\hline $\mathrm{CaO}$ & 5.53 & 5.21 & 33.5 & 5.84 & 23.7 & 0.92 & 5.82 & 2.55 & 1.08 \\
\hline $\mathrm{Cr}_{2} \mathrm{O}_{3}$ & 0.028 & 0.031 & .. & .. & $-\cdot$ & $\cdots$ & 0.042 & 0.033 & .. \\
\hline CuO & 0.013 & 0.014 & -- & -- & - & -- & 0.045 & 0.014 & $-\cdot$ \\
\hline $\mathrm{Fe}_{2} \mathrm{O}_{3}$ & 3.78 & 4.99 & 2.87 & 2.75 & 2.57 & 4.87 & 7.11 & 5.35 & 2.67 \\
\hline $\mathrm{K}_{2} \mathrm{O}$ & 0.51 & 1.05 & 0.46 & 0.46 & 0.47 & 0.47 & 1.25 & 0.74 & 0.40 \\
\hline MgO & 0.435 & 0.534 & 1.56 & 0.426 & 0.855 & 0.358 & 0.614 & 0.508 & 0.297 \\
\hline $\mathrm{MnO}_{2}$ & 0.016 & 0.020 & 0.015 & -. & 0.013 & 0.012 & 0.031 & 0.044 & -. \\
\hline $\mathrm{Na}_{2} \mathrm{O}$ & 0.29 & 0.33 & 0.24 & 0.30 & 0.22 & 0.26 & 0.36 & 0.26 & 0.28 \\
\hline NiO & 0.034 & 0.041 & 0.041 & 0.028 & 0.033 & 0.029 & 0.065 & 0.047 & 0.034 \\
\hline $\mathrm{SiO}_{2}$ & 70.7 & 63.4 & 28.2 & 73.3 & 43.9 & 72.5 & 53.2 & 71.7 & 77.6 \\
\hline Sro & 0.012 & 0.057 & 0.036 & -. & 0.023 & 0.019 & 0.083 & 0.015 & 0.007 \\
\hline $\mathrm{THO}_{2}$ & 0.984 & 0.865 & 0.423 & 0.941 & 0.587 & 1.13 & 0.739 & 0.780 & 1.15 \\
\hline $\mathrm{ZrO}_{2}$ & 0.061 & 0.046 & 0.018 & 0.064 & 0.022 & 0.029 & 0.046 & 0.087 & 0.121 \\
\hline $\begin{array}{l}\text { Total } \\
\text { Oxide }\end{array}$ & 88.7 & 87.1 & 70.8 & 89.4 & 77.1 & 89.1 & 80.8 & 91.6 & 87.5 \\
\hline $\begin{array}{l}\text { Moisture } \\
\text { Content }\end{array}$ & 20.4 & 16.4 & 14.3 & 28.3 & 24.2 & 13.8 & 18.4 & 15.8 & 30.4 \\
\hline
\end{tabular}


APPENDIX C

AEDC SITE 10 ORIGINAL SOIL ORGANIC CONCENTRATIONS 
APPENDIX C

\section{AEDC SITE 10 ORIGINAL SOIL ORGANIC CONCENTRATIDNS}

\section{EXPERIMENTAL}

Twenty-six preburn soil samples were analyzed for nonpolar organics by gas chromatography (GC). The soil samples were air dried at room temperature, weighed, and spiked with a combination of $\mathrm{nC}_{12}$ and $\mathrm{nC}_{36}$ hydrocarbons. Each sample, weighing approximately $20 \mathrm{~g}$, was extracted with $40-\mathrm{mL}$ hexane or cyclohexane by shaking for $1 \mathrm{~min}$, sonicating in an ultrasonic bath for $20 \mathrm{~min}$, and pouring off the supernatant; this procedure was repeated three times. The extract was concentrated to dryness using a rotoevaporator at a temperature of $35^{\circ} \mathrm{C}$, transferred to a graduated test tube or reacti-vial, and concentrated under $\mathrm{N}_{2}$ to a final volume of 0.5 or $0.6 \mathrm{~mL}$ for $\mathrm{GC}$ analysis.

The gas chromatographic system consisted of a Hewlett-Packard HP-5880A GC operated in the splitless injector mode and equipped with a flame ionization detector (FID). A $30-\mathrm{m}(0.25-\mathrm{mm}$ inside diameter, $0.25-\mu \mathrm{m}$-thick film) bonded-phase DB-5 fused-silica capillary column (J\&W Scientific, Rancho Cordova, California) with a helium flow rate of $3 \mathrm{~mL} / \mathrm{min}$ was used for separations. Sample injection size was typically 1.4 to $1.7 \mu \mathrm{L}$. The oven temperature was held at $50^{\circ} \mathrm{C}$ for $1 \mathrm{~min}$, then programmed at $20^{\circ} \mathrm{C} / \mathrm{min}$ to $300^{\circ} \mathrm{C}$ where it was held for $17 \mathrm{~min}$. The rapid program rate was acceptable because the goals were to determine the total area of the chromatogram rather than the area of the individual peaks and to qualitatively determine the corresponding hydrocarbon range of the peaks.

An appropriate standard was needed for quantitation, i.e., one which would most closely approximate the general characteristics of the sample chromatogram. A number of oils or their distillate cuts were eliminated because of lack of a comparable "humpane" or comparable hydrocarbon spread; these included kerosene, Prudhoe Bay crude oil, Cerro Negro crude oil, Boscan crude oil, Rio Blanco shale oil, and a minimum quality diesel fuel. A Bunker $C$ residual fuel oil (WP681, USEPA-API reference 011 ) was chosen as the 
best match in our collection of oil standards, though its hydrocarbon range was typically somewhat lower than that of the samples (see the data summary for details). Because this reference standard was not ideal and because the integration circumstances were not ideal (i.e., integrating a hump rather than baseline-separated peaks), the data should be considered semiquantitative, i.e., trends are accurate but numbers are estimates.

Because the initial trial samples that we examined exhibited very low concentrations of nonpolar organics, it was necessary to minimize procedural contaminations. (These samples were originally chosen on the basis of the field photoionization measurements as having the greatest concentrations of organics, though it appears that this was an inaccurate assumption.) Concentrated hexane was found to contain a number of low-molecular-weight contaminants (below $\mathrm{nC}_{13}$ ); concentrated cyclohexane contained contaminants only below $\mathrm{nC}_{\mathrm{g}}$. While it appeared that the hexane impurities might create problems in the low-concentration initial samples, in fact neither solvent interfered with the actual samples analyzed. We initially planned to use a sonicator probe to extract the samples; however, blank runs indicated a contamination problem in the $\mathrm{nC}_{25}$ to $\mathrm{nC}_{30}$ range. Therefore, shaking and a sonicator bath were substituted; no contamination problems were observed with this method. The trial samples were dried with $\mathrm{Na}_{2} \mathrm{SO}_{4}$ (reagent grade, baked at $400^{\circ} \mathrm{C}$ ) to permit efficient mixing of the solvent with the soil. The $\mathrm{Na}_{2} \mathrm{SO}_{4}$ was checked for contamination by extraction with hexane and was found to exhibit peaks in the $\mathrm{nC}_{15}$ to $\mathrm{nC}_{32}$ range. Because of the low concentrations of hydrocarbons in the initial samples, it appeared likely that the $\mathrm{Na}_{2} \mathrm{SO}_{4}$ would interfere with the analyses; therefore, the samples were air dried prior to extraction.

\section{RESULTS}

The results of the analyses are tabulated in Table C.1. As discussed above, the results were calibrated relative to bunker fuel oil. A different standard would probably yield different numbers, though their relative concentrations would be consistent. The maximum concentrations are found in the center cores at 3-4 ft and 1-2 ft depth intervals. There is a decrease in concentration with depth in the center cores beyond $4 \mathrm{ft}$ until the 8-9 ft

$$
\text { C.2 }
$$


TABLE C.1. Preburn Soil Samples, Gas Chromatography Analysis

(pph)

\begin{tabular}{|c|c|c|c|c|c|}
\hline \multirow{2}{*}{\multicolumn{2}{|c|}{$\frac{\text { Position and }}{\text { Depth, ft }}$}} & \multicolumn{3}{|c|}{$\frac{\text { Relative to Bunker Fuel } 0 i l}{\text { Maximum HC Peak/ }}$} & \multirow[b]{2}{*}{$\begin{array}{c}\text { Hump/Peak } \\
\text { Relationship }\end{array}$} \\
\hline & & $\frac{m g}{g \text { Soil }}$ & $\begin{array}{l}\text { Maximum HC Peak/ } \\
\text { Maximum Hump } \\
\end{array}$ & Hump Spread & \\
\hline \multirow{14}{*}{ Center } & $0-1$ & 0.14 & $\mathrm{C}_{22}$ & $c_{16}$ & ? \\
\hline & $1-2$ & 2.4 & $? / C_{2}$ & & Hump 〉>Peaks \\
\hline & $2-3$ & 0.74 & $c_{17}$ & & Peaks $>$ Hump \\
\hline & $3-4$ & 2.5 & $\mathrm{C}_{20} / \mathrm{C}_{24}$ & $c_{13}$ & Hump $>$ Peaks \\
\hline & $4-5$ & 0.29 & $c_{17} / c_{20}$ & & Hump Peaks \\
\hline & $5-6$ & 0.29 & $c_{22}$ & & Hump $>$ Peaks \\
\hline & $6-7$ & 0.23 & $c_{14} / c_{19}$ & $c_{13}$ & Peaks $>$ Hump \\
\hline & $7-8$ & 0.07 & $c_{17} / c_{22}$ & & Peaks _Hump \\
\hline & $8-9$ & 0.18 & $c_{14} / c_{19}$ & & Peaks $>$ Hump \\
\hline & $9-10$ & 0.50 & $c_{14} / c_{18}$ & $c_{11}$ & Peaks $>$ Hump \\
\hline & $10-11$ & 0.12 & $c_{14}, c_{17} / C_{20}$ & & Peaks $>$ Hump \\
\hline & $11-12$ & 0.24 & $c_{17} / c_{20}$ & & Peaks>Hump \\
\hline & $12-13$ & 0.08 & $\mathrm{C}_{15} ? / ?$ & $\mathrm{C}_{1}$ & Peaks $>$ Hump \\
\hline & $13-14$ & 0.10 & $\mathrm{C}_{14} / \mathrm{C}_{22}$ & & Peaks_Hump \\
\hline \multirow[t]{3}{*}{ South } & $4-6$ & 0.14 & $c_{15} / c_{15}, c_{20}$ & & Peaks >Hump \\
\hline & $6-8$ & 0.33 & $c_{17} / c_{21}$ & & Hump $>$ Peaks \\
\hline & $8-10$ & 0.04 & $? / C_{23} ?$ & & Hump >Peaks \\
\hline \multirow[t]{3}{*}{ East } & $4-6$ & 0.18 & $c_{17} / c_{21}$ & & Hump $>$ Peaks \\
\hline & $6-8$ & 0.11 & $c_{17} / c_{21}$ & & Hump $>$ Peaks \\
\hline & $8-10$ & 0.07 & $c_{12} / c_{21}$ ? & & Hump Peak \\
\hline \multirow[t]{3}{*}{ West } & $4-6$ & 0.32 & $c_{14}, c_{15} / c_{21}$ & & Hump $>$ Peaks \\
\hline & $6-8$ & 0.21 & $C_{20} ? / C_{22}$ & $c_{14}$ & Hump $>$ Peaks \\
\hline & $8-10$ & 0.40 & $C_{14} / C_{19}$ & $c_{13}-c_{25}$ & Peaks $>$ Hump \\
\hline $\mathrm{Bl}$ ank & & 0.07 & $\cdots$ & -. & -- \\
\hline \multirow[t]{3}{*}{ North } & $4-6$ & 0.04 & $c_{19} ? / C_{25}$ & $c_{16}-c_{34}$ & Peaks-Hump \\
\hline & $6-8$ & 0.77 & $c_{17} / c_{14}, c_{17}$ & $C_{12}$ & Peaks - Hump \\
\hline & $8-10$ & 1.1 & $C_{14} / C_{14}, C_{19}$ & & Peaks $>$ Hump \\
\hline \multicolumn{3}{|c|}{ Bunker $C$} & $c_{16}$ & 26 & \\
\hline
\end{tabular}


depth interval is reached. At 9-10 ft there is a large increase, followed by a sharp decrease. There is another slight increase at 11-12 ft comparable to the concentration at the $6-\mathrm{ft}$ interval before a continued decrease with depth. The hydrocarbon concentration varied with depth in the south, east, west, and north core samples. The highest concentrations are found at the 8-10 ft interval in the north core, and are comparable to the concentration at the center core 9-10 ft interval. The east core samples exhibit the lowest concentrations of hydrocarbons. A procedural blank was clean; its value of $70 \mathrm{ppm}$ should be considered a detection limit for the analytical method. The recovery of the C36 standard was generally close to $100 \%$, with some unexplained exceptions. The recovery of the $\mathrm{C} 12$ standard was frequently poor, probably caused by evaporation loss during the concentration step of the procedure. This indicates that the concentrations of the lower molecular weight hydrocarbons may be underestimated in these calculations.

Table C.1 also indicates the alkane with the maximum discrete peak height as well as the alkane equivalent corresponding to the maximum hump height (the assumption is being made that the homologous series of peaks are indeed alkanes.) The alkane range incorporated by the hump is indicated in the column labeled "hump spread." The upper range is only an approximate value, because it is very difficult to ascertain the end of the hump in the chromatogram. The last column of the table gives a rough indication of whether the discrete peaks on the hump were significant or minor. The distribution of peaks varied considerably depending on location. The maximum discrete peak varied from $C_{14}$ to $C_{22}$; the alkane equivalent at maximum hump height varied from $C_{14}$ to $C_{25}$; the hump spread varied from $C_{11}$ to $C_{35}$. By comparison, the Bunker $\mathrm{C}$ oil had a discrete peak maximum and a hump maximum at $C_{16}$ and a peak spread from $C_{10}$ to $C_{26}$. 


\section{DISTRIBUTION}

No. of

Copies

\section{OFFSITE}

12 DOE/Office of Scientific

and Technical Information

DOE Office of the Assistant

Secretary for Nuclear Energy GTN

Washington, DC 20545

ATTN: J. A. Coleman

DOE Office of Defense Waste \& Transportation Management GTN

Washington, DC 20545

ATTN: S. P. Mathur

DOE Office of Remedial Action

GTN

$\&$ Waste Technology

Washington, DC 20545

ATTN: H. F. Walter, NE-24

DOE Albuquerque Operations Office

P.0. Box 5400

Albuquerque, NM 87185

ATTN: J. McGough

4 DOE Idaho Operations Office

785 DOE Place

Idaho Falls, ID 83402

ATTN: M. W. Shupe

J. P. Hamric

C. R. Enos

S. A. Morreale

2 Argonne National Laboratory

9700 South Cass Avenue

Argonne, IL 60439

ATTN: C. S. Abrams

J. H. Kittel
No. of

Copies

10 Arnold Engineering Development Center

Arnold AFB, TN 37389

ATTN: R. C. Edwards (5)

J. K. Lominac (5)

2 Battelle Memorial Institute

Project Management Division

505 King Avenue

Columbus, $\mathrm{OH} 43201$

ATTN: W. A. Carbiener

S. H. Basham

6 EG\&G Idaho

P.0. Box 1625

Idaho Falls, ID 83415

ATTN: S. 0. Bates

R. A. Callow

B. L. Charboneau

T. L. Clements

J. L. Landon

R. M. Schletter

3 E.I. du Pont de Nemours Company Savannah River Laboratory

Aiken, SC 29801

ATTN: M. D. Boersma

J. Haselow

J. Steele

Electric Power Research Institute

3412 Hillview Avenue

P.0. Box 10412

Palo Alto, CA 94304

ATTN: R. A. Shaw

4 Geosafe Corporation

Kirkland Park Place

303 Park Place, Suite 126

Kirkland, WA 98033

ATTN: J. G. Carter

V. F. FitzPatrick

J. E. Hansen

T. G. Murray 
No. of

Copies

3 Laboratory Records Department P.0. BoX X

Bldng. 4500-N, Room H-205

Oak Ridge National Laboratory

Oak Ridge, TN 37831

Lawrence Livermore National Laboratory

University of California

P.0. Box 808

Livermore, CA 94550

ATTN: L. D. Ramspott

2 Los Alamos National Laboratory

P.0. Box 1663

Los Alamos, NM 87544

ATTN: D. T. Oakley

$$
\text { J. Winzel }
$$

11 Martin Marietta Energy Systems

$$
\text { Inc. }
$$

FEDC Building

104 Union Valley Road

Oak Ridge, TN 37831

ATTN: B. E. Adams

G. L. Dippo (10)

5 Oak Ridge National Laboratory

P.0. BoX Y

Oak Ridge, TN 37830

ATTN: R. Adams

L. Mezga

T. H. Row

B. P. Spalding

T. Tamura

2 Rockwell International

Rocky Flats Plant

P.0. Box 464

Golden, CO 80402-0464

ATTN: P. G. Hagen

K. McKinley

West Valley Nuclear Services

Company

P.0. Box 191

West Valley, NY 14171

ATTN: J. M. Pope
No. of

Copies

ONSITE

4 DOE Richland Operations office

M. J. Furman, A6-80

R. E. Gerton, $A 6-80$

R. B. Goranson, $A 5-90$

D. M. Smith, A6-55

6 Westinghouse Hanford Company

J. W. Cammann, H4-54

R. E. Lerch, H4-51

H. E. McGuire, H4-51

D. A. Turner, R1-10

D. D. Wodrich, Rl-48

R. D. Wojtasak, H4-17

53 Pacific Northwest Laboratory

C. E. Bigelow, P7-44

W. F. Bonner, P7-44

J. L. Buelt, P7-44

H. C. Burkholder, P7-41

B. E. Campbe11, P7-44

R. K. Farnsworth, P7-44

C. H. Kindle, P7-44

S. S. Koegler, P7-44

W. L. Kuhn, P7-14

P. S. Lowery, K5-21

J. L. McElroy, P7-46

M. C. Miller, K4-28

K. A. Parnel1, P7-18

M. E. Peterson, P7-44

J. W. Shade, P8-37

J. A. Stottlemyre, K6-78

L. E. Thompson, P7-41

C. L. Timmerman, (30) P7-44

Publishing Coordination

Technical Report Files 